\title{
Comportamiento de híbridos de maíz ante una cepa de Aspergillus flavus en la provincia de Córdoba
}

Tesis presentada para optar al título de Magister Scientiae de la Facultad de Ciencias Agrarias y Forestales, Universidad Nacional de La Plata.

Ing. Agr. RODRIGUEZ, Ana Valeria

Fitopatología- INTA EEA Manfredi, Córdoba 
Directora

Ing. Agr., M.Sc., Dra. GIMENEZ PECCI, María de la Paz (INTA - CIAP - IPAVE, Córdoba)

\section{Codirectora}

Ing. Agr. SISTERNA, Marina

(Fitopatología, FCAyF - UNLP - CICPBA)

Jurado

Ing Agr., M.Sc. Dr. PRESELLO, Daniel

Ing. Agr., M.Sc., Dr. CARMONA, Marcelo

Ing. Agr. Dra. FORMENTO, Ángela Norma

Fecha de defensa:

9 de noviembre de 2018 
A mi madre, quien me dio su apoyo incondicional desde el día que elegí esta hermosa profesión. 


\section{AGRADECIMIENTOS}

A José por ser incondicional y a mi niña Eluney.

A mi familia y amigos por estar siempre.

A Francisco, por confiar en mí desde el principio, a Luis y Julio por su ayuda desinteresada, por su apoyo constante en mi perfeccionamiento profesional.

A María de la Paz y Marina quienes sin conocerme aceptaron guiarme en este estudio y me han ayudado y alentado desde el comienzo.

A mis compañeros y colegas que de alguna manera ayudaron y colaboraron desinteresadamente en este estudio.

A las instituciones que hicieron posible mi estudio, INTA EEA Manfredi y Facultad de Ciencias Agrarias y Forestales UNLP. 


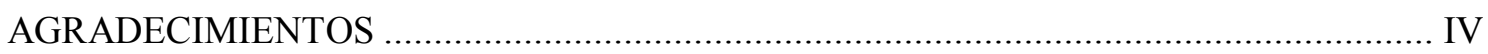

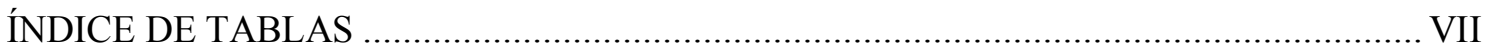

ÍNDICE DE FIGURAS …....................................................................................... VIII

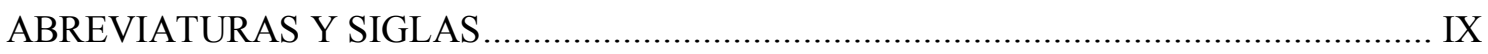

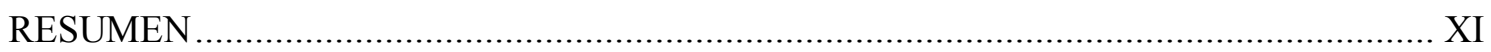

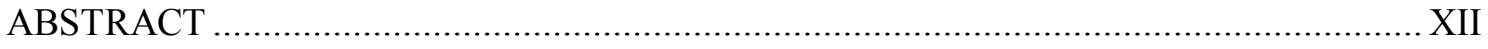

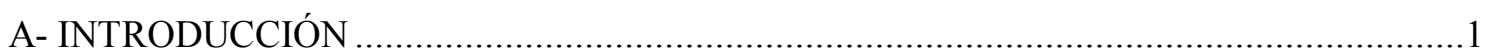

A.1. Presentación del problema ……….......................................................................... 1

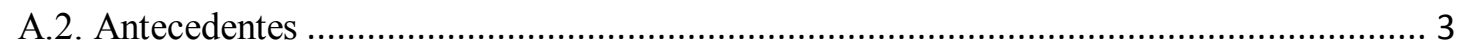

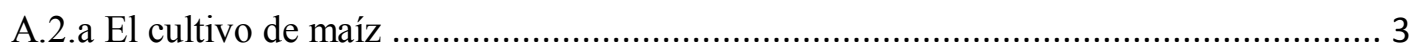

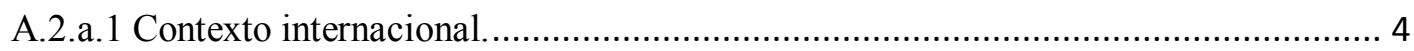

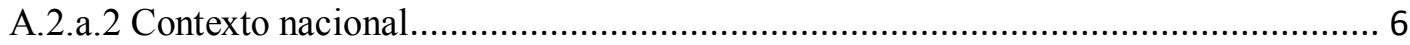

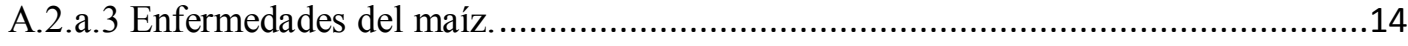

A.2.b El género Aspergillus ........................................................................................16

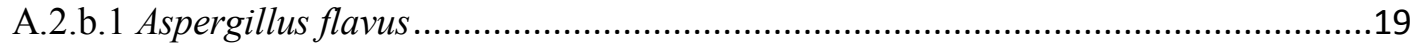

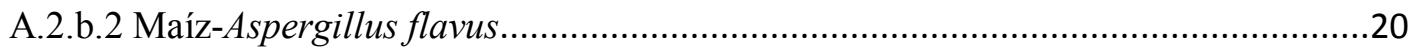

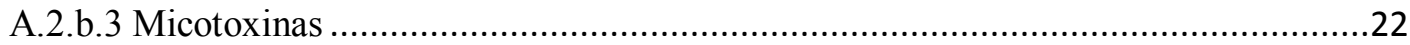

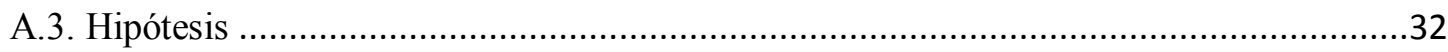

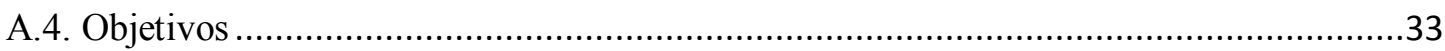

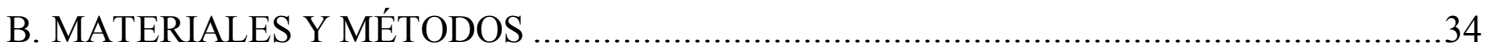

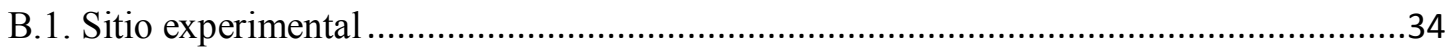

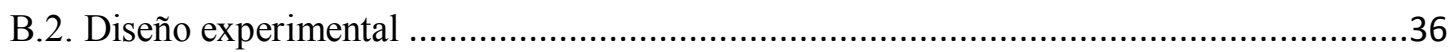

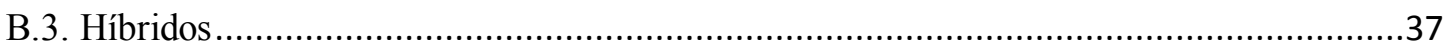

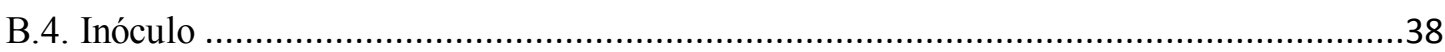

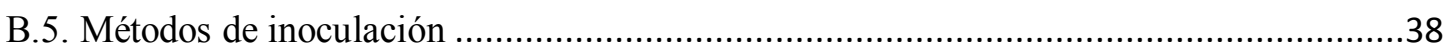

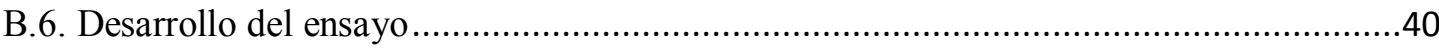

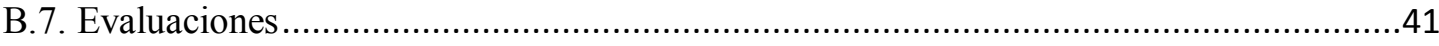

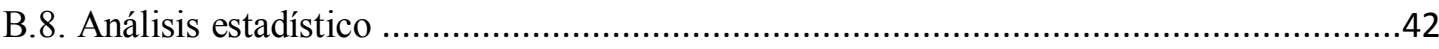

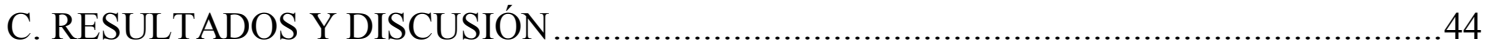

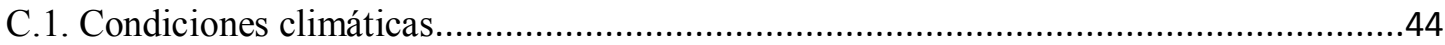


C.2. Parámetros de cuantificación de sanidad..................................................................45

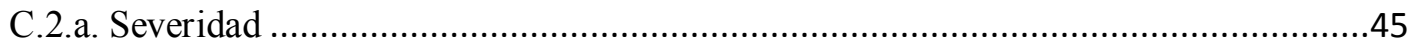

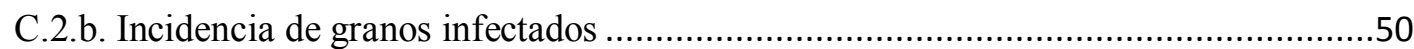

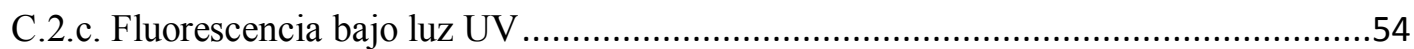

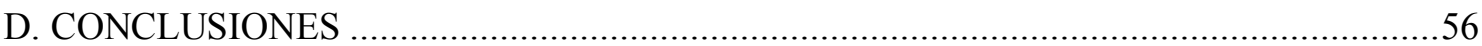

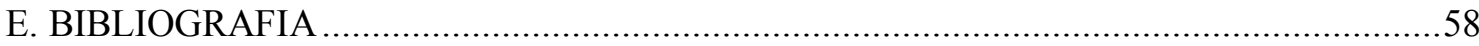

F. ANEXO

F1. Base de datos para la determinación de A. flavus en maíz.............................................72

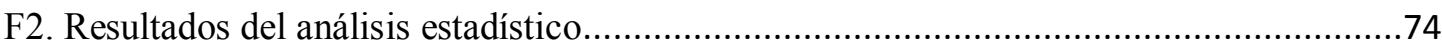

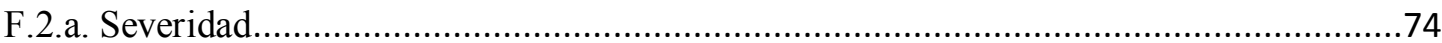

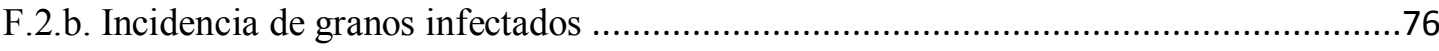

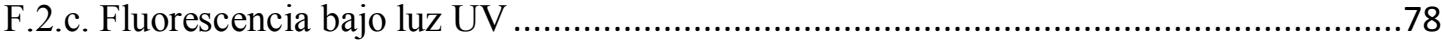




\section{ÍNDICE DE TABLAS}

Tabla 1: Producción mundial de maíz. Campaña 2016/17 ........................................... 5

Tabla 2: Características de los grupos/secciones de Aspergillus................................. 18

Tabla 3: Límites máximos admisibles de concentración de aflatoxinas en el

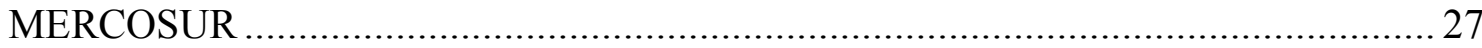

Tabla 4: Niveles tolerables máximos para aflatoxina en distintos países y regiones. .... 28

Tabla 5: Características de los híbridos utilizados en los ensayos en Manfredi, Córdoba

Tabla 6: Escala de evaluación de severidad para Aspergillus flavus

Tabla 7: Diferencia de medias del indice de severidad para la interacción técnica de inoculación x híbrido, en dos fechas de siembra.

Tabla 8: Diferencia de medias de la incidencia para la interacción técnica de inoculación $\mathrm{x}$ híbrido, en dos fechas de siembra. 52

Tabla 9: Tabla general de los resultados para el modelo usado para la detección de Aspergillus flavus por fluorescencia bajo luz UV

Tabla 10: Medidas de ajuste del modelo para la detección de Aspergillus flavus por fluorescencia bajo luz UV

Tabla 11: Prueba de hipótesis marginales para los efectos fijos para la detección de Aspergillus flavus por fluorescencia bajo luz UV 54

Tabla 12: Base de datos para determinar el comportamiento de Aspergillus flavus ...... 72

Tabla 13: Media de Mínimos Cuadrados para la variable índice de severidad. 74

Tabla 14: Media de Mínimos Cuadrados para la variable incidencia..... 76

Tabla 15: Medias ajustadas y errores estándares para fecha de siembra para la detección de Aspergillus flavus por fluorescencia bajo luz UV 78 Tabla 16: Medias ajustadas y errores estándares para cultivar para la detección de Aspergillus flavus por fluorescencia bajo luz UV 78

Tabla 17: Medias ajustadas y errores estándares para técnicas de inoculación para la detección de Aspergillus flavus por fluorescencia bajo luz UV ..... 79 


\section{ÍNDICE DE FIGURAS}

Figura 1: Planta de maíz.

Figura 2: Precipitación y temperatura media anual de la región maiceera templada de Argentina 7

Figura 3: Producción y superficie sembrada de maíz en Argentina (ciclo 1979/80 2015/16).

Figura 4: Producción y superficie sembrada de maíz en la provincia de Córdoba (ciclo 1979/80 - 2015/16). 10

Figura 5: Cadena de maíz de la provincia de Córdoba ................................................. 12

Figura 6: Formas básicas de las cabezas conidiales de Aspergillus ........................... 17

Figura 7: Estructuras microscópicas de Aspergillus ................................................ 18

Figura 8: Colonia de Aspergillus flavus sobre semilla de maíz en medio de cultivo. .... 19

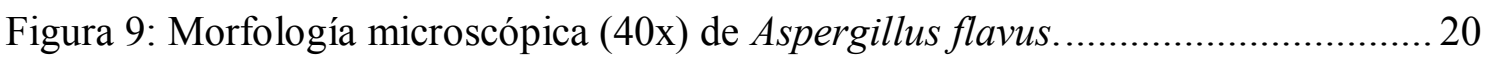

Figura 10: Ciclo de Aspergillus flavus en maíz. ........................................................... 22

Figura 11: Sitio experimental para estudios de Aspergillus flavus en el cultivo de maíz 34

Figura 12: Zonas Agroeconómicas Homogéneas de la provincia de Córdoba 35

Figura 13: Escala fenológica del maíz utilizada para determinar los momentos de inoculación 38

Figura 14: Maíz en estado R1 e instrumental utilizado para inocular 39

Figura 15: Maíz en estado R3 e instrumental utilizado para inocular 40

Figura 16: Precipitaciones ocurridas durante la campaña 2014/15 y 2015/16 y promedio histórico 1931-2016 en la EEA Manfredi

Figura 17: Temperatura media y húmedad relativa mínima durante las campañas 2014/15 y 2015/16 en la EEA INTA Manfredi, Córdoba.

Figura 18: Síntoma de Aspergillus flavus en mazorca de maíz. 46

Figura 19: Índice de severidad de Aspergillus flavus en los híbridos evaluados utilizando dos técnicas de inoculación en dos fecha de siembra 47

Figura 20: Incidencia de Aspergillus flavus en los híbridos evaluados bajo dos técnicas de inoculación en dos fecha de siembra 51

Figura 21: Supuestos para la variable índice de severidad ..................................... 76

Figura 22: Supuestos para la variable incidencia ................................................. 78 


\section{ABREVIATURAS Y SIGLAS}

APG: agar papa glucosado

B1: tipo de aflatoxina

B2: tipo de aflatoxina

CNPAMM: Confederación Nacional de Productores Agrícolas de Maíz de México

DBCA: Diseño en bloques completos al azar

EEA: Estación Experimental Agropecuaria

ESTs: etiqueta de secuencia expresada

ETM: evapotranspiración máxima

FADA: Fundación Agropecuaria para el Desarrollo de Argentina

FAO: Food and Agriculture Organization

FDA: Administración de Alimentos y Medicamentos de Estados Unidos (siglas en inglés)

G1: tipo de aflatoxina

G2: tipo de aflatoxina

GIPSA: The Grain Inspection, Packers and Stockyards Administration

IARC: Agencia Internacional para la Investigación en Cáncer (siglas en inglés)

INASE: Instituto Nacional de Semillas

INTA: Instituto Nacional de Tecnología Agropecuaria

IPAVE: Instituto de Patología Vegetal

IS: índice de severidad 
M1: producto metabólico hidroxilado de la aflatoxinas B1 y B2

M2: producto metabólico hidroxilado de la aflatoxinas B1 y B2

MAGyP: Ministerio de Agricultura, Ganadería y Pesca de la Nación

MAIZAR: Asociación Maíz Argentino

MERCOSUR: Mercado Común del Sur

MMha: millones de hectáreas

MMt: millones de toneladas

OJ: Official Journal of the European Union

RIAN: Red de Información Agropecuaria Nacional

USDA: United States Department of Agriculture

ZAH: Zonas Agroeconómicas Homogéneas 


\section{RESUMEN}

Aspergillus flavus es la principal especie asociada a la contaminación con aflatoxinas en granos de maíz. Altos niveles de esta toxina en subproductos de maíz fueron reportados en la industria maicera argentina. Es muy escasa la información acerca de la respuesta de híbridos de maíz a A. flavus empleados en la provincia de Córdoba, información necesaria para desarrollar estrategias de manejo a fin de lograr bajo nivel de incidencia y severidad de este patógeno y de aflatoxinas en grano. El objetivo de este trabajo fue evaluar la respuesta de híbridos de maíz a la infección experimental con A. flavus en la zona centro de la provincia de Córdoba. El ensayo se realizó en el INTA Manfredi durante las campañas 2014/15 y 2015/16. Se utilizó un diseño de parcela dividida, donde la parcela principal fue la fecha de siembra y las parcelas secundarias fueron los cultivares y dentro de éstas fueron asignadas las técnicas de inoculación. La siembra se efectuó en 2 fechas, septiembre y diciembre. Se evaluó la severidad en la espiga con el uso de una escala de síntomas diagramática, la incidencia mediante incubación de granos en medio agar y la presencia mediante la técnica de luz UV ( $\lambda$ : $365 \mathrm{~nm})$. La determinación de la incidencia del hongo fue más confiable que la severidad ya que la espiga puede o no presentar síntomas y la técnica de luz UV dio falsos positivos. La mejor técnica de inoculación de A. flavus en espigas de maíz fue el uso de jeringa automática inyectando en el canal de estigmas y la fecha de siembra menos afectada fue diciembre. Existe un comportamiento diferencial de los híbridos al patógeno, información valiosa que permite a los productores tomar decisiones de manejo a fin de evitar o disminuir la enfermedad.

Palabras claves: A. flavus, cultivares, fecha de siembra, inoculación, maíz. 


\begin{abstract}
Aspergillus flavus is the main species associated with aflatoxin contamination in corn. In Argentina, high levels of this toxin were informed by the corn industry. However, there is little information about how corn cultivars used in the province of Cordoba, Argentina, respond to A. flavus infection. Such information is essential to developing management strategies aimed at lowering both the severity and incidence levels of the infection caused by this pathogen and aflatoxin contamination in corn grains. The main goal of this study was to evaluate corn cultivars' response to the artificial infection of $A$. flavus in the central region of the province of Cordoba. The trial was carried out at INTA Manfredi over the 2014/15 and 2015/16 crop seasons. The design used was split plot, where the main plot was the sowing dates and the secondary plots were the cultivars and within these assigned the inoculation techniques. Sowing was carried out on two different times on September and December. Severity was assessed using a visual scale; incidence was measured by grain incubation on agar medium, and presence was determined using the bright greenish yellow fluorescence (BGYF) presumptive test ( $\lambda 365)$. The determination of the incidence of the fungus is more reliable than the severity since the spike may or might not present symptoms and the BGYF false positives. The best technique of inoculation of $A$. flavus in corn spikes is the use of automatic syringe injecting into the channel of stigmas, the sowing date less affected was December and there is a differential behavior of the cultivars to the pathogen. This is a valuable source of information which allows corn growers to make management decisions in order to avoid or decrease the disease.
\end{abstract}

Key words: A. flavus, corn, hybrids, inoculation, sowing date. 


\section{A- INTRODUCCIÓN}

\section{A.1. Presentación del problema}

Las aflatoxinas, producidas por hongos del género Aspergillus conforman un grupo de micotoxinas relevante, para el que muchos mercados han establecido umbrales máximos de contaminación (Etcheverry et al., 1999; MAFF, 1999). A medida que se genera nueva información respecto al riesgo que implica la exposición a estos compuestos, los mercados tienden a incrementar las restricciones generando la necesidad de lograr tecnología para reducir los niveles de contaminación al mínimo técnicamente posible. En este sentido se han reportado altos niveles de aflatoxinas en subproductos de la industria maicera argentina. En algunas campañas agrícolas más del 30\% de la cosecha de algunas regiones ha registrado la presencia de la toxina (Camiletti et al., 2017).

Aspergillus flavus Link: Fr. y Aspergillus parasiticus Speare, incluidos en la sección Flavi, son consideradas las especies mayormente asociadas a la contaminación con aflatoxinas en maíz. A. flavus es la especie prevalente y que causa mayores problemas de contaminación en la mayoría de los ecosistemas estudiados (Cardwell and Cotty, 2002; McGee et al., 1996).

Se han hecho prospecciones de enfermedades en algunas localidades de la región maicera argentina como en la provincia de Buenos Aires, sobre muestras de grano y subproductos de maíz (Etcheverry et al., 1999) y en la provincia de Córdoba, sobre muestras de suelo, rastrojos e insectos obtenidas en campos cultivados con maíz, indicando que $A$. flavus también es prevalente en Argentina (Nesci y Etcheverry, 2002). Torrico et al. (2016) evaluaron la incidencia de patógenos de semilla en maíz durante 3 campañas consecutivas $(2012 / 13$, 2013/14 y 2014/15) en 59 lotes ubicados en la región agrícola central de Argentina, encontrando en las 2 primeras campañas 66 cepas de $A$. flavus de los cuales 3 no produjeron aflatoxinas.

Actualmente, en Córdoba se cuenta con escasos estudios acerca del comportamiento de híbridos de maíz a $A$. flavus. Esta información sería muy útil y necesaria como estrategia de manejo para este patógeno de espigas y, consecuentemente, evitar aflatoxina en grano. 
Cleveland y Bhatnagar (1992) indicaron que el desarrollo y uso de híbridos resistentes a Aspergillus spp. y/o a la acumulación de aflatoxinas es considerado como uno de los enfoques más efectivos para reducir la contaminación, la caracterización de la población del patógeno es un paso relevante en el desarrollo de resistencia genética.

Las técnicas de inoculación experimental empleadas a campo hasta el presente no han logrado obtener buenas evaluaciones para la infección con A. flavus, herramienta básica para los patólogos y mejoradores para poder continuar con estudios de interés. Como así también el uso de una técnica empleada en la industria de la molienda húmeda maicera que la detección de la presencia de $A$. flavus en granos de maíz con fluorescencia bajo luz UV, técnica mediante la cual según sus resultados, los cuales son muy subjetivos, se acepta o rechazan los camiones con granos provenientes directamente del campo.

También las fechas de siembra de maíz en la zona central del país van siendo cada vez más tardías, principalmente por la falta de precipitaciones en los meses de primavera, esta modificación del ambiente del cultivo puede afectar el comportamiento del genotipo y del patógeno. 


\section{A.2. Antecedentes}

\section{A.2.a. El cultivo de maíz}

El maíz (Zea mays L.) es una gramínea originaria de América, con centro de origen en América Central y México y varios centros de diversidad a lo largo de la Cordillera de los Andes. Se han formulado diversas teorías respecto del origen del maíz cultivado, y en general se acepta que las especies silvestres teosinte y Tripsacum han estado asociadas al proceso de evolución del maíz. Se trata de una especie diploide, que consta

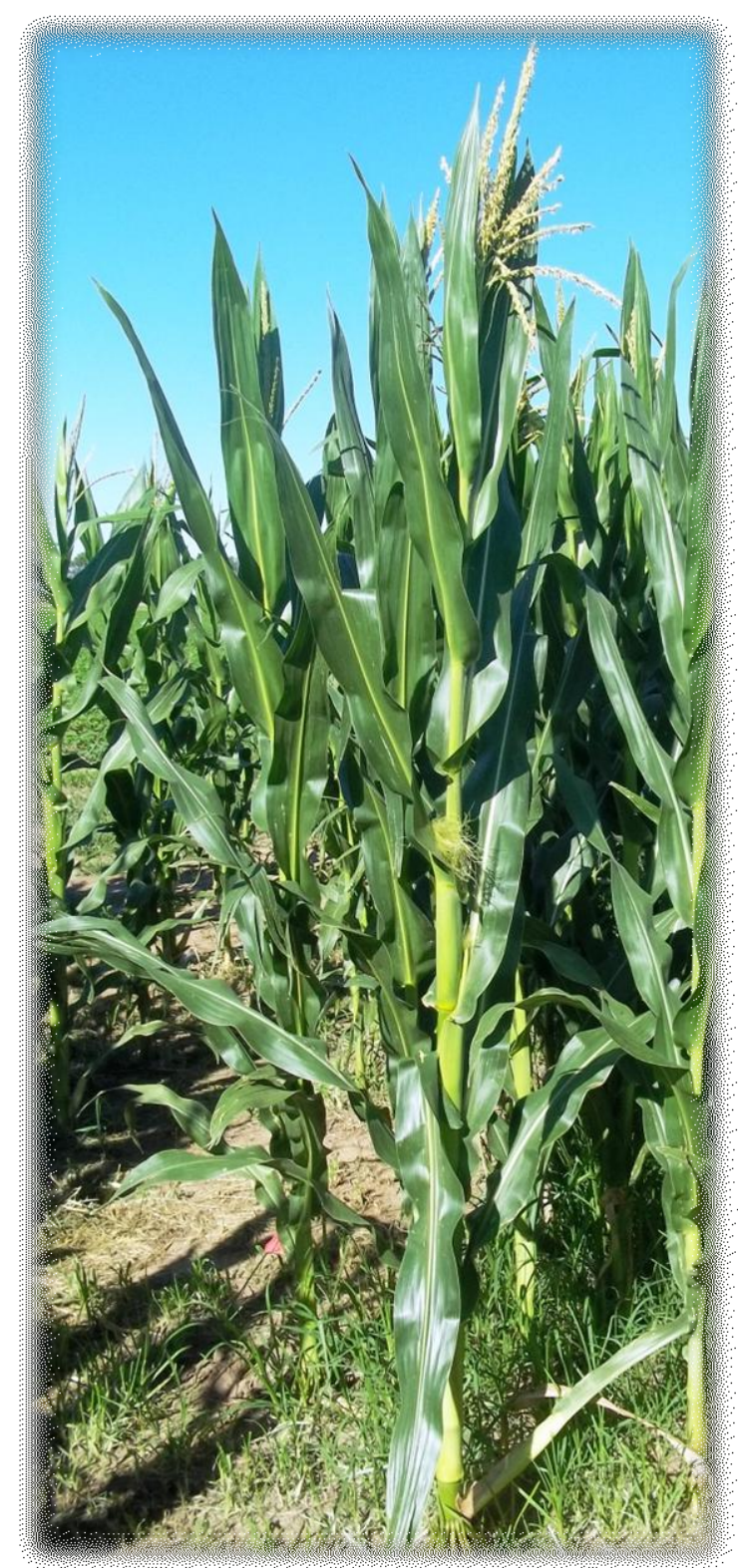
de diez pares de cromosomas $(2 \mathrm{n}=2 \mathrm{x})$, se reproduce por semillas resultantes de la fecundación cruzada de óvulos dispuestos en una inflorescencia femenina (espiga), generalmente única y ubicada en posición axial. La fecundación se realiza con granos de polen producidos en una inflorescencia masculina (panoja) ubicada en la porción apical del tallo. La polinización es anemófila y el porcentaje de autofecundación es muy reducido. (Eyhérabide, 2012)

Figura 1: Planta de maíz. 
El maíz, es una especie monocotiledónea anual perteneciente a la familia de las Poáceas (gramíneas) que no se encuentra en estado silvestre (Buntig et al., 1982). Es una de las plantas domesticadas más antiguas y fue cultivada durante muchos siglos por los indígenas del continente americano, quienes obtuvieron mejoras genéticas sobresalientes, logrando variedades de maíces amiláceos, dulces, duros y dentados. Es uno de los alimentos más importante de los habitantes de México, Centro América y varios países de América del Sur (INTA, 1980), como así también en el continente africano (Rheeder et al., 1992).

\section{A.2.a.1. Contexto internacional.}

\section{Producción}

La producción mundial de maíz creció en los últimos 35 años a una tasa promedio anual del 2,9\%, ritmo que implica la duplicación de la cosecha en menos de tres décadas. De esta manera, se pasó de cerca de 300 millones de toneladas (MMt) promedio en la década del '70 a 818,8 millones en el año 2009 (Goizueta, 2014).

Los mayores productores mundiales de maíz son Estados Unidos y China (Tabla 1). Según los analistas del mercado (Muñoz, 2016) la producción esperada 2016/17 en EEUU, principal país productor, superará a la del ciclo anterior en $21 \mathrm{MMt}$ con lo que el stock final crecerá en $8 \mathrm{MMt}$ y la relación stock final /consumo se ampliará de 14,4\% a 16,4 \%. A su vez, a nivel mundial la producción esperada será de 1.011,8 MMt, con un aumento de 45,4MMt sobre el ciclo pasado manteniéndose una relación stock /consumo en $20 \%$, esto hace que el precio esperado mundial se mantenga en niveles similares a los de la última campaña (Ghida Daza, 2016). 
Tabla 1: Producción mundial de maíz. Campaña 2016/17 (CNPAMM, 2017)

\begin{tabular}{|c|c|}
\hline Países & Producción (MMt) \\
\hline 1. Estados Unidos & 383 \\
\hline 2. China & 216 \\
\hline 3. Brasil & 82,5 \\
\hline 4. Unión Europea & 61 \\
\hline 5. Argentina & 36,5 \\
\hline 6. Ucrania & 26 \\
\hline 7. México & 24,5 \\
\hline 8. India & 24,5 \\
\hline 9. Rusia & 14 \\
\hline 10. Sudáfrica & 13 \\
\hline
\end{tabular}

\section{Consumo}

El consumo mundial de maíz ha crecido constantemente en los últimos 20 años a una tasa promedio anual del 3\%, pasando de las 473,4 MMt anuales en 1990/91 a 842,4 MMt en el año 2010/11 (USDA, 2011). El maíz destinado a consumo alimentario e industrial, que representaba el 30\% del consumo mundial en el año 2000/01, pasó al $41 \%$ en el año 2010/11 en detrimento del maíz con destino a alimentación animal. En este aspecto es importante destacar que de las 209,5 MMt que aumentó el consumo industrial entre el 2000/01 y el 2010/11, unas 112 MMt corresponden a lo que demanda la industria del etanol sólo en Estados Unidos (Goizueta, 2014).

Entre los países de mayor consumo se encuentran EEUU (35\% del consumo mundial), China (20\%) y el conjunto de la UE (7\%); con un peso relativo menor le siguen Brasil, México y Japón (Goizueta, 2014).

\section{Comercio}

Argentina es uno de los países del mundo que más maíz exporta en relación al maíz que produce (alrededor del 60\%, cuando en Brasil es el 20\% y en Estados Unidos el 15\%). El hecho que un elevado porcentaje de maíz se exporte como grano significa que Argentina está desaprovechando oportunidades de transformación de ese maíz en otros productos (carnes, huevos, leche, productos industriales) (Garzón y Rossetti, 2013). 
Las exportaciones de maíz en grano representan el $45 \%$ del total del valor de las exportaciones mundiales del complejo de maíz; el otro 55\% corresponde a productos industrializados, entre los cuales el producto más importante es el alimento para animales $(55,8 \%)$, seguido por el etanol $(17,8 \%)$, los cereales para desayuno y barras $(10,7 \%)$ y los endulzantes $(6,2 \%)$ (Goizueta, 2014).

El maíz es el segundo cereal más sembrado en el mundo, después del trigo. De acuerdo a estadísticas del Departamento de Agricultura de Estados Unidos (USDA), se siembran cerca de 177 millones de hectáreas (MMha) de maíz en el mundo. Un porcentaje importante de estas semillas son provistas vía comercio internacional. Las estadísticas de comercio mundial refieren a 1,2 MMt de semillas exportadas en el 2012, mercado en el cual Argentina participa con menos del 5\% (Garzón y Rossetti, 2013).

\section{Inserción de Argentina en el mercado mundial}

La importancia de los cereales en Argentina queda claramente reflejada en los niveles de producción de grano, el lugar que ocupa el país como productor a nivel mundial, su nivel de industrialización, los volúmenes de exportación (Eyhérabide, 2012).

El cultivo del maíz constituye en el año 2010 el segundo rubro en importancia dentro de la producción primaria de granos, representando el 24\% (22,7 MMt) de la producción de cereales y oleaginosas y el 12,6\% (3,7 MMha) de las hectáreas sembradas en el país. Del total producido, 15,5 MMt se destinaron a la exportación (68\%) y el resto se consumió internamente, utilizándose en la industria o en la elaboración de raciones. Del maíz destinado a consumo interno, 5,8 MMt (26\%) se utilizó en producción animal (del cual 2,3 MMt tiene como destino la industria del balanceado) y 1,3 MMt (6\%) a la industria de la molienda húmeda y seca (MAGyP, 2011).

La producción y la exportación de maíz describen trayectorias similares entre 2002 y 2010, presentando un incremento del 54\% y 85\%, respectivamente (Goizueta, 2014).

\section{A.2.a.2. Contexto nacional}

\section{Zonas productoras}

La región maicera templada de Argentina se extiende entre los paralelos de $31^{\circ}$ y $40^{\circ} \mathrm{L}$ $\mathrm{S}$ y entre los meridianos $57^{\circ}$ y $65^{\circ} \mathrm{L} \mathrm{O}$ de la pampa húmeda y subhúmeda (Figura 2). En esta área, los factores climáticos (lluvias, temperaturas, evaporación, etc.), a través 
de su acción individual o conjunta, introducen el «azar» en los sistemas productivos, hecho que repercute fuertemente en el volumen total producido. (Totis de Zeljkovich, 2012)
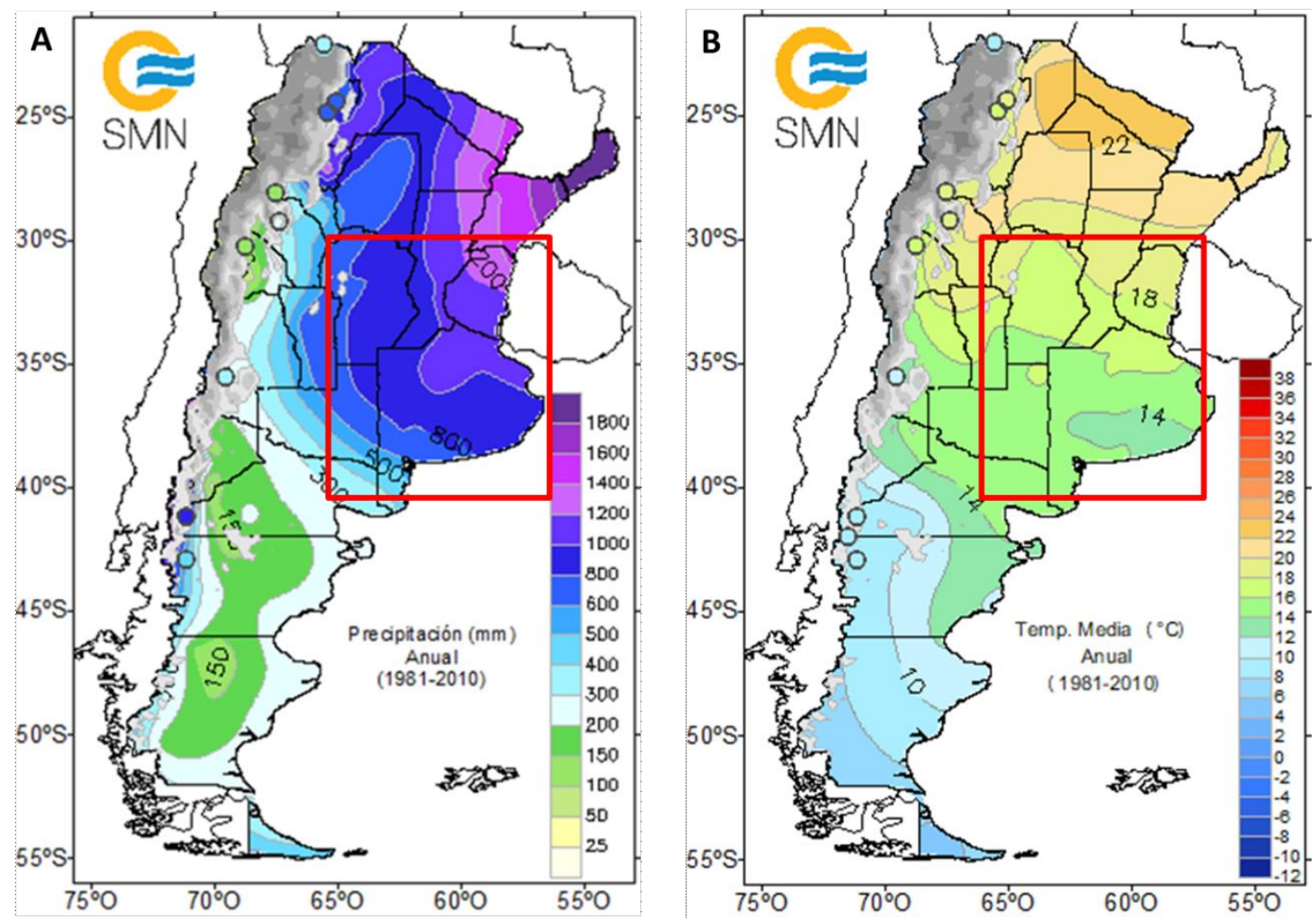

Figura 2: A) Precipitación anual de Argentina periodo 1981-2010 B) Temperatura media anual de Argentina periodo 1981-2010. En recuadro la región maicera templada.

Fuente: Servicio Meteorológico Nacional (2018)

De acuerdo con la caracterización climática de Koeppen, la región pampeana corresponde a un clima subtropical húmedo, con un verano muy cálido, y sin estación seca (Guevara, 1991). El período medio libre de heladas varía entre 180 y 260 días por año, con una disminución desde el N-NE hacia el S-SO, presenta una marcada variabilidad interanual tanto en la fecha de la primera como de la última helada. La amplitud térmica anual es de 12 a $15^{\circ} \mathrm{C}$ y aumenta de $\mathrm{E}$ a $\mathrm{O}$. El cociente fototermal o relación entre la radiación y la temperatura media sobre el umbral de crecimiento para el cultivo $\left(8^{\circ} \mathrm{C}\right)$, el cual presenta una asociación positiva con los rendimientos del maíz en condiciones hídricas, densidades y fechas de siembra óptimas (Andrade, 1992), presenta valores menores en el $\mathrm{N}\left(1,74 \mathrm{Mj} / \mathrm{m}^{2}\right.$ día $^{\circ} \mathrm{C}$ para Pergamino, Bs. As. $)$ y mayores en el $\mathrm{S}$ (2,13 Mj/m² día ${ }^{\circ}$ c para Viedma, Río Negro) (Totis de Zeljkovich, 2012). 
El cultivo se lleva a cabo en un amplio rango de temperaturas medias que oscilan entre $13-32^{\circ} \mathrm{C}$, con precipitaciones entre 500-2000 $\mathrm{mm}$ (Buntig et al., 1982). Las precipitaciones se reciben en mayor proporción desde la primavera hasta el otoño, incrementándose las lluvias invernales hacia el S. Las precipitaciones de la región presentan, además, gran variabilidad espacial, y elevada intensidad, hecho que sumado a las características físicas de gran parte de los suelos y a los elevados valores de evapotranspiración máxima (ETM) que se registran durante el verano, determina la ocurrencia de sequías de distinta intensidad y duración. Estas son las causas principales de la variabilidad interanual de los rendimientos del cultivo de maíz en el área y de la respuesta a la fertilización nitrogenada (Totis de Zeljkovich et.al., 1992; Totis de Zeljkovich, 2012).

La fecha de siembra del cultivo de maíz es otro aspecto a considerar. En la zona núcleo maicera la estabilidad del rendimiento en siembras tempranas se ve comprometida debido a la ocurrencia de sequías en el período crítico, momento en que el cultivo tiene una elevada demanda hídrica. Por otro lado, si se atrasan las siembras, el cultivo está más expuesto a ataques de orugas de Lepidópteros que afectan severamente el rendimiento y aparecen enfermedades que no están presentes en las siembras tempranas. Con la aparición de híbridos Bt y el desarrollo de tecnologías para el control de las principales orugas que afectan la planta y la espiga, es posible retrasar la fecha de siembra a principios de diciembre, de modo que la floración ocurra a mediados de febrero y así escapar a los períodos de sequía durante el período crítico. Como desventaja, el cultivo florece con menor intensidad de radiación, debido al acortamiento de los días, y el potencial de rendimiento es menor (Presello et al., 2016).

La fecha de siembra afecta a otros caracteres como el secado de grano a campo y las enfermedades, teniendo en cuenta que los ambientes de ambas épocas predisponen al cultivo a diferentes patógenos.

\section{Producción}

El área sembrada con maíz y sorgo crece a un $10 \%$ anual al considerar como punto de partida la evolución de la superficie de las campañas 2005, 2006 y 2007 donde se comenzó a reflejar el cambio en la demanda mundial de granos forrajeros destinados a la industrialización con mayor valor agregado (MAIZAR, 2008). 
En el país, la superficie promedio de los últimos años destinada a este cereal es de 3,5 MMha, con un rendimiento de $7.000 \mathrm{~kg} / \mathrm{ha}$ aproximadamente (Figura 3) (MAGyP, 2017). La mejora tecnológica, la siembra directa, la fertilización, el riego, la eficiencia de cosecha y el alto rendimiento, han posicionado a la Argentina como el segundo exportador mundial de grano de maíz luego de Estados Unidos y el principal destino de éstos es para la elaboración de alimentos para las producciones pecuarias de todo el mundo (INTA, 2012).

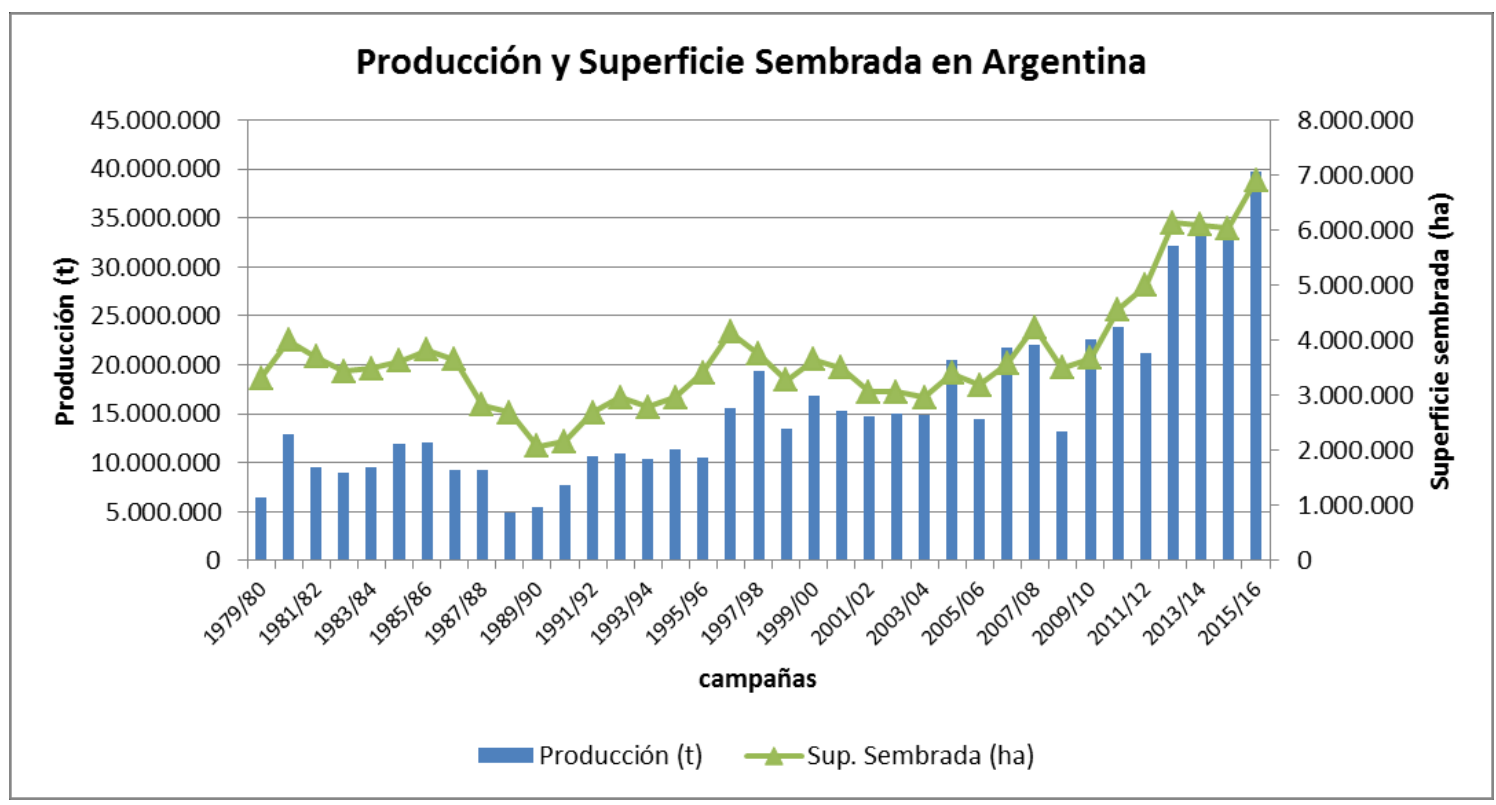

Figura 3: Producción y superficie sembrada de maíz en Argentina (ciclo 1979/80 - 2015/16). Fuente: elaboración propia con datos de MAGyP (2017)

Desde un punto de vista microeconómico, en la zona núcleo maicera argentina, el maíz se halla en desventaja frente a la soja y al trigo, pues es el que mayor inversión requiere en términos de gastos directos. Dentro de los costos, implantación y protección del cultivo, la semilla del híbrido es el componente de mayor peso (Lieutier, 2002). El área sembrada con maíz se encuentra entre los 3,5 y 4 MMha, a pesar de haber llegado a registros de 2 MMha a fines de los '80 y 3 MMha a principio del 2000. Esta evolución del área sembrada está asociada además a una relocalización del cultivo hacia áreas marginales. En efecto, en las principales zonas se observa cierto desplazamiento a favor de la soja, debido a factores locales e internacionales que le han dado mayor rentabilidad a ese producto. El aumento de los rendimientos compensa la estabilización del área sembrada, con lo cual la producción mantiene una tendencia creciente que pasa de 6,4 MMt en 1980 a 22,7 MMt en el 2010 (Goizueta, 2014). 
En Argentina el maíz se produce en una extensa superficie, aunque el $72 \%$ de la superficie sembrada y el $83 \%$ de la producción se concentran en las provincias de Córdoba, Buenos Aires y Santa Fe con 27\% y 30\%, 31\% y 36\%, y 14\% y 17\% de área sembrada y producción respectivamente (Goizueta, 2014). En Córdoba ocupa el segundo lugar de área sembrada con un 35\% después del cultivo de soja, con una superficie promedio en los últimos 30 ciclos agrícolas, de 980.268 ha y una producción estimada en 4.651.814 t. (Figura 4) (MAGyP, 2017).

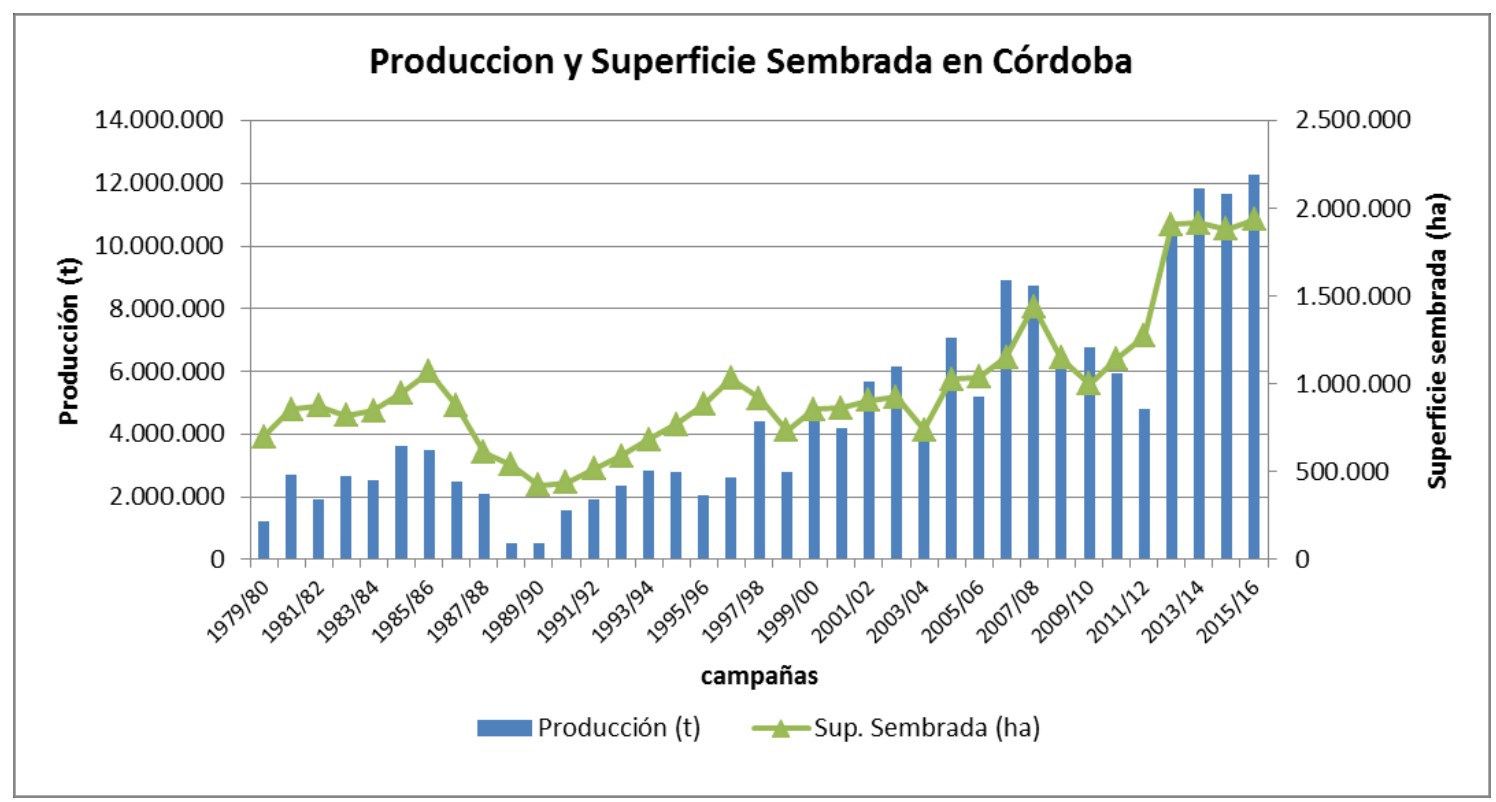

Figura 4: Producción y superficie sembrada de maíz en la provincia de Córdoba (ciclo 1979/80 2015/16). Fuente: elaboración propia con datos de MAGyP (2017)

Las excepcionales condiciones edafoclimáticas de Córdoba (buena fertilidad y adecuado nivel de lluvias) permiten que en la actualidad sea una de las principales productoras de granos de Argentina, especialmente en cereales y oleaginosas. El territorio de la provincia tiene una extensión de $165.321 \mathrm{~km}^{2}$ (que equivale a 16,5 MMha), según el barrido del Censo Nacional Agropecuario 2008, aproximadamente 11,2 MMha revelaron uso agropecuario de diversa intensidad (agricultura extensiva e intensiva, y ganadería extensiva e intensiva) (Garzón et al., 2015).

El incremento del área de cultivo de maíz en la región núcleo argentina es altamente adecuado para lograr un esquema de rotaciones compatible con la sustentabilidad ambiental y para ello es importante el resultado económico del cultivo. Las diferencias en el comportamiento de los híbridos observadas en distintos ensayos ayudan a la elección del cultivar como estrategia de manejo para lograr mayores y más estables 
rendimientos, manejar problemas relacionados a estreses bióticos y abióticos o aprovechar precios diferenciales relacionados a atributos de calidad del grano (Presello et al., 2016).

\section{Industrialización}

Junto con el trigo y el arroz son los tres principales cultivos cerealeros del mundo (INTA. 2012). La transformación de materias primas en productos de mayor valor es esencial para el desarrollo de nuestro país y el grano de maíz es la principal materia prima para sectores cada vez más relevantes de la economía de los países. Algunos sectores encuentran por primera vez en su historia una oportunidad de crecimiento única pudiendo aspirar a transformarse en líderes mundiales con productos de alta calidad basados en la disponibilidad de maíz en gran cantidad a un bajo costo. Los puntos centrales son: avicultura, ganadería vacuna, cerdos, lechería, molienda húmeda, molienda seca, biocombustibles y energías renovables, biomateriales (MAIZAR, 2008).

Actualmente es una de las materias primas más importantes, ya que es el sustento de la producción animal en el mundo como también para la industria de alimentos. Con la aparición de los biocombustibles, se transformó en el principal insumo utilizado para la fabricación de etanol, biogás y biodiesel y es también esencial para el desarrollo de los nuevos materiales biodegradables como los bioplásticos. El maíz presenta ventajas sobre los derivados del petróleo, ya que es un recurso renovable, los productos finales obtenidos son biodegradables y su degradación no altera el balance de anhídrido carbónico atmosférico. Así los países que no podían aumentar sus materias primas agrícolas, están invirtiendo para crear cadena de valor alimenticias y de energía renovables (MAIZAR, 2008).

Esta diversidad de usos la convierte en una cadena de alta complejidad por la heterogeneidad de actores, actividades y procesos industriales (Figura 5). Paralelamente, le da la característica de poseer un importante potencial para el desarrollo y profundización de alternativas con agregado de valor (Goizueta, 2014). 


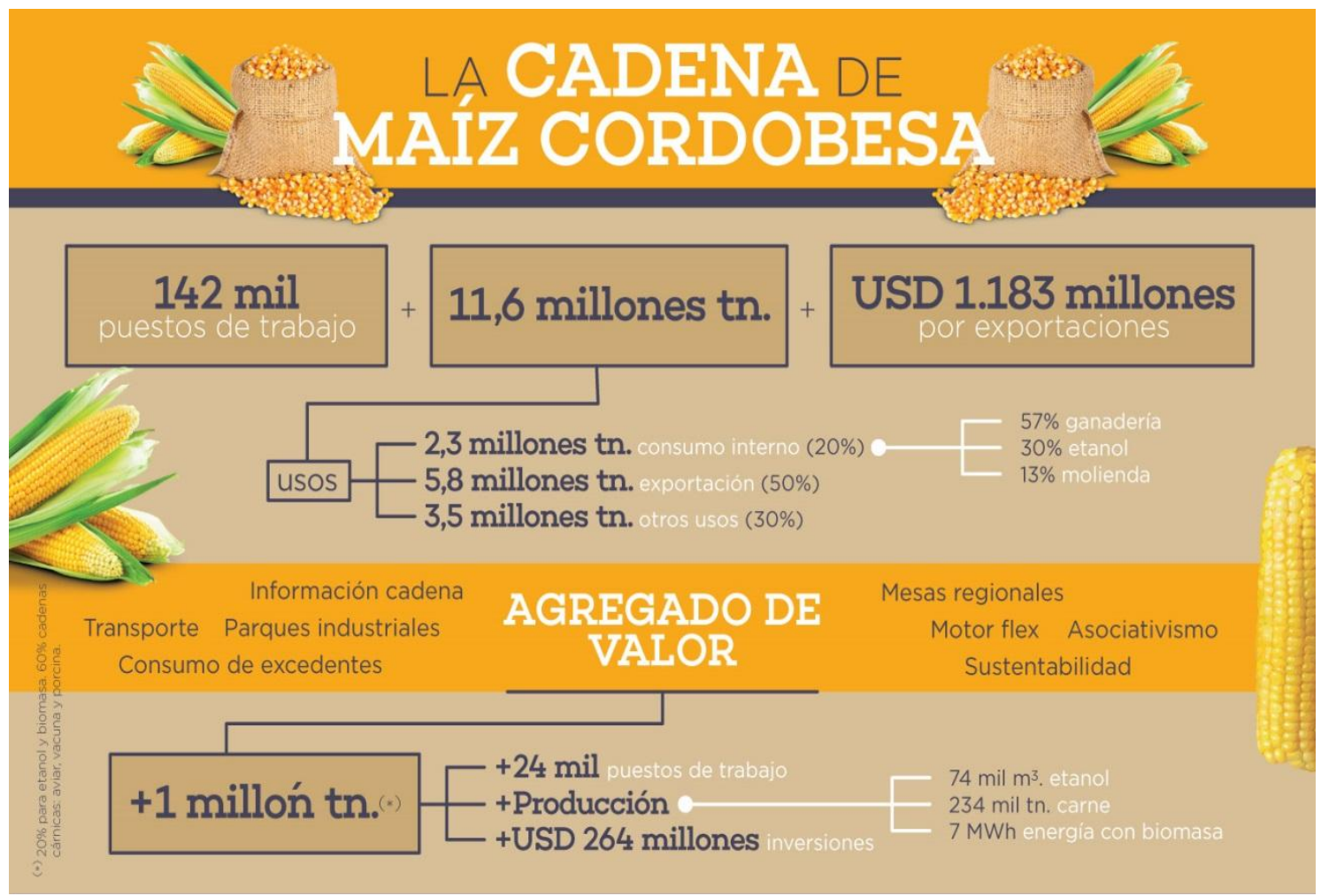

Figura 5: Cadena de maíz de la provincia de Córdoba (FADA, 2016)

La calidad de uso del maíz está determinada principalmente por la estructura y composición del grano. (Cirilo y Andrade, 1998; Watson, 1988). Las diferencias en estructura y composición dependen del cultivar así como de las prácticas de manejo, el clima, el suelo y los métodos de cosecha y poscosecha. Los cultivares de maíz difieren en atributos de la calidad del grano, tanto físicos como químicos (Eyhérabide et. al., 2007, MAIZAR, 2012).

La industria de la molienda seca de maíz consiste en un proceso industrial de transformación del cereal mediante el cual se elaboran harinas, sémolas y trozos, productos que se diferencian básicamente por su granulometría. Los destinos principales de los productos de estos molinos pueden ser el consumo humano o el uso en otras industrias alimenticias (Garzón et al., 2015).

La molienda húmeda es tecnológicamente más sofisticada que la molienda seca; consiste en la separación de las partes del grano (germen, fibra, gluten y almidón) mediante procesos físicos, continuos que se realizan en agua. De los cuatro componentes del grano de maíz, el objetivo de la molienda húmeda es la obtención del almidón, pero en ese proceso se van obteniendo otros productos (Garzón et al., 2015). Durante el procesamiento de la molienda húmeda las aflatoxinas se concentran en los 
subroductos con gluten. Una estimación aproximada es que los niveles de aflatoxinas en estos subproductos alimenticios son tres veces más que las de maíz entero (Munkvold et al., 2012)

Incentivada por factores impositivos (Ley $\mathrm{N}^{\circ} 26.093$ ), productivos (posibilidad de transformar el abundante maíz disponible) y del contexto del mercado energético (pérdida del autoabastecimiento energético), la producción de bioetanol a base de maíz en Argentina aumentó considerablemente. Este fuerte incremento en la producción se debió fundamentalmente al uso del maíz en la actividad. Hasta el año 2012 solo se producía etanol a base de caña de azúcar, mientras que a partir de ese año, cuando se inaugura la primera planta a base de maíz, la producción crece exponencialmente año a año, siendo que la de caña lo hace muy poco y luego se estabiliza. Así, ya en 2013, con sólo dos plantas en actividad hasta finales de año, el maíz representó el 35\% de la producción total de bioetanol, y en 2014, con cincos plantas funcionando, se estima una participación del 58\% del total (Garzón et al., 2015).

Siguiendo la definición del INASE, semillas fiscalizadas son aquellas cuyo proceso de producción comienza en el control del origen de la semilla que se siembra, continúa con la inspección de los lotes de producción y cosecha y finaliza en el acondicionamiento, envasado y rotulado del producto final. Considerando los principales cultivos de la provincia de Córdoba, la producción de semillas para híbridos de maíz, sorgo y girasol tiene un importante grado de especialización, las labores a realizar son mayores y por lo tanto el costo de producción, por lo que usualmente estos campos se destinan en forma exclusiva a la producción de semillas. Córdoba aportó el 17,5\% de la producción nacional de semillas fiscalizadas de maíz durante la campaña 2011/12. Resulta importante advertir que la mazorca producida en la provincia se exporta a plantas ubicadas en provincias vecinas, donde la semilla será tratada, embolsada y enviada a los distintos destinos y mercados, entre ellos, la propia provincia de Córdoba (Garzón et al., 2015).

La calidad de las semillas de maíz también es definida a través de su pureza varietal, vigor, poder germinativo y sanidad. Este último atributo merece especial consideración, ya que una gran cantidad de microorganismos pueden ser transportados por semillas y sobreviven con ella por largos períodos. Cuidar las semillas frente al ataque de diversos patógenos, en el inicio del ciclo, es de fundamental importancia ya que la viabilidad será 
un factor determinante en el futuro stand de plantas, lo que sin duda repercutirá directamente en el rendimiento final del cultivo (INTA, 2012).

\section{A.2.a.3. Enfermedades del maíz}

La mayor parte de las enfermedades de las plantas son causadas por hongos, los cuales pueden ser parásitos o saprófitos. Algunos pueden vivir de una $\mathrm{u}$ otra forma dependiendo de las condiciones de ambiente y otros son parásitos obligados, requiriendo tejido vivo (Botta y Gonzalez, 2012).

Los hongos pueden atacar todas las partes de la planta y causar una amplia variedad de síntomas, desde podredumbre de raíces y manchas en hojas, hasta marchitamientos y enanismos. El método y sitio de infección están muy relacionados con la forma de diseminación. Los hongos patógenos habitantes del suelo son diseminados por el movimiento del suelo o por el rastrojo de plantas infectadas; en cambio los que atacan la parte aérea son diseminados por las corrientes de aire, la salpicadura de las lluvias o los insectos. Muchos hongos son diseminados por semillas infectadas u otros tejidos (Botta y Gonzalez, 2012).

En la Argentina la diversificación de ambientes en donde actualmente se cultiva maíz y la ampliación de la fecha de siembra, entre otros factores, han creado un corredor verde de este cultivo que se extiende prácticamente todo el año calendario. Esto genera, especialmente en años Niño, con otoños templados-cálidos e inviernos benignos, ambientes propicios para el progreso de enfermedades tradicionales y la detección y aumento de nuevas patologías (Couretot et al., 2016).

Las principales enfermedades fúngicas en el cultivo de maíz son: la roya común (Puccinia sorghi) y el tizón foliar (Exserohilum turcicum) que se presentan todos los años con diferentes niveles de severidad según las condiciones climáticas, el material genético sembrado y los biotipos de los patógenos presentes. Así mismo en las últimas campañas, se observaron con distintos niveles de severidad, lesiones foliares de origen bacteriano así como también nuevas enfermedades fúngicas (Couretot et al., 2016).

Las podredumbres de raíz y base del tallo también son enfermedades de importancia en la zona núcleo maicera. Los patógenos asociados a este tipo de podredumbre son un complejo de hongos necrotróficos y ocasionalmente bacterias (Carmona et al., 2006; Díaz, 2011; Marinelli et al., 2010; Parisi y Couretot, 2010). Los hongos más 
frecuentemente detectados son: Fusarium graminearum, Fusarium verticilloides, Stenocarpella macrospora, Stenocarpella maydis, Colletotrichum graminicola, Macrophomina phaseolina (De Rossi et al., 2017).

De los patógenos que se encuentran en el suelo, el más común es Pythium spp., además de hongos de los géneros Fusarium, Penicillium y Aspergillus (Botta y Gonzalez, 2012).

Los hongos asociados a la semilla son comúnmente aquellos que producen la podredumbre de la espiga y los detectados frecuentemente son: Fusarium graminearum, Fusarium verticilloides, Stenocarpella maydis, Aspergillus spp., Penicillium spp. (De Rossi et al., 2017).

Para el manejo de las enfermedades, es recomendable aplicar buenas prácticas, donde las principales medidas son: selección de materiales tolerantes o resistentes, utilizar semillas sanas y con tratamiento de fungicida correcto, sembrar en la época adecuada para evitar que los períodos críticos del cultivo coincidan con las condiciones ambientales más favorables para el desarrollo de las enfermedades, rotar cultivos, fertilización equilibrada, densidad de plantas adecuada, control de malezas e insectos, aplicación de fungicidas cuando es necesario y recomendado, cosechar correctamente en tiempo y forma (Munkvold \& White, 2016; Reis et al., 2004) y monitoreo de los lotes. Estas medidas, además de traer un beneficio inmediato al productor por reducir el potencial inóculo de los patógenos presentes en el lote, contribuyen a la durabilidad y estabilidad de la resistencia genética presente en los híbridos comerciales por reducir la población de agentes patogénicos. (De Rossi et al., 2017).

La resistencia a hongos toxicogénicos en maíz es de tipo parcial, es decir que todos los híbridos son colonizados por el patógeno, pero mientras los más susceptibles presentan un alto porcentaje de espigas con síntomas severos, con bajo peso y alta concentración de micotoxinas, los menos susceptibles mantienen sus espigas en un rango de severidad de síntomas leve con escaso impacto en el rendimiento y la inocuidad del grano (Presello et al., 2016).

El germoplasma de maíz argentino expresa mecanismos de defensa ante la invasión fúngica, que incluyen una alta tasa de senescencia de estigmas que disminuye la exposición y la posterior entrada del hongo al grano por esa vía, la emisión de 
compuestos volátiles en estigma y grano, o el espesor y el contenido de compuestos fenólicos del pericarpio. Estos son mecanismos de resistencia amplia, es decir efectivos para varias especies fúngicas. La resistencia a podredumbres de espiga implica un menor desarrollo de micelio y por lo tanto menor posibilidad de concentración de micotoxinas en grano (Fernández et al., 2014, Oviedo et al., 2014).

\section{A.2.b. El género Aspergillus}

En 1729 el género Aspergillus fue mencionado por primera vez por el biólogo italiano Pier Antonio Micheli quien usó el nombre Aspergillum por el parecido del hongo con el instrumento usado para dispersar agua bendita. La descripción hecha por Micheli de este género de hongo en su obra Nova Plantarum Genera tiene importancia histórica, al ser reconocido como el punto inicial de la ciencia de la micología (https://www.ecured.cu/AspergilLus flavus).

Aspergillus es un género que contiene alrededor de 200 especies (mohos), y es ubicuo. Es un hongo filamentoso (compuesto de cadenas de células, llamadas hifas), diferente a las levaduras, estas últimas compuestas de una sola célula redondeada.

El color es la principal característica macroscópica para la identificación de los grupos de Aspergillus. Poseen distintos tonos de verde, pardo, amarillo, blanco, gris y negro. Las cabezas conidiales presentan bajo el microscopio cuatro formas básicas: globosa, radiada, columnar o claviforme (Figura 6) y a simple vista las más grandes suelen parecer diminutas cabezas de alfiler sobre el substrato (Kozakiewicz 1989). 


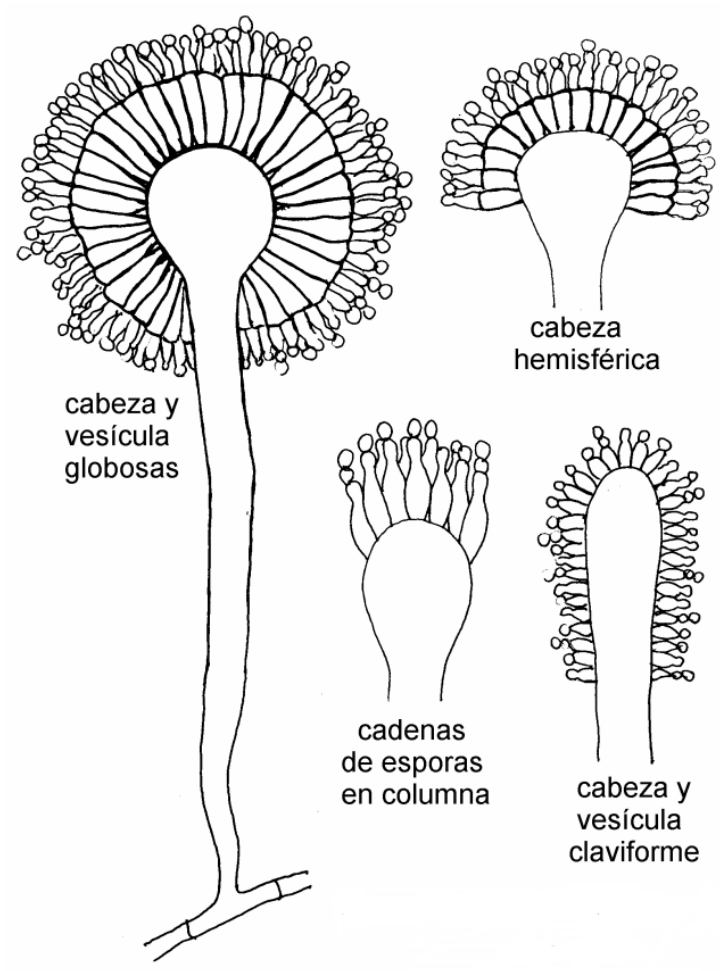

Figura 6: Formas básicas de las cabezas conidiales de Aspergillus (Carrillo, 2003).

En este género, los conidios constituyen cadenas que se originan en la célula conidiógena o fiálide y en algunos hay células adyacentes a las fiálides denominadas métulas o células de soporte. Poseen una o dos series de células sobre la vesícula, o bien presentan simultáneamente cabezas de ambos tipos (Kozakiewicz 1989).

Las características macro y micromorfológicas, como el color de los conidios, la forma de la cabeza, la superficie y dimensiones del conidióforo, la forma y textura de las esporas, han permitido agrupar las especies de Aspergillus en secciones o grupos (Tabla 2) (Klich and Pitt, 1992). 
Tabla 2: Características de los grupos/secciones de Aspergillus (Klich and Pitt, 1992).

\begin{tabular}{|c|c|c|c|c|c|c|}
\hline Sección & Especie & Conidios & Métula & Vesícula & \begin{tabular}{|l|} 
Conidióforos \\
\end{tabular} & Otros \\
\hline Aspergilli & A. glaucus & verde, rugoso & no & globosa a espatulada & liso & $\begin{array}{l}\text { cleistotecio amarillo o } \\
\text { anaranjado, osmófilo }\end{array}$ \\
\hline Candidi & A. candidus & blanco & si & globosa & liso & esclerocio \\
\hline Cervini & A. cervinus & anaranjado & no & globosa & liso & - \\
\hline Circumdati & A. ochraceus & amarillo & si & globosa & liso o rugoso & esclerocio amarillo \\
\hline Clavati & A. clavatus & verde claro & no & claviforme & liso & \\
\hline Cremei & $\begin{array}{l}\text { A. } \\
\text { cremeoflavus }\end{array}$ & verde, pardo & si/no & globosa & liso & cleistotecio crema, osmófilo \\
\hline Flavipedes & A. flavipes & pálido, canela & si & espatulada & liso, pardo & células de Hülle \\
\hline Flavi & A. flavus & verde, pardo & si/no & globosa & rugoso & esclerocio \\
\hline Fumigati & A. fumigatus & verde azulado & no & espatulada & liso & - \\
\hline Nidulantes & A. nidulans & verde oscuro & si & espatulada & liso, pardo & $\begin{array}{c}\text { ascosporos rojos, células de } \\
\text { Hülle }\end{array}$ \\
\hline Nigri & A. niger & negro & si/no & globosa & liso & esclerocio \\
\hline Ornati & A. ornatulus & $\begin{array}{c}\text { aceituna, verde no } \\
\text { amarillento }\end{array}$ & no & espatulada & liso & - \\
\hline Restricti & A. restrictus & $\begin{array}{c}\text { verde oscuro, no } \\
\text { forma de tonel }\end{array}$ & no & piriforme & liso & osmófilo \\
\hline Sparsi & A. sparsus & aceituna, pardo & si & globosa a piriforme & rugoso & - \\
\hline Terrei & A. terreus & canela, pardo & si & globosa & liso & - \\
\hline Usti & A. ustus & gris aceituna & si & oval & liso, pardo & - \\
\hline \begin{tabular}{|l|} 
Versicolores \\
\end{tabular} & A. versicolor & verde & si & variable & liso & células de Hülle \\
\hline Wentii & A. wentii & beige & si & variable & liso a rugoso & - \\
\hline
\end{tabular}

La estructura microscópica de Aspergillus es única. Tienen hifas tabicadas y conidióforos cuya cabeza está localizada en el extremo de una hifa, compuesta por una vesícula rodeada por una corona de fiálides en forma de botella directamente inserta sobre la vesícula. De las fiálides se desprenden las esporas (conidios) (Figura 7) (Alcalá et al., 1997).

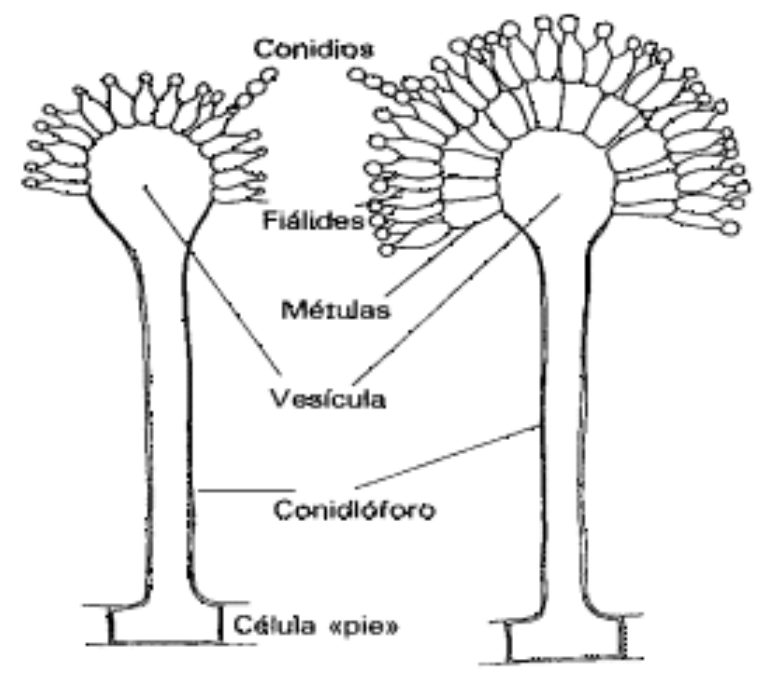

Figura 7: Estructuras microscópicas de Aspergillus (Alcalá et al., 1997). 
La mayoría de las especies del género Aspergillus son saprófitas que desempeñan un papel esencial en la degradación de la materia orgánica. Su hábitat natural es el suelo donde sobreviven y se desarrollan sobre materia en descomposición. Este género es uno de los más abundantes en la naturaleza y puede encontrarse en cualquier ambiente; se reproduce por conidios cuya germinación da origen a las hifas. Para su crecimiento, Aspergillus requiere de humedad relativa entre el 70 y $90 \%$, contenido de agua en la semilla entre 15 y $20 \%$ y un rango de temperatura amplio $\left(0\right.$ a $\left.45^{\circ} \mathrm{C}\right)(\mathrm{Klich}, 2002)$.

\section{A.2.b.1. Aspergillus flavus}

Aspergillus flavus se identifica taxonómicamente dentro del reino Plantae, clase Eurotiomycetes, orden Eurotiales, Familia Trichocomaceae (https://www.ecured.cu/Aspergillus flavus).

Forma colonias de crecimiento rápido, entre 3 a 5 días, éstas comienzan con una tonalidad blanco-amarillenta, algodonosas y con el tiempo se tornan pulverulentas y con tonalidades verdosa o verde-amarillentas (Figura 8) (Bonifaz, 2012; Tangarife, 2011).

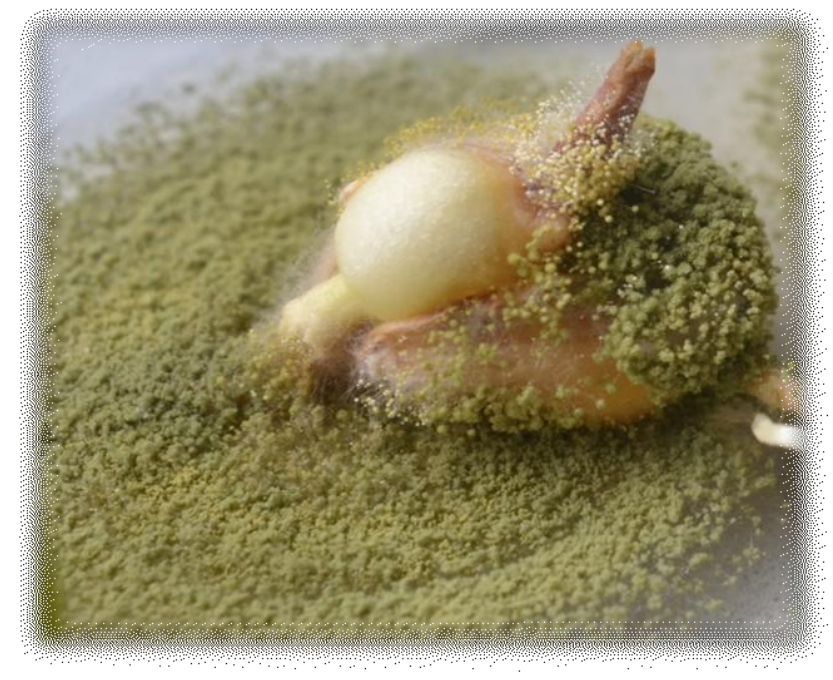

Figura 8: Colonia de Aspergillus flavus sobre semilla de maíz en medio de cultivo.

Al microscopio presenta un micelio septado, hialino, ramificado, con conidióforos largos, cenocíticos, cerca de la vesícula se forma una parte rugosa, las vesículas son esféricas, cubiertas en $360^{\circ}$ y contienen de 1 a 2 series de fiálides (Figura 9) (Bonifaz, 2012; Larone, 2011). 


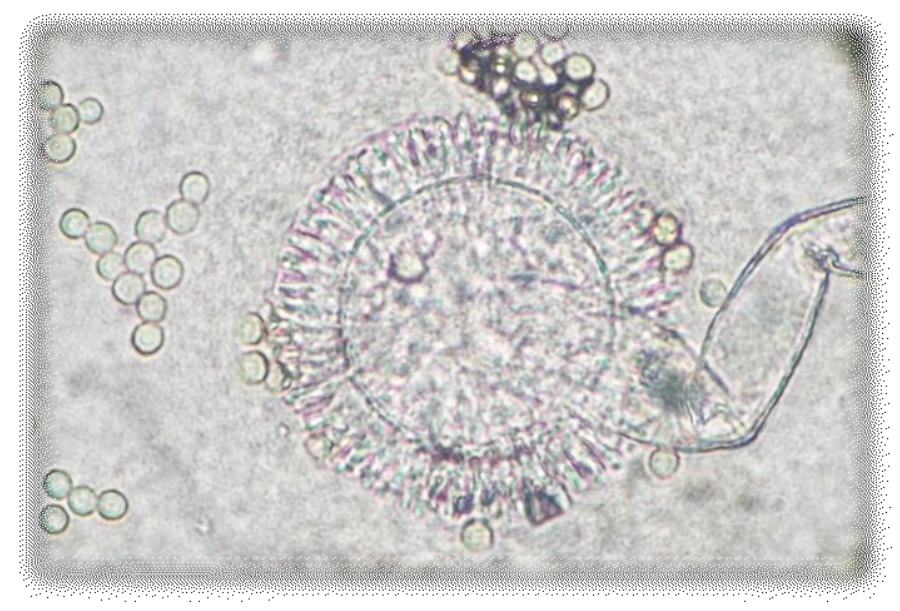

Figura 9: Morfología microscópica (40x) de Aspergillus flavus.

En 2005 el Instituto de Investigación Genómica de Estados Unidos liberó la secuencia del genoma de A. flavus, la que se actualizó en 2010 (Cleveland et al., 2009; Payne and $\mathrm{Yu}, 2010)$. Posteriormente, se generaron 7.218 etiquetas de secuencia expresada (ESTs) únicas de $A$. flavus. El tamaño del genoma de A. flavus es de aproximadamente de 37 $\mathrm{Mb}$ distribuidos en 8 cromosomas y que codifican para más de 12 mil genes funcionales (Chang and Ehrlich, 2010; Payne and Yu, 2010). Su genoma es ligeramente mayor que el de A. fumigatus (aproximadamente $30 \mathrm{Mb}$ ), A. terreus (30 Mb), A. niger (34 Mb) y A. nidulans $(31 \mathrm{Mb})$. Un aspecto importante es que $A$. flavus y $A$. oryzae tienen copias extra de genes específicos al linaje. Aunque no se han secuenciado sus genomas, en base a estudios cariotípicos se ha sugerido similitud en el tamaño del genoma de $A$. parasiticus y A. sojae con respecto a A. flavus (Amaike and Keller, 2011).

Kozakiewicz (1989) informó que la producción de esclerocios es una característica rara de los aislamientos de A. flavus y Abbas et al. (2005) determinaron que su tamaño es un carácter fenotípico. Cotty (1989) indicó que los aislamientos L no producen o producen pocos esclerocios mayores a $400 \mu \mathrm{m}$ y grandes cantidades de conidios; por su parte los aislamientos $\mathrm{S}$ producen numerosos esclerocios con un diámetro menor a $400 \mu \mathrm{m}$ y pocos conidios. La producción de aflatoxinas en aislamientos $\mathrm{L}$ es muy variable, algunos son altamente toxigénicos y otros atoxigénicos, mientras que los aislamientos $\mathrm{S}$ producen altas y consistentes concentraciones de aflatoxinas (hasta $10.000 \mu \mathrm{g} / \mathrm{kg}$ ) (Probst et al., 2010).

\section{A.2.b.2. Maíz-Aspergillus flavus}

Los hongos que comúnmente atacan al maíz tanto en campo como en almacenamiento pertenecen a los géneros Aspergillus, Fusarium y Penicillium, todos potenciales 
productores de micotoxinas (Hernández et al., 2007; Montes et al., 2009). El crecimiento de Aspergillus y la contaminación de los productos alimenticios con aflatoxinas son consecuencia de la interacción entre el hongo, el hospedero y el ambiente. La interacción de dichos factores determina la infestación y la colonización del sustrato, así como el tipo y la cantidad de las aflatoxinas producidas (García and Heredia, 2006). El consumo de alimentos contaminados con estas toxinas causa enfermedades en humanos y animales que pueden llegar a ser fatales (Presello et al., 2009).

En el caso de la relación $A$. flavus-maíz, se ha demostrado que la penetración del hongo en las mazorcas de maíz puede ocurrir cuando los estigmas están en su estado fisiológico posterior a la polinización (Marsh and Payne, 1984a y 1984b). Existe la posibilidad de que algunos compuestos del maíz presentes en ese momento sean muy exclusivos y determinantes para que la cascada de señales de comunicación entre hongo y planta ocurran, dando como consecuencia la colonización del hongo y la posible síntesis de aflatoxinas (Buccio Villalobos et al.,, 2007).

Bajo condiciones de alta temperatura y baja actividad de agua, A. flavus se vuelve muy competitivo y puede convertirse en una de las especies dominantes de hongos en el suelo (Giorni et al., 2007; Payne, 1992). En época de estrés hídrico la única fuente de agua del hongo son las plantas y los ataques son más severos que en los cultivos con riego, donde la contaminación por A. flavus disminuye (Carvajal, 2010). Se asume que el conidio es el inóculo primario, desde el suelo es transportado y depositado por el viento o insectos en los estigmas o en granos dañados (Giorni et al., 2007; Payne, 1992).

El ciclo de la podredumbre de la espiga por Aspergillus (Figura 10) comienza a partir de esporas que sobrevivieron el invierno en cultivos, principalmente en cereales o en rastrojos. Las esporas son transportadas por agentes abióticos (viento, impacto de gotas de lluvia) y bióticos (insectos, pájaros) hacia la espiga de maíz donde encuentran las dos principales vías de entrada: los estigmas y las heridas en los granos en formación. La penetración y colonización de los estigmas ocurre con mayor intensidad luego de la polinización y puede prolongarse hasta la senescencia de los mismos, según el microorganismo patógeno. Una vez que los estigmas fueron infectados, las hifas pueden crecer a través de los mismos llegando a los granos. Generalmente estos hongos no 
invaden los granos a través del pericarpio sano, pero cuando ocurren daños físicos o heridas a las brácteas foliáceas ("chalas"), unos pocos granos pueden ser colonizados y a partir de ellos comienza la infección de toda la espiga (Carrillo, 2003; Presello et al., 2004).

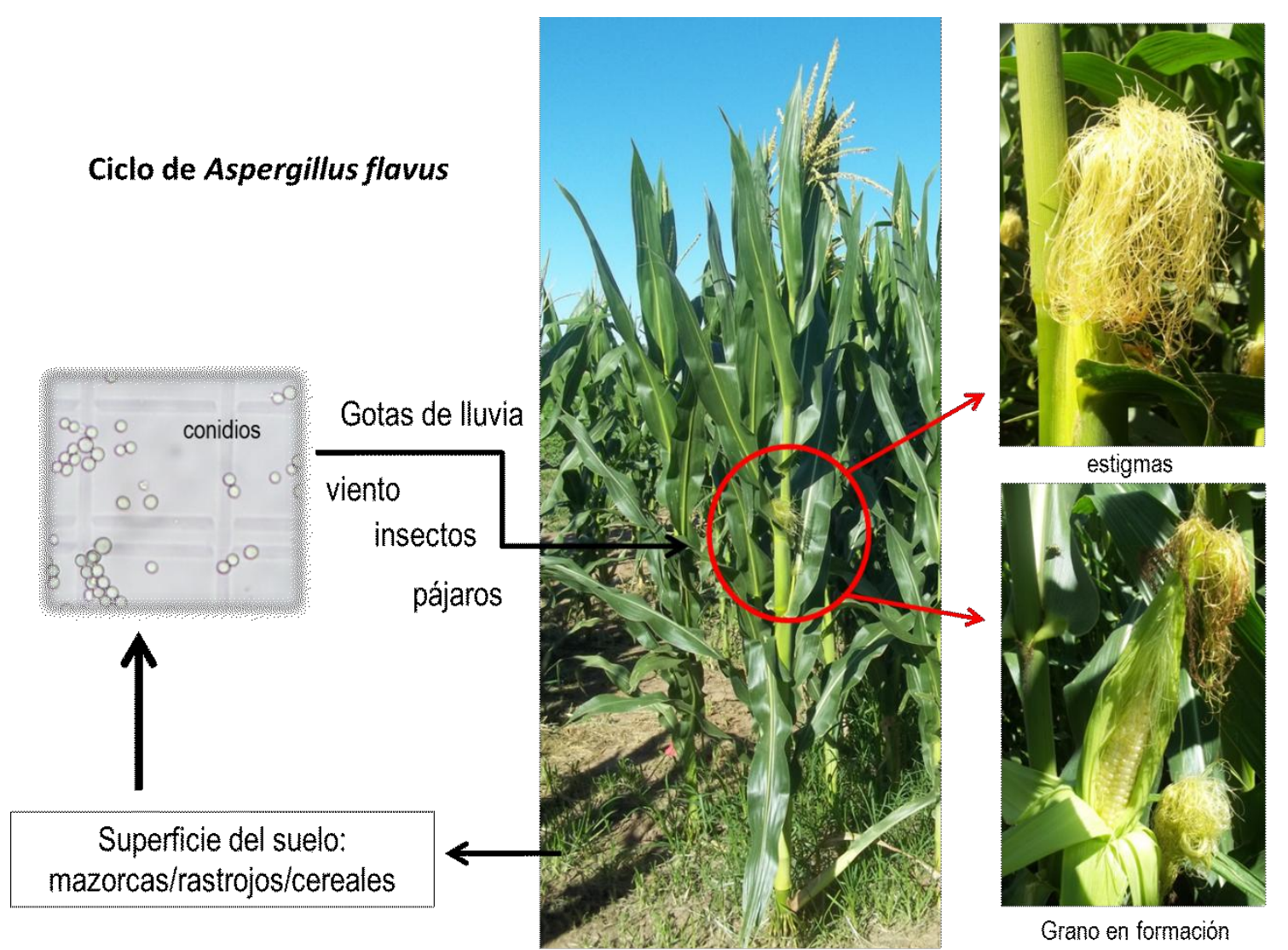

Figura 10: Ciclo de Aspergillus flavus en maíz.

En semillas de maíz, las colonias de A. flavus son por lo general de color verde claro, verde amarillento claro, verde intenso, café oliváceo o café. Las semillas de maíz severamente afectadas son incoloras y arrugadas. En medio de cultivo, el color de la colonia varía de verde amarillento a verde oliváceo, micelio blanco, esclerocios marrón oscuro a negros, reverso incoloro, marrón claro o naranjo, textura de la colonia lanosa o algodonosa, pero la identificación macroscópica no basta para la identificación del hongo (Abarca, 2000).

\section{A.2.b.3. Micotoxinas}

La palabra micotoxina, deriva del griego mikes y toxina, que significan hongo y veneno respectivamente. Diversos géneros y especies de hongos son capaces de producir micotoxinas que son metabolitos secundarios producidos por aislamientos toxigénicos, 
que tienen efectos nocivos en la salud humana y animal (Fokunang et al., 2006; Lacey, 1989; Soriano, 2007). Cuando el crecimiento del hongo termina o es interrumpido por la reducción de algún nutriente esencial, los procesos de síntesis del hongo se encaminan hacia la producción de metabolitos secundarios. Este grupo de sustancias incluye pigmentos, antibióticos y micotoxinas, los cuales son producidos en gran cantidad durante la fase estacionaria del hongo (Lacey, 1989). La producción de micotoxinas está asociada al proceso de esporulación del hongo y estrechamente relacionada con las condiciones ambientales y la concentración de nutrientes en el medio (Guzmán de Peña et al., 1998).

Dado su carácter inevitable e imprevisible, la contaminación por micotoxinas plantea un problema especial para la inocuidad de los alimentos (López et al., 1999). No solo afectan la salud de los consumidores, sino que también producen pérdidas económicas asociadas a la reducción del rendimiento, el valor de los granos, la productividad animal y a los costos en salud humana (Presello et al., 2016).

Son varios los metabolitos secundarios del género Aspergillus que son considerados micotoxinas: aflatoxinas, esterigmatocistina y otros, algunos de los cuales también son producidos por especies de Penicillum, por ejemplo al ácido ciclopiazónico (Abbas et al., 2011) y las ocratoxinas (Smith and Ross, 1991).

Los cultivos que se contaminan frecuentemente con micotoxinas son: maíz, sorgo, cebada, trigo, centeno, mijo, arroz, maní, nueces y semillas de algodón. La contaminación en los granos generalmente es un proceso aditivo; puede iniciarse en el campo, aumentar durante la cosecha y en las operaciones de secado y continuar acumulándose durante el almacenamiento y procesado de alimentos. El contenido de agua y la temperatura del grano son factores críticos que afectan la producción de micotoxinas (Borgantes-Ledezma et al., 2004).

Las micotoxinas pueden entrar a la cadena alimenticia de humanos y animales, por contaminación directa o indirecta. En la primera, la cepa toxicogénica crece sobre el material alimenticio y en la segunda, se presenta cuando un alimento es contaminado por una micotoxina (Smith and Hacking, 1983). Muchos hongos son capaces de producir más de una micotoxina y varias micotoxinas pueden ser producidas por más de una especie de hongos. Con frecuencia, más de una micotoxina se encuentra en un mismo sustrato (Hussein and Brasel, 2001). 
Se han descrito alrededor de 300 micotoxinas, de las cuales sólo unas pocas reciben una atención especial por el riesgo que representan para la salud animal y humana. Las que toman un especial interés biológico y económico son: aflatoxinas, ocratoxinas, tricotecenos, zearalenona, fumonisina y alcaloides ergóticos (Carvajal, 2010; D’Mello y McDonald, 1997; Resnik, 1997; Soriano, 2007).

\section{Aflatoxinas}

Una de las particularidades de las especies de Aspergillus es su capacidad para producir micotoxinas, en este caso, aflatoxinas (Carvajal, 2013). La importancia de las aflatoxinas radica en el riesgo que representan para la salud pública, así como las pérdidas económicas por la baja calidad del grano, limitaciones en las exportaciones, costo de manejo, análisis y eliminación de material contaminado (Acosta, 1994).

Las micotoxinas surgieron como compuestos de interés toxicológico luego de descubrir su rol como agentes etiológicos de la "enfermedad X" de los pavos. Esta enfermedad, asociada al consumo de una harina de maní procedente de Brasil, causó la muerte de más de 100.000 pavitos en Inglaterra en los años 60 (Sargeant, et al., 1961). Debido a que la causa era desconocida en ese momento, los investigadores del Tropical Products Institute de Inglaterra la llamaron "Turkey X Disease" (Ayres et al., 1980). Poco después, una enfermedad similar causó pérdidas severas en patos de Kenya (Carnaghan and Sargeant, 1961). Al mismo tiempo se reportaron casos de carcinoma hepatocelular, en truchas arcoiris de criaderos en Estados Unidos y en Europa (Sargeant et al., 1961). Las sustancias tóxicas fluorescentes aisladas del alimento de estos pavos fueron denominadas "aflatoxinas" ya que el principal hongo productor de éstas resultó ser $A$. flavus (Sargeant et al., 1963).

Las aflatoxicosis producen principalmente alteraciones hepáticas con daño de tejido, disminución en la producción de huevos, leche y carne, anemia y supresión inmunitaria. Además, se ha demostrado que poseen potente efecto carcinogénico en animales de laboratorio y efectos toxicológicos agudos en humanos. La Agencia Internacional para la Investigación en Cáncer (IARC) considera a la aflatoxina B1 como agente carcinogénico en humanos.

Cabe destacar que la capacidad de síntesis de aflatoxinas es característica del aislamiento, no de la especie (Abbas et al., 2011) y existe una amplia variación en 
cuanto a su habilidad para producir toxinas. En algunos casos no se detecta la producción de éstas, lo que indica que el crecimiento del hongo no implica necesariamente la formación de aflatoxinas (Díaz, 1996).

Los tipos de aflatoxinas son denominados B1, B2, G1, G2 o sus productos metabólicos M1 y M2. Las letras B y G se refieren al color de la fluorescencia (celeste y verdosa) observada bajo luz UV mientras que los subíndices 1 y 2 indican componente mayor y menor respectivamente. Según Detroy (1971) en estado puro son polvos cristalinos que se descomponen al alcanzar el punto de fusión B1 $\left(268-269^{\circ} \mathrm{C}\right), \mathrm{B} 2\left(286-289^{\circ} \mathrm{C}\right), \mathrm{G} 1$ $\left(244-246^{\circ} \mathrm{C}\right), \mathrm{G} 2\left(237-240^{\circ} \mathrm{C}\right), \mathrm{M} 1\left(299^{\circ} \mathrm{C}\right)$ y M2 $\left(330^{\circ} \mathrm{C}\right)$. Estas toxinas se encuentran con más frecuencia sobre oleaginosas aunque también en cereales, especialmente de zonas cálidas. Las aflatoxinas M1 y M2 son el producto metabólico hidroxilado de las B1 y B2. Alrededor del 1\% de la aflatoxina B1 consumida con el forraje es excretada en leche como M1 (Moss, 1991).

En condiciones óptimas $A$. flavus produce en 15 días, aproximadamente $300 \mathrm{ng}$ de aflatoxinas por $\mathrm{mL}$ de medio YES (15\% de sacarosa y $2 \%$ de extracto de levadura), a 30 ${ }^{\circ} \mathrm{C}$ y actividad del agua de 0,990 (Gqaleni et al.,, 1997). No se han encontrado aflatoxinas B2, G1 o G2, en ausencia de B1 (Henry et al.,, 1998). A pH 4 o menor, la formación de esclerocios se reduce un $50 \%$ mientras la producción de aflatoxinas es máxima (Calvo et al., 2002).

El rango de temperatura para la producción de aflatoxinas se encuentra entre 7,5 - 12 y $40-41^{\circ} \mathrm{C}$ según las cepas y las condiciones experimentales. Humedad relativa menor al $85 \%$ detiene el crecimiento de los hongos productores de estas toxinas, lo que corresponde a un contenido de humedad del maíz de $16 \%$ y una actividad del agua (aw) igual a 0,85 . La elaboración de las toxinas se produce poco después de la infección de las mazorcas a temperatura ambiente y en dos días puede alcanzar una concentración de $200 \mathrm{ng} / \mathrm{g}$, llegando a $2.000 \mathrm{ng} / \mathrm{g}$ luego de nueve días a $26-34^{\circ} \mathrm{C}$. Se observa una gran variación de la contaminación fúngica, transmitida por insectos, entre los granos de una misma mazorca y entre las mazorcas de un mismo cultivo. El estrés hídrico de la planta asociado con altas temperaturas son las principales condiciones predisponentes de contaminación, también contribuyen una escasa o exceso de disponibilidad de fuente nitrogenada en el suelo (Widstrom, 1992). 
La asociación entre $A$. flavus y la planta de maíz en el campo no termina con la cosecha pues se encontraron aflatoxinas en los rastrojos, además de esclerocios (Widstrom, 1992). La contaminación de los productos agrícolas con micotoxinas de Aspergillus se debe a la invasión del hongo saprobio oportunista sin capacidad patogénica, así las cepas de A. flavus suelen infectar antes de la cosecha las semillas de algodón, maníes o granos de maíz en crecimiento (Lillehoj, 1992). Los insectos están asociados a la presencia de aflatoxinas en granos debido a que pueden actuar como vectores, pero sus larvas no son inmunes al efecto tóxico. La aplicación de insecticidas limita el daño por insectos, pero no suele eliminarlos ni evita la infección fúngica de los granos (Widstrom, 1992).

La presencia de aflatoxinas en los cereales está asociada tanto a las condiciones de almacenamiento inadecuadas como a la contaminación del producto en el campo. Entre los factores que afectan la contaminación de los granos se incluyen la cantidad de esporas inoculadas, las poblaciones de insectos y ácaros, los daños causados por otros hongos, las variedades susceptibles o resistentes, el daño mecánico, por tormenta, y por aves, la nutrición mineral de la planta y la temperatura ambiente (Rodríguez et al., 1993).

Las interacciones con otros microorganismos pueden afectar la producción de micotoxinas. Brevibacterium linens y Streptococcus lactis inhiben la síntesis de aflatoxinas pero es estimulada por Lactobacillus plantarum y Acetobacter aceti (Moss 1991). Se observa una disminución de la cantidad de aflatoxinas cuando A. flavus crece en un cultivo mixto con Penicillium oxalicum u otros hongos, y una alteración de la relación G1/B1 en el caso de A. parasiticus (Widstrom, 1992). Por su parte A. flavus afecta a la capacidad de formación de toxinas de A. ochraceus o A. versicolor (Devi and Polasa, 1987).

La exposición a las aflatoxinas es difícil de evitar porque no es sencillo prevenir el crecimiento fúngico en los granos y otros productos. Los límites a la concentración de aflatoxinas para proteger la salud humana y animal establecida por distintos países e instituciones son variables. Por ejemplo, Canadá aceptó el límite de 50 ng de aflatoxina M1/L de leche, propuesto por la Comisión Codex sobre Contaminantes y Aditivos Alimentarios (FAO-WHO), no así en Brasil (Tabla 3), pues su aplicación provocaría un gran impacto económico. Un ng/kg de peso corporal/día de aflatoxina B1 o aún menos 
contribuye al riesgo de contraer cáncer hepático (Codex 2001). La Administración de Alimentos y Medicamentos (FDA) de Estados Unidos estableció como límites máximos la concentración de $20 \mathrm{mg} / \mathrm{kg}$ para granos y otros forrajes destinados a la alimentación animal y especialmente de vacas lecheras, $100 \mathrm{mg} / \mathrm{kg}$ para granos destinados a ganado y cerdos reproductores, así como en gallinas ponedoras, $200 \mathrm{mg} / \mathrm{kg}$ para granos empleados en el engorde de cerdos y $300 \mathrm{mg} / \mathrm{kg}$ para los destinados al engorde de la hacienda (GIPSA, 1998).

Tabla 3: Límites máximos admisibles de concentración de aflatoxinas en el MERCOSUR. (MERCOSUR 2002)

\begin{tabular}{|c|c|c|}
\hline Alimento & Aflatoxina & Limite \\
\hline $\begin{array}{l}\text { 1. Leche } \\
\text { 1.1 Leche fluida } \\
\text { 1.2 Leche en polvo }\end{array}$ & $\begin{array}{l}\text { M1 } \\
\text { M1 }\end{array}$ & $\begin{array}{l}0.5 \mu \mathrm{g} / \mathrm{L} \\
5 \mu \mathrm{g} / \mathrm{kg}\end{array}$ \\
\hline $\begin{array}{l}\text { 2. Maíz } \\
\text { 2.1 Maíz en grano (entero, partido, aplastado, } \\
\quad \text { mondado) } \\
\text { 2.2 Harinas o sémolas de maíz }\end{array}$ & $\mathrm{B} 1+\mathrm{B} 2+\mathrm{G} 1+\mathrm{G} 2$ & $20 \mu \mathrm{g} / \mathrm{kg}$ \\
\hline $\begin{array}{l}\text { 3. Maní } \\
\text { 3.1 Maní ( } \sin \text { descascarar, descascarado, crudo } \\
\text { o tostado) } \\
\text { 3.2 Maní en pasta (pasta de maní o manteca de } \\
\quad \text { maní) }\end{array}$ & $\mathrm{B} 1+\mathrm{B} 2+\mathrm{G} 1+\mathrm{G} 2$ & $20 \mu \mathrm{g} / \mathrm{kg}$ \\
\hline
\end{tabular}

Los efectos tóxicos de las aflatoxinas dependen de la dosis, duración de la ingestión, edad, especie, sexo y del estado nutricional de la persona o animal (Juan et al., 2007). Los niveles tolerables máximos de "aflatoxina total", que es la suma de 4 aflatoxinas B1, B2, G1 y G2 para una serie de países y regiones según Wu et al. (2013) se presentan en la Tabla 4. 
Tabla 4: Niveles tolerables máximos para aflatoxina en distintos países y regiones.

Fuente: FAO (2004)

\begin{tabular}{|l|c|}
\hline País o región & Maíz (ng/g) \\
\hline Argelia & 20 \\
\hline Australia y Nueva Zelanda & 15 \\
\hline Brasil & 30 \\
\hline Canadá & 15 \\
\hline China & 40 \\
\hline Chile & 5 \\
\hline Colombia & 20 \\
\hline Egipto & 20 \\
\hline Unión Europea & 4 \\
\hline Honduras & 2 \\
\hline India & 30 \\
\hline Indonesia & 20 \\
\hline Irán & 30 \\
\hline Israel & 15 \\
\hline Japón & 20 \\
\hline Jordania & 30 \\
\hline Kenia & 20 \\
\hline Corea & 20 \\
\hline Malawi & 10 \\
\hline México y parte de América Latina & 20 \\
\hline Marruecos & 20 \\
\hline Nigeria & 20 \\
\hline Nepal & 40 \\
\hline Filipinas & 20 \\
\hline Perú & 15 \\
\hline Rusia & 10 \\
\hline Sudáfrica & 10 \\
\hline Sureste de Europa & 10 \\
\hline Sudan & 15 \\
\hline Siria & 10 \\
\hline Taiwán & 15 \\
\hline Tanzania & 20 \\
\hline Túnez & \\
\hline Turquía & 10 \\
\hline Estados Unidos & 20 \\
\hline Uruguay & 20 \\
\hline Venezuela & 20 \\
\hline Zimbabue & 20 \\
\hline
\end{tabular}


En Argentina también hay límites máximos admisibles (Tabla 3), establecidos en la resolución: MERCOSUR/GMC/RES. N²5/02, en la cual se aprueba el Reglamento Técnico MERCOSUR sobre límites máximos de aflatoxinas admisibles en leche fluida y en polvo, maníes y maíz y sus derivados. También incluye los métodos oficiales de muestreo y de análisis. Estos límites son comunes para los países integrantes del MERCOSUR.

La exposición a las aflatoxinas también se produce por el polvo suspendido en el aire, generado durante la cosecha en el campo (67 ng/m3), la descarga de los granos (92 ng/m3), la limpieza de los silos (4849 ng/m3) y las operaciones de alimentación animal (421 ng/m3) según Juchems et al., (2002). Los polvos contaminados están asociados a un aumento de la incidencia de tumores de las vías respiratorias superiores (Henry et al., 1998).

La Unión Europea indica que para este tipo de sustancias no existe ningún umbral por debajo del cual no se hayan observado efectos nocivos, por lo tanto no considera pertinente fijar una dosis diaria tolerable y ha seguido el criterio de fijar los límites legales en los niveles más bajos posibles. Así que admitiendo que no es posible la eliminación total de la presencia de aflatoxinas en los alimentos, la concentración permitida de B1 está establecida entre 2 y $8 \mu \mathrm{g} / \mathrm{kg}$ dependiendo de los diferentes géneros alimenticios (Official Journal of the European Union, 2003).

La clave para prevenir la pudrición de mazorca a campo y problemas de moho en el almacenamiento es detectarlos en etapas tempranas. Las siguientes prácticas pueden reducir el riesgo de la contaminación por aflatoxinas en el grano: 1. Control de plagas en el campo que dañan a la mazorca, lo que permite la entrada del hongo al tejido, provocando la infección. 2. Monitoreo. La detección temprana puede prevenir grandes pérdidas. Para esto se debe obtener información especializada sobre la incidencia potencial de los patógenos en el área. 3. Ajustar la cosechadora para minimizar el daño al grano, los cuales serán más susceptibles a la infección por hongos presentes en el almacenamiento que aquellos que están intactos. 4. Mantener limpios los contenedores y equipos de manipulación antes del almacenamiento. 5. Después de la cosecha, el maíz debe mantenerse a 16 o $17 \%$ de humedad. El maíz que presenta moho debe secarse inmediatamente a $15 \%$ de humedad o menos. 6. Enfriar todos los granos después del secado y mantener la temperatura de 1.5 a $4.5^{\circ} .7$. Control de plagas durante 
almacenamiento. 8. Verificar en el grano cada 2 semanas durante su almacenamiento cambios de temperatura, formación de costras, puntos calientes, humedad y presencia de moho. 9. Pueden ser aplicados agentes fungicidas a los granos para reducir el crecimiento de moho durante su almacenamiento (Munkvold et al., 2012).

Otras prácticas usadas para la descontaminación de granos enteros de maíz son: mediante amoníaco al $2 \%$ durante una hora a $55 \mathrm{~atm}$ de presión y $40-45^{\circ} \mathrm{C}$ destruye hasta el 93\% de las toxinas (Martínez et al., 1994). El tratamiento con hipoclorito de sodio al $0,5-1 \%$ a pH 4 degrada las aflatoxinas B1 y G1 de un substrato contaminado a cualquier temperatura, mientras que la cantidad de B2 y G2 decrece al calentar, desapareciendo ambas a $100^{\circ} \mathrm{C}$. El tratamiento con bisulfito de sodio al $1 \%$ tiene poco efecto sobre aflatoxina $\mathrm{B} 1$ a $20^{\circ} \mathrm{C}$, pero a $100^{\circ} \mathrm{C}$ solamente persiste el $10 \%$. Igual cantidad residual se observa luego del tratamiento a $20^{\circ} \mathrm{C}$ con persulfato de amonio al $0,1 \%$, y a $60^{\circ} \mathrm{C}$ con agua oxigenada al $0,1 \%$. La molienda húmeda reduce la concentración de toxinas en las fracciones con almidón a 1\% del valor original que poseían los granos (Tabata et al., 1994) y la molienda seca a $10 \%$.

El número de granos contaminados en una muestra, así como el nivel de contaminación de los mismos puede variar ampliamente, presentando una variabilidad considerable en las muestras, haciendo necesario utilizar métodos de detección que minimicen dicha variabilidad, entre ellos están: prueba de luz negra y las pruebas comerciales con kits.

La luz negra, también llamada luz ultravioleta, es una prueba preliminar rápida que consiste en una inspección visual captando la presencia de fluorescencia verde amarillento brillante bajo luz con longitud de onda de $365 \mathrm{~nm}$, dicho color se observa igual que una luciérnaga e indica la presencia de $A$. flavus en el grano (Munkvold et al., 2012). Esta fluorescencia está confinada a la parte amilácea de la semilla y a las partes periféricas del embrión y se debe a una reacción entre el ácido kojico producido por el hongo y una peroxidasa presente en la semilla viva, ya que en semilla muerta no se produce la fluorescencia (). Es una prueba de detección inicial para determinar la presencia del hongo y no la presencia de la toxina, si hay menos de ocho partículas fluorescentes por muestra de $2.5 \mathrm{~kg}$ no garantiza que esta esté libre de aflatoxinas pero tampoco es seguro que la misma muestra desencadene futuros brotes. Por otra parte, los granos que presenten partículas brillantes no están necesariamente contaminados con aflatoxinas. A pesar de ello, las muestras necesitan más pruebas de determinación, 
aunque es potencialmente una clasificación inicial rápida para el manejo del grano (Munkvold et al., 2012).

El uso de kit de pruebas comerciales es emplear técnicas de inmunoensayo o ELISA para pruebas in situ para la detección de aflatoxinas. El análisis de inmunoensayo se basa en la detección de proteínas específicas que se encuentran en las aflatoxinas utilizando anticuerpos para la identificación de estas proteínas. Algunas de estas técnicas de detención sólo determinan su presencia o ausencia, otras solo pueden cuantificar dentro de un rango la cantidad de aflatoxinas presentes, por lo que si una gran cantidad de granos de maíz es rechazada en base a resultados derivados de la prueba de un kit de inmunoensayo, esta muestra deberá someterse a un análisis de laboratorio, donde serán confirmados los resultados. Los laboratorios utilizan múltiples procedimientos de detención tales como cromatografía en capa fina, mini columnas, cromatografía de gases o espectroscopia de masas para la determinación niveles de aflatoxinas, dichos procedimientos son altamente precisos y cuantitativos (Munkvold et al., 2012). 


\section{A.3. Hipótesis}

1. La eficiencia de infección es diferente según los métodos de inoculación experimental utilizados.

2. A. flavus presenta un comportamiento distinto según la fecha de siembra de los híbridos de maíz.

3. Los híbridos de maíz tienen un comportamiento diferencial frente al patógeno, lo que puede medirse con parámetros de sanidad. 


\section{A.4. Objetivos}

\section{General}

Evaluar la respuesta de híbridos de maíz a la infección experimental de Aspergillus flavus en Manfredi, provincia de Córdoba.

Específicos

Comparar métodos de inoculación experimental a campo de A. flavus a espigas de maíz: a través del canal de estigmas y por daño en brácteas.

$>$ Evaluar los parámetros de sanidad de distintos híbridos de maíz frente a un aislado de $A$. flavus.

$>$ Evaluar distintos híbridos de maíz frente a un aislado de A. flavus haciendo uso de parámetros de sanidad. 


\section{B. MATERIALES Y MÉTODOS}

\section{B.1. Sitio experimental}

Los ensayos se llevaron a cabo en el campo experimental de INTA EEA Manfredi

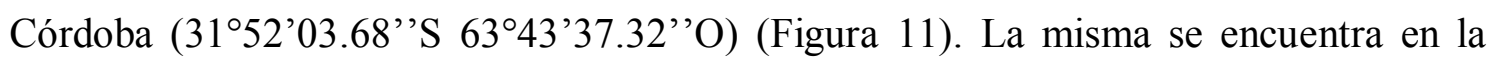
zona centro de la provincia, departamento Río Segundo.

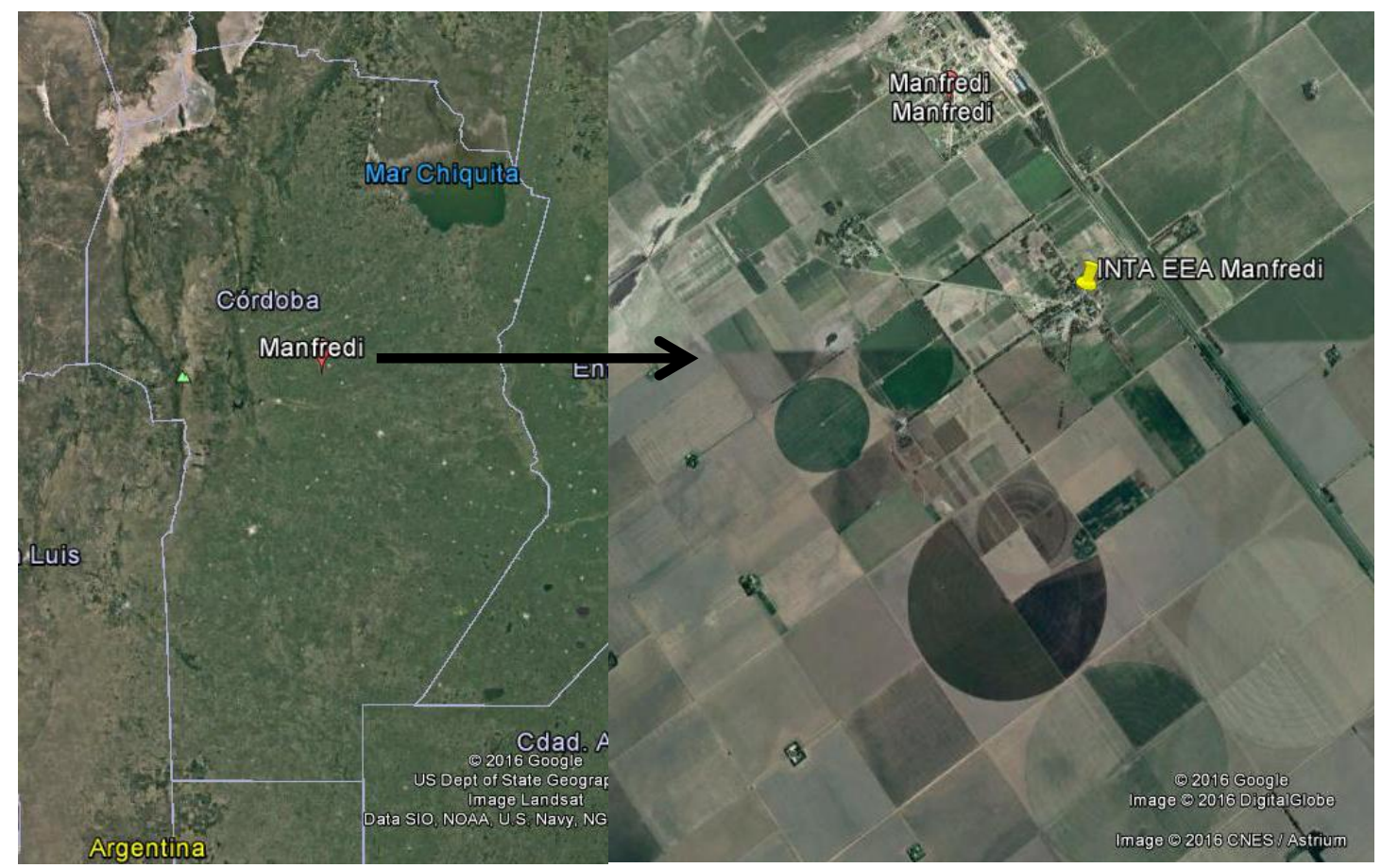

Figura 11: Sitio experimental para estudios de Aspergillus flavus en el cultivo de maíz. Fuente: Google Earth (2013).

La Red de Información Agropecuaria Nacional (RIAN) del INTA realizó en el año 2006 una zonificación de la región pampeana conformando quince áreas de homogeneidad agroecológica que las definieron como zonas y, además, para cada una de ellas especificaron subzonas. La definición de estas zonas responde a factores edáficos y de aptitud de uso del suelo en forma general y los límites de las mismas obedecen a los límites políticos de departamentos y/o partidos (Bellini et al., 2011). De acuerdo a Gorgas (2006) la provincia de Córdoba se divide en cinco Zonas Agroeconómicas Homogéneas (ZAH). El territorio comprende la totalidad de la Zona $\mathrm{X}$ : Zona agrícola ganadera del Centro de Córdoba, una pequeña parte de la Zona $\mathrm{V}$ : Zona mixta del NO de Buenos Aires, E de La Pampa, S de Córdoba y E de San Luis y de la Zona XI: Zona ganadera del NO de Córdoba y N de San Luis (Figura 12). Por lo tanto, las subzonas del territorio son: la Subzona XI-E Cosquín Serrana de producción ganadera extensiva (el territorio sólo incluye los departamentos Calamuchita y Santa 
María); la Subzona X-B Río Primero. Semiárida del Centro Norte; la Subzona X-B Oncativo. Semiárida Central y la Subzona V-D Laboulaye. Semiárida subhúmeda SE (el territorio sólo incluye la pedanía Carnerillo del departamento Juárez Celman.
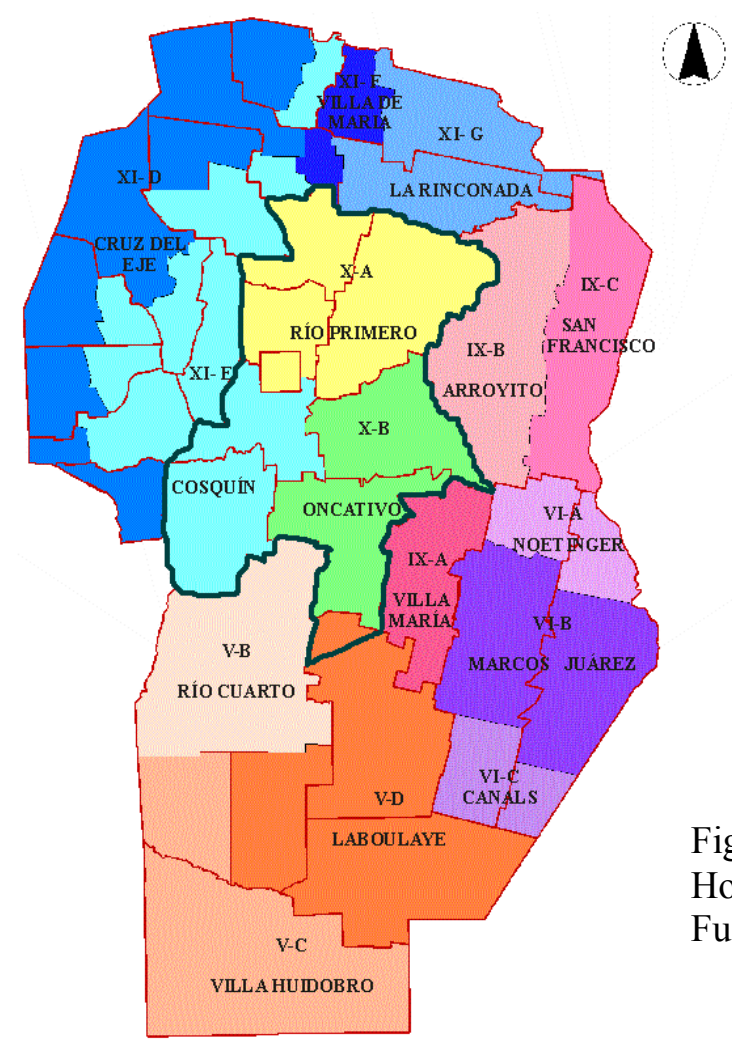

Figura 12: Zonas Agroeconómicas Homogéneas de la Provincia de Córdoba. Fuente: Ghida Daza y Sánchez (2009)

Manfredi se ubica en Subzona X-B Oncativo, Semiárida Central de producción agrícola que corresponde con la Pampa Loéssica Alta y con la Pampa Loéssica Plana que es la llanura central cordobesa. La primera va desde 600 hasta 200 m.s.n.m., con pendientes entre 2 y 3 por mil de gradiente. Constituye un plano basculado hacia el Este, cubierto por una potente acumulación de sedimentos eólicos franco limosos. Está surcada por cursos que nacen en las sierras donde exhiben importantes procesos de erosión vertical y lateral, para dar luego lugar a procesos de sedimentación en áreas de derrame que suceden hacia el Este. En la Pampa Loéssica Plana, que se extiende al Este, (Departamento Río Segundo), derrames del río Xanaes dan lugar a una reelaboración fluvial de los depósitos eólicos originales, entremezclándolos con sedimentos arenogravosos o pelíticos. El relieve es marcadamente plano y la capa freática fluctúa entre 6 y $2 \mathrm{~m}$, pudiendo llegar a afectar a los suelos (Gorgas, 2006). 
El clima se caracteriza por un régimen térmico con una temperatura media anual de $16^{\circ} \mathrm{C}$ y una amplitud térmica de $14^{\circ} \mathrm{C}$, el período libre de heladas es de 265 días que va desde noviembre a mayo. La pluviometría es de $850 \mathrm{~mm}$ anual con una distribución estacional de tipo monzónico. El período de precipitaciones se extiende de octubre a marzo $(580 \mathrm{~mm})$, el cual representa el $80 \%$ de las precipitaciones anuales. El déficit hídrico presenta una variación de $180 \mathrm{~mm}$ al Este (Gorgas, 2006).

Los suelos son ricos en limos y carbonato de calcio, profundos, bien drenados, fértiles y productivos, aunque poseen cierta fragilidad e inestabilidad estructural, que se manifiesta por una tendencia al encostramiento y al "planchado" (Gorgas, 2006). Un alto porcentaje de los suelos, $72 \%$ en el Departamento Río Segundo, son aptos para la agricultura principalmente de clase III (Sánchez y Barberis, 2013).

La zona Centro presenta una importante participación en la producción y superficie implantada de cereales y oleaginosas, es responsable de casi el 25\% de la producción provincial y del $28 \%$ del área sembrada en la provincia. En la región los principales cultivos son soja, maíz, trigo y sorgo. El cultivo con mayor participación dentro de la superficie sembrada del territorio es la soja que ocupa más del 74,2\% de las hectáreas cultivadas, le sigue el maíz con el 12,9\% y el trigo con el 7,1.

\section{B.2. Diseño experimental}

Experimentalmente se utilizó un diseño de parcela dividida, llamado SPLIT PLOT, donde la parcela principal fueron las fechas de siembra y las parcelas secundarias fueron los cultivares y dentro de estas asignadas las técnicas de inoculación. Las parcelas principales fueron de 12,5 metros de ancho por 35 metros de largo, mientras que las parcelas secundarias fueron de 4 surcos de ancho a 0,52 metros entre surcos y una densidad de 75.000 plantas/hectárea.

La siembra se efectuó en dos fechas, septiembre (temprano) y diciembre (tardío) durante las campañas 2014/15 y 2015/16, considerando a años en que se midieron las mismas fechas de siembra como repeticiones. Todos los ensayos fueron en secano. 


\section{B.3. Híbridos}

Se utilizaron 5 híbridos comerciales de maíz considerados los más difundidos de la zona y un cultivar experimental susceptible a Aspergillus (Presello et al., 2009) (Tabla 5).

Tabla 5: Características de los híbridos utilizados en los ensayos en Manfredi, Córdoba. Fuente: elaboración propia con datos proporcionados por las empresas.

\begin{tabular}{|c|c|c|c|c|c|}
\hline Híbridos & Distribución & Ciclo & $\begin{array}{l}\text { Tipo de } \\
\text { grano }\end{array}$ & $\begin{array}{l}\text { Peso de } \\
1000 \\
\text { granos } \\
(\mathrm{g}) \\
\end{array}$ & Enfermedades \\
\hline $\begin{array}{l}\text { DM } 2738 \\
\text { MGRR2 }\end{array}$ & $\begin{array}{l}\text { Buenos Aires, } \\
\text { centro y sur de } \\
\text { Santa Fe y } \\
\text { Córdoba, La } \\
\text { Pampa y Entre } \\
\text { Ríos }\end{array}$ & $\begin{array}{l}\text { Intermedio } \\
119 \text { días }\end{array}$ & $\begin{array}{l}\text { Semi- } \\
\text { dentado } \\
\text { anaranjado }\end{array}$ & 300 & $\begin{array}{l}\text { Roya: } 2 \\
\text { Tizón: } 4 \\
\text { Mal de Rio IV: } 3 \\
\text { Vuelco: } 2 \\
\text { (escala de } 1 \text { a } 5,1 \\
\text { tolerante }-5 \text { susceptible) }\end{array}$ \\
\hline $\begin{array}{l}\text { AX } 887 \\
\text { HCLMG }\end{array}$ & $\begin{array}{l}\text { Zona central y } \\
\text { zona centro - } \\
\text { norte del país }\end{array}$ & $\begin{array}{l}\text { Largo } \\
175 \text { días }\end{array}$ & $\begin{array}{l}\text { Semi- } \\
\text { dentado } \\
\text { oscuro }\end{array}$ & 340 & $\begin{array}{l}\text { Roya y tizón: } \\
\text { excelente } \\
\text { comportamiento } \\
\text { Mal de Río IV: med- } \\
\text { tolerante } \\
\text { Vuelco y quebrado: } \\
\text { muy buen } \\
\text { comportamiento }\end{array}$ \\
\hline LT 626 VT 3P & $\begin{array}{l}\text { Córdoba, Santa } \\
\text { Fe, Entre Ríos, } \\
\text { La Pampa, } \\
\text { centro - norte - } \\
\text { oeste de } \\
\text { Buenos Aires }\end{array}$ & $\begin{array}{l}\text { Intermedio } \\
\text { / corto } \\
126 \text { días }\end{array}$ & anaranjado & 340 & $\begin{array}{l}\text { Roya: } 1 \\
\text { Tizón: } 2 \\
\text { Mal de Río IV: } 2 \\
\text { (escala de } 1 \text { a } 9,1 \\
\text { tolerante }-9 \text { susceptible) } \\
\text { Vuelco: muy buen } \\
\text { comportamiento }\end{array}$ \\
\hline SYN960TD/TG & $\begin{array}{l}\text { Córdoba, } \\
\text { centro-sur } \\
\text { Santa Fe, Entre } \\
\text { Ríos, centro- } \\
\text { norte La } \\
\text { Pampa, centro-- } \\
\text { norte - oeste de } \\
\text { Buenos Aires y } \\
\text { este San Luis }\end{array}$ & $\begin{array}{l}\text { Largo } \\
154 \text { días }\end{array}$ & $\begin{array}{l}\text { Colorado } \\
\text { duro }\end{array}$ & & $\begin{array}{l}\text { Roya: tolerancia } \\
\text { media } \\
\text { Mal de río IV: } \\
\text { tolerancia alta } \\
\text { Tizón: tolerancia } \\
\text { baja } \\
\text { Enf. Espiga: } \\
\text { tolerancia alta } \\
\text { Vuelco: tolerancia } \\
\text { alta }\end{array}$ \\
\hline P1780YR & & $\begin{array}{l}\text { Intermedio } \\
151 \text { días }\end{array}$ & & & $\begin{array}{l}\text { Roya: tolerancia alta } \\
\text { Tizón: tolerancia alta } \\
\text { Mal de río IV: } \\
\text { tolerancia media } \\
\text { Vuelco: tolerancia } \\
\text { alta }\end{array}$ \\
\hline L6856xL4674 & Experimental & & & & \\
\hline
\end{tabular}




\section{B.4. Inóculo}

El inóculo se obtuvo a partir de un aislado de A. flavus de maíz del ciclo agrícola 2012/13 del INTA EEA Manfredi, conservado en la Micoteca del Laboratorio de Fitopatología de INTA EEA Manfredi y en el Instituto de Patología Vegetal (IPAVE) en Córdoba Capital. Esta cepa es no aflatoxigénica (Camiletti et al., 2018). El aislado se multiplicó en placas de Petri con agar papa glucosado (APG) 2\% durante 7 días en condiciones controlada de temperatura $\left(30^{\circ} \mathrm{C}+/-1^{\circ} \mathrm{C}\right)$ y fotoperiodo $(12 \mathrm{hs} \mathrm{luz}$ y $12 \mathrm{hs}$ oscuridad). La suspensión para las inoculaciones se obtuvo mediante el lavado con agua destilada estéril de las placas de Petri que contenían colonias esporuladas, se agregó una gota de Tween 80 y posteriormente se contaron las esporas en la suspensión utilizando un hematocímetro (cámara de Neubauer). La concentración final de la suspensión para las inoculaciones se ajustó a $1 \times 10^{6}$ conidios/mL. Esta suspensión se realizó antes de ir al campo, previo a cada inoculación.

\section{B.5. Métodos de inoculación}

La escala fenológica utilizada para determinar los estados fenológicos donde se efectuaron las inoculaciones fue la de Ritchie and Hanway (1982) (Figura 13).

\begin{tabular}{|c|l|}
\hline Denominación & \multicolumn{1}{|c|}{ Estado } \\
\hline V & Estados Vegetativo \\
\hline Ve & Emergencia \\
\hline V1 & $1^{\circ}$ hoja desarrollada \\
\hline V2 & $2^{\circ}$ hoja desarrollada \\
\hline V3 & $3^{\circ}$ hoja desarrollada \\
\hline V4 & $4^{\circ}$ hoja desarrollada \\
\hline V5 & $5^{\circ}$ hoja desarrollada \\
\hline V6 & $6^{\circ}$ hoja desarrollada \\
\hline V7 & $7^{\circ}$ hoja desarrollada \\
\hline V8 & $8^{\circ}$ hoja desarrollada \\
\hline V9 & $9^{\circ}$ hoja desarrollada \\
\hline V10 & $10^{\circ}$ hoja desarrollada \\
\hline Vt & Panojamiento \\
\hline R & Estados Reproductivo \\
\hline R1 & Emergencia de estigma \\
\hline R2 & Cuaje (ampolla) \\
\hline R3 & Grano lechoso \\
\hline R4 & Grano pastoso \\
\hline R5 & Grano dentado \\
\hline R6 & Madurez fisiológica \\
\hline
\end{tabular}

Figura 13: Escala fenológica del maíz utilizada para determinar los momentos de inoculación (Ritchie and Hanway, 1982). 
Al estado R1, estado en que emergen los estigmas (Zummo and Scott, 1992), ubicados en la zona apical de la mazorca en formación, se inoculó el canal de estigmas con una jeringa automática, modelo Primor-matic con una capacidad de $10 \mathrm{cc}$ (código IA001) y aguja hipodérmica de acero inoxidable Provac (tamaño 2.0*30 mm, 14G*1 1/4") (Figura 14) inyectando $2 \mathrm{~mL}$ de la suspensión conidial.
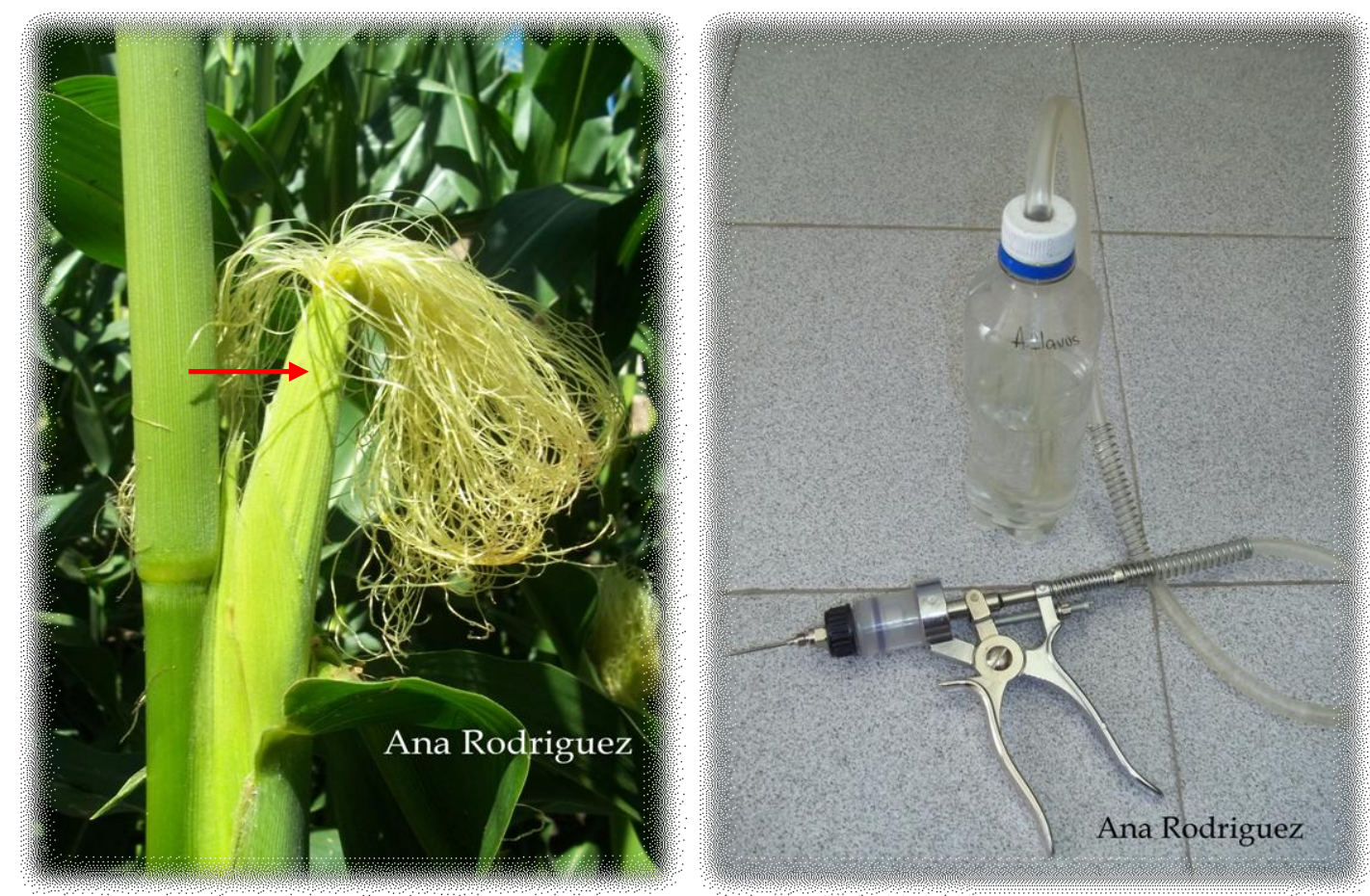

Figura 14: Maíz con estigmas de 5 días, la flecha indica zona del canal de estigmas (izq.). Jeringa automática para inoculación de estigmas (der.)

\section{Método 2. Inoculación del grano}

12 días después de la formación de la espiga, en R3 (grano lechoso), a través de un dispositivo de presión (pinche) se dañaron las brácteas foliáceas (Figura 15) atravesando las "chalas" y grano, dejando en ellos el inóculo adherido por inmersión previa en la suspensión conidial, El pinche se realizó de manera artesanal con cuatro clavos, de $1 \mathrm{~mm}$ de diámetro por $3 \mathrm{~cm}$ de largo, dispuestos en un cuadrante de 7 x 10 mm sobre un palo circular macizo (Daniel Presello, comunicación personal, 14 de enero de 2014). 

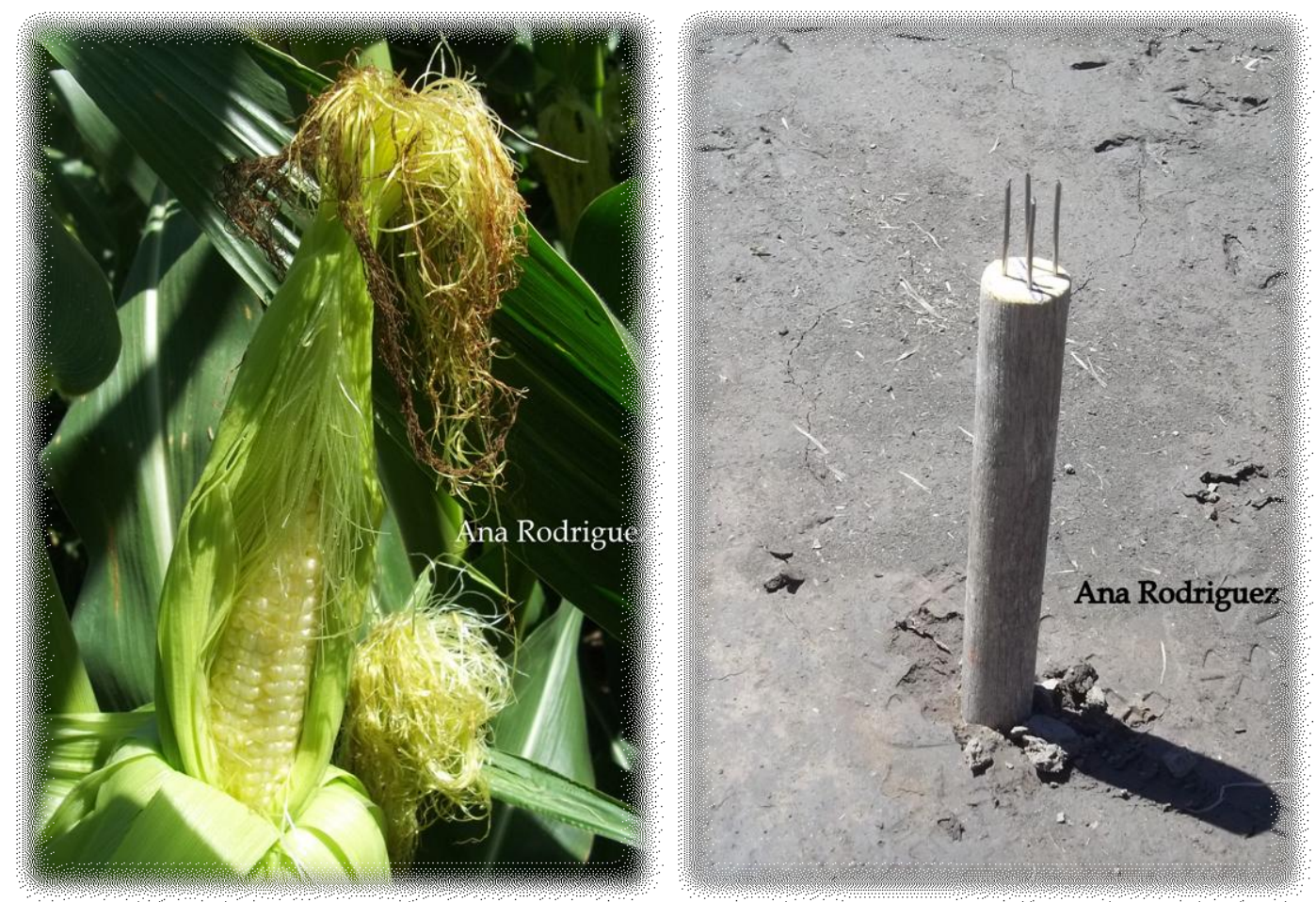

Figura 15: Maíz con estigmas de 12 días y grano en desarrollo (izq.). Pinche para inocular (der.).

En resumen los niveles del factor Inoculación fueron:

○ T1: Inoculación con jeringa automática (Inoculación 1)

○ T2: Inoculación con jeringa automática sólo con agua más Tween 80 (Testigo 1)

○ T3: Inoculación con pinche (Inoculación 2)

○ T4: Inoculación con pinche sólo con agua más Tween 80 (Testigo 2)

\section{B.6. Desarrollo del ensayo}

Los ensayos de campo se visitaron con una frecuencia diaria desde iniciada la floración: desde el 22 de diciembre al 15 de enero para los ensayos sembrados en septiembre y desde el 10 febrero al 25 de febrero para los sembrados en diciembre en cada campaña agrícola. Las espigas de plantas que estaban en el estado fenológico adecuado para la inoculación fueron inoculadas según el método a utilizar.

Para cada método de inoculación se trataron 30 plantas por cultivar y por fecha de siembra, usando la primera espiga, contando desde arriba de la planta hacia abajo. 
Las espigas inoculadas se cubrieron con bolsas para reducir posteriores infecciones naturales. Las bolsas, de papel color madera, eran aptas para trabajos de polinización por lo que duraban hasta cosecha ayudando a evitar daños y pérdidas ocasionadas por aves.

Una vez cosechadas las espigas, y luego de ser evaluada la severidad, se desgranaron y guardaron en bolsas rotuladas en condiciones de baja temperatura y humedad para evitar el desarrollo de hongos en almacenamiento.

\section{B.7. Evaluaciones}

Al finalizar el ciclo de cultivo se cosecharon las espigas inoculadas de cada tratamiento y se evaluaron los siguientes parámetros de sanidad para A. flavus: severidad, incidencia y presencia por fluorescencia bajo luz UV.

La severidad se determinó utilizando la escala visual de síntomas propuesta por Reid et al., (1996), posterior a R6 (madurez fisiológica). La escala de 7 puntos está basada en el porcentaje de la espiga afectada por el hongo (Tabla 6).

Tabla 6: Escala de evaluación de severidad para Aspergillus flavus en mazorcas de maíz (Reid et al., 1996).

\begin{tabular}{|c|c|}
\hline Grados & Daño en espigas (\%) \\
\hline 1 & Sin síntomas \\
\hline 2 & $1-3$ \\
\hline 3 & $4-10$ \\
\hline 4 & $11-25$ \\
\hline 5 & $26-50$ \\
\hline 6 & $51-75$ \\
\hline 7 & $76-100$ \\
\hline
\end{tabular}

Para el análisis de la severidad se trabajó con el índice de severidad (IS) desarrollado por Oddino et al., (2006):

$$
\text { IS: } \mathrm{X}_{0} * \mathrm{P}_{0}+\mathrm{X}_{1} * \mathrm{P}_{1}+\ldots \ldots+\mathrm{X}_{6} * \mathrm{P}_{6}
$$

Dónde: 
- $\mathrm{X}_{\mathrm{i}}$ corresponde al grado de severidad de la escala

- $\mathrm{P}_{\mathrm{i}}$ corresponde a la frecuencia relativa de dicho grado

Cada mazorca se evaluó según la escala de severidad y se le determinó el IS. Un IS igual a 1 es sinónimo de ausencia de síntomas de $A$. flavus en la mazorca evaluada.

La incidencia de granos infectados con $A$. flavus se determinó según el método de Machado (1988). De cada espiga cosechada/tratamiento/cultivar se tomaron al azar 20 granos con los que se formó una muestra compuesta de 200 granos/tratamiento/cultivar. Los granos se desinfectaron en solución de hipoclorito de sodio al $2 \%$ por 10 minutos, luego se enjuagaron dos veces con agua destilada estéril y posteriormente se sembraron en placas de Petri con APG 2\% a razón de 10 semillas/placa. Se incubaron durante 5 días en cámara con condiciones controladas de temperatura entre $30-32^{\circ} \mathrm{C}$ y fotoperiodo de 12 hs luz y 12 hs oscuridad. Las lecturas se realizaron bajo microscopio estereoscópico $40 \mathrm{X}$.

La determinación de la presencia de A. flavus a través de la técnica de la luz negra (U.V. $\lambda: 365 \mathrm{~nm}$ ), es un método presuntivo empleado en la industria para la detección de contaminación de A. flavus. Esta técnica detecta partes de granos que brillan con una fluorescencia verde-amarillento brillante. Granos que presenten dicha fluorescencia serán los casos positivos o que indiquen presencia del hongo y la ausencia de la fluorescencia serán los casos negativos o ausencia del hongo.

\section{B.8. Análisis estadístico}

El análisis estadístico de los resultados de incidencia y severidad del ensayo, en diferentes fechas de siembra, cultivares y técnicas de inoculación, se realizó y ajustó con modelos lineales generalizados mixtos.

La variable observada Incidencia posee una distribución binomial, con función link Logit. Fecha de siembra se asumió como factor de efectos fijos con dos niveles y técnica de inoculación se asumió como factor de efectos fijos con 4 niveles, e interesó evaluar la interacción de ambas para cada fecha de siembra del cultivo. Se evaluó la composición de la matriz de varianzas y covarianzas mediante la sentencia COVTEST. Debido a que dos de las tres covarianzas arrojaron valores altamente significativos, implica que los cultivares no responden a los efectos aleatorios de las fechas de siembra 
(incluidos en la sentencia COVTEST), de la misma manera. Los resultados fueron obtenidos directamente de las comparaciones múltiples de Tukey- Kramer con un nivel de confianza de 5\%. Se utilizó la técnica de estimación Maximum Likelihood (ML) con la aproximación de Laplace. El modelo se condujo con el software SAS UNIVERSITY V.6. (SAS 2018), mediante la aplicación PROC GLIMMIX.

La variable observada Severidad posee una distribución lognormal, con función link Identity. Se asumió fecha de siembra como factor de efectos fijos con dos niveles, a Técnica de Inoculación también como factor de efectos fijos con 4 niveles, e interesó evaluar la interacción de ambas para cada fecha de siembra del cultivo. Se evaluó la composición de la matriz de varianzas y covarianzas mediante la sentencia COVTEST. Debido a que dos de las tres covarianzas arrojaron valores altamente significativos, implica que los cultivares no responden a los efectos aleatorios de las fechas de siembra (incluidos en la sentencia COVTEST), de la misma manera. Los resultados fueron obtenidos directamente de las comparaciones múltiples de Tukey- Kramer con un nivel de confianza de 5\%. Se utilizó la técnica de estimación Restricted Maximum Likelihood (REML). El modelo se condujo con el software SAS. UNIVERSITY V.6. (SAS 2018), mediante la aplicación PROC GLIMMIX.

Para la detección de $A$. flavus por fluorescencia bajo luz UV se utilizó el programa estadístico InfoStat (Di Rienzo et al., 2015). La variable también se evaluó a través de modelos lineales generalizados mixtos (MLGM), posee una distribución binomial con enlace logit. Se asumió fecha de siembra, cultivares y técnicas de inoculación como efectos fijos. Los resultados se analizaron con comparación de medias LSD Fisher con un nivel de confianza del 5\%. 


\section{RESULTADOS Y DISCUSIÓN}

\section{C.1. Condiciones climáticas}

Durante las campañas en que se llevaron a cabo los ensayos, 2014/15 y 2015/16, las condiciones climáticas fueron normales para la zona pero destacándose los meses de febrero con altas precipitaciones, superando la media histórica (Figura 16), haciendo que la humedad mínima relativa fuera alta (Figura 17). En diciembre de 2015 ocurrieron precipitaciones menores a lo normal, pero la humedad relativa mínima y temperatura media se mantuvieron en valores normales. Diciembre y febrero fueron los meses claves para nuestro estudio, ya que las inoculaciones se realizaban en dichos meses por estar los maíces en estado fenológico R1 y R3, dependiendo si la fecha de siembra fue en septiembre o diciembre.

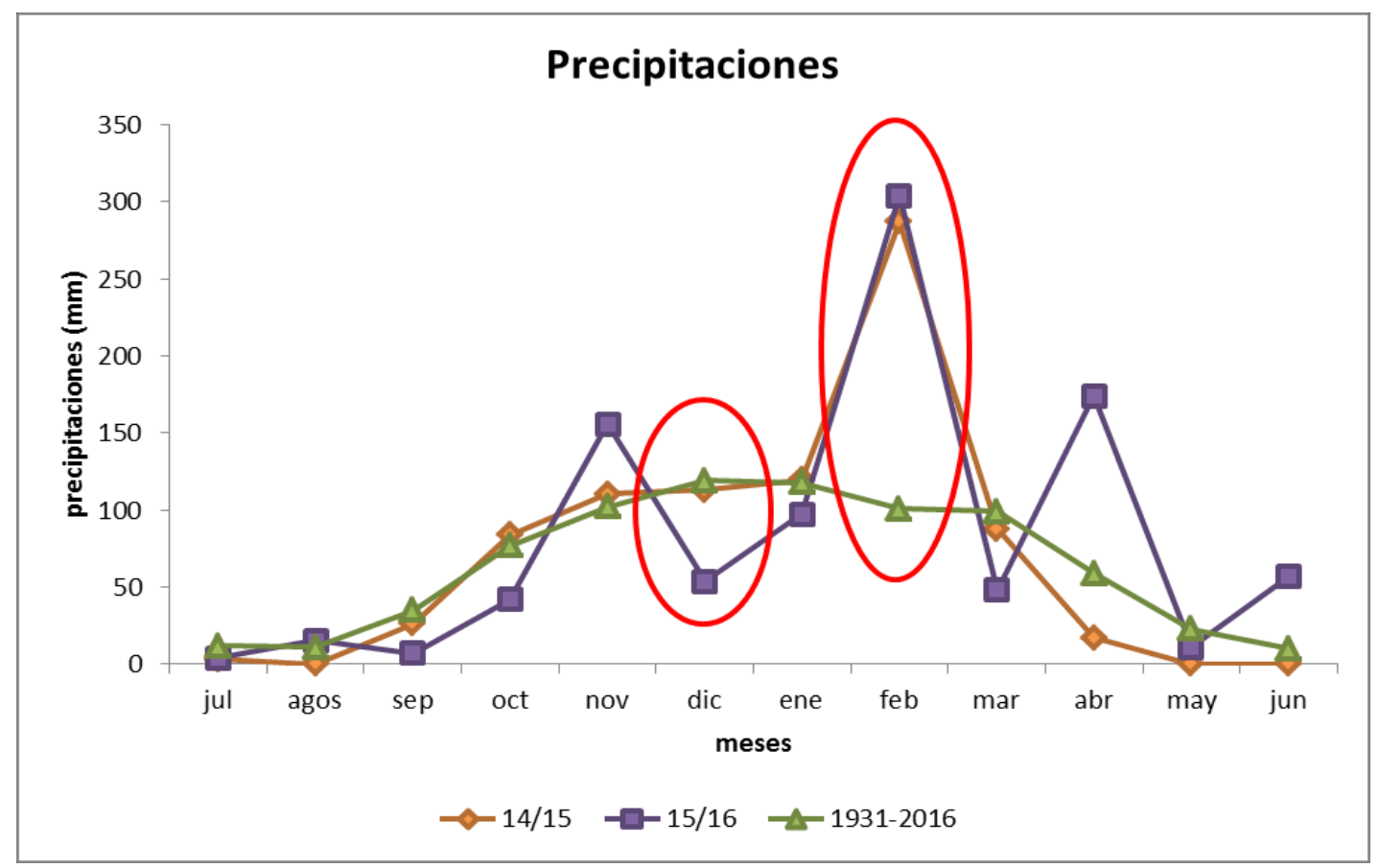

Figura 16: Precipitaciones ocurridas durante la campaña 2014/15 y 2015/16 y promedio histórico 1931-2016 en la EEA INTA Manfredi. Fuente: elaboración propia con datos de estación agrometeorológica de la EEA INTA Manfredi.

La temperatura ambiente, considerada como un factor determinante para la infección por A. flavus (O'Brian et al., 2007), fue normal para la zona de estudio, identificada con círculos en la Figura 17, y se mantuvo dentro del rango favorable para el desarrollo del hongo que requiere entre el 70 y $90 \%$ de humedad relativa, un contenido de agua en la semilla entre 15 y $20 \%$ y un rango de temperatura muy amplio $\left(0\right.$ a $\left.45{ }^{\circ} \mathrm{C}\right)(\mathrm{Klich}$, 2002). 


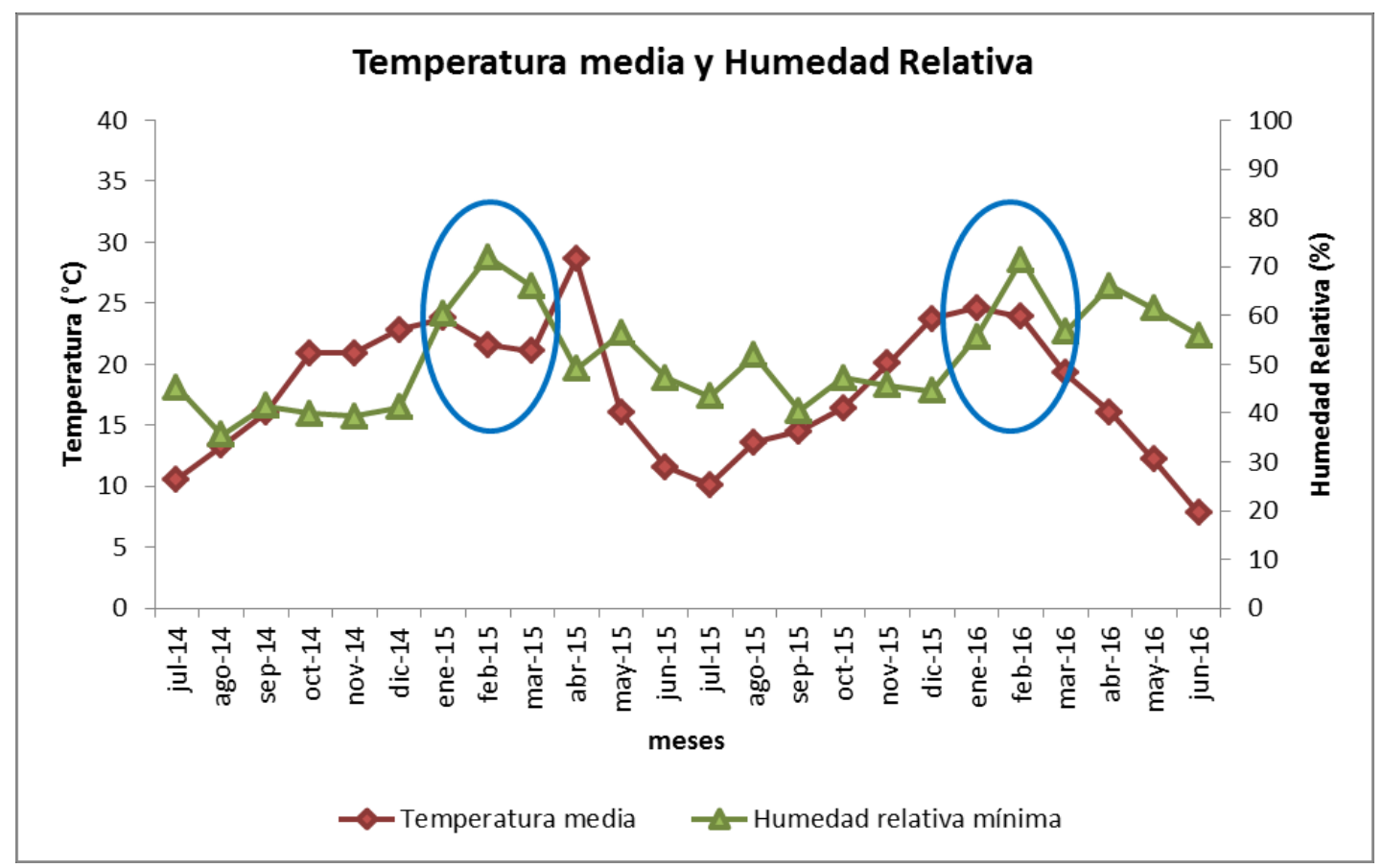

Figura 17: Temperatura media y humedad relativa mínima durante las campañas 2014/15 y 2015/16 en la EEA INTA Manfredi, Córdoba. Fuente: elaboración propia con datos de estación agrometeorológica de la EEA Manfredi.

\section{C.2. Parámetros de cuantificación de sanidad}

\section{C.2.a. Severidad}

A. flavus puede o no verse a simple vista en el momento de evaluar las mazorcas de maíz. La limitada capacidad de infección a través de la planta y de un grano a otro (Quezada-Viay et al., 2011) se identifica por la formación de una esporulación verdeamarillenta mayormente localizada en la zona de inoculación (Rodríguez, 2015) cuando se realizan infecciones forzadas. Esto pudo comprobarse cuando se realizó la observación de las mazorcas cosechadas, encontrándose muy pocas con síntomas y a su vez éstos se hallaban en baja proporción, con grado 1 y 2 de la escala de severidad (Figura 18). No obstante, se ha demostrado que las fuentes de inóculo, como conidios y esclerocios que permanecen latentes, en condiciones de poscosecha de alta temperatura y humedad relativa pueden llevar a cabo el desarrollo fúngico con la consecuente producción de aflatoxinas (Scheidegger and Payne, 2003). 


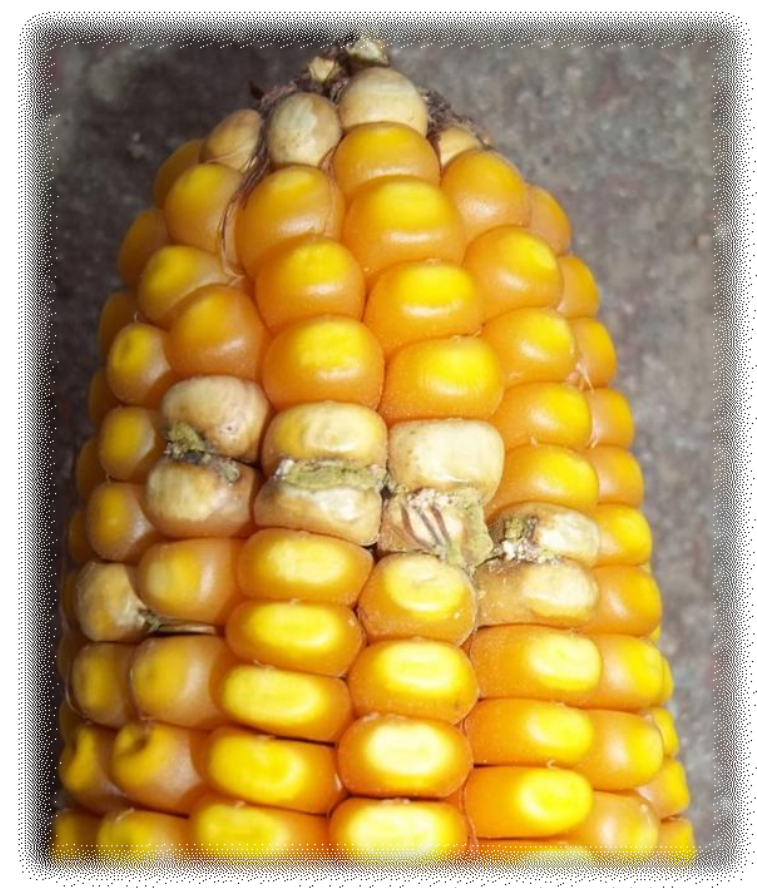

Figura 18: Síntoma de Aspergillus flavus en mazorca de maíz.

Se colectaron 30 mazorcas/tratamiento/cultivar/fecha de siembra, otorgándole a cada una un valor de 1 a 7 de la escala de severidad según su daño. Con estos datos se calculó el índice de severidad (IS) para cada tratamiento. Los datos registrados se presentan en la Tabla 12 del ANEXO. El análisis estadístico encontró algunas diferencias significativas entre las dos fecha de siembra, septiembre y diciembre (Figura 19) (Tabla 13 ANEXO). El IS fue mayor en fechas de siembra septiembre, en los híbridos P1780YR y SY960TD/TG cuando se usaron la técnica de inoculación en el canal de estigmas (técnica A), su testigo (técnica B) y la técnica de inoculación en grano (técnica C), en el híbrido DM2738MGRR2 para la técnica de inoculación A y B y para el híbrido AX887HCLMG solo para cuando se usó la técnica de inoculación A. Los híbridos LT626VT3P y L6856xL4674 no presentaron diferencias significativas entre fechas de siembra. Con fecha de siembra diciembre, solo se encontraron diferencias significativas entre el híbrido L6856xL4674 y el resto de los híbridos cuando se usó la técnica A. Que el IS en todos los casos haya sido mayor en fechas de siembra de septiembre puede ser resultado de las condiciones climáticas favorables (temperatura y precipitaciones) al momento de inoculación y el estado fenológico de los híbridos en el momento de mayor exposición al hongo. Cuando los híbridos se siembran en septiembre alcanzan la emisión de estigmas (R1) en la segunda quincena del mes de diciembre y el estado de grano lechosos (R3) en la primer quincena del mes de enero, donde las condiciones climática como altas temperaturas y baja humedad favorecen la 
infección de A. flavus. Esto coincide con lo establecido por Carvajal (2010), quien halló que en cultivos bajo riego la severidad es menor y aumenta en época de sequía, donde la única fuente de agua del hongo son las plantas. Por el contrario, los sembrados en el mes de diciembre, en febrero alcanzan los estados fenológicos R1 y R3, siendo las condiciones climáticas de temperaturas medias y alta humedad dada por las altas precipitaciones ocurridas en el transcurso del mes de febrero.

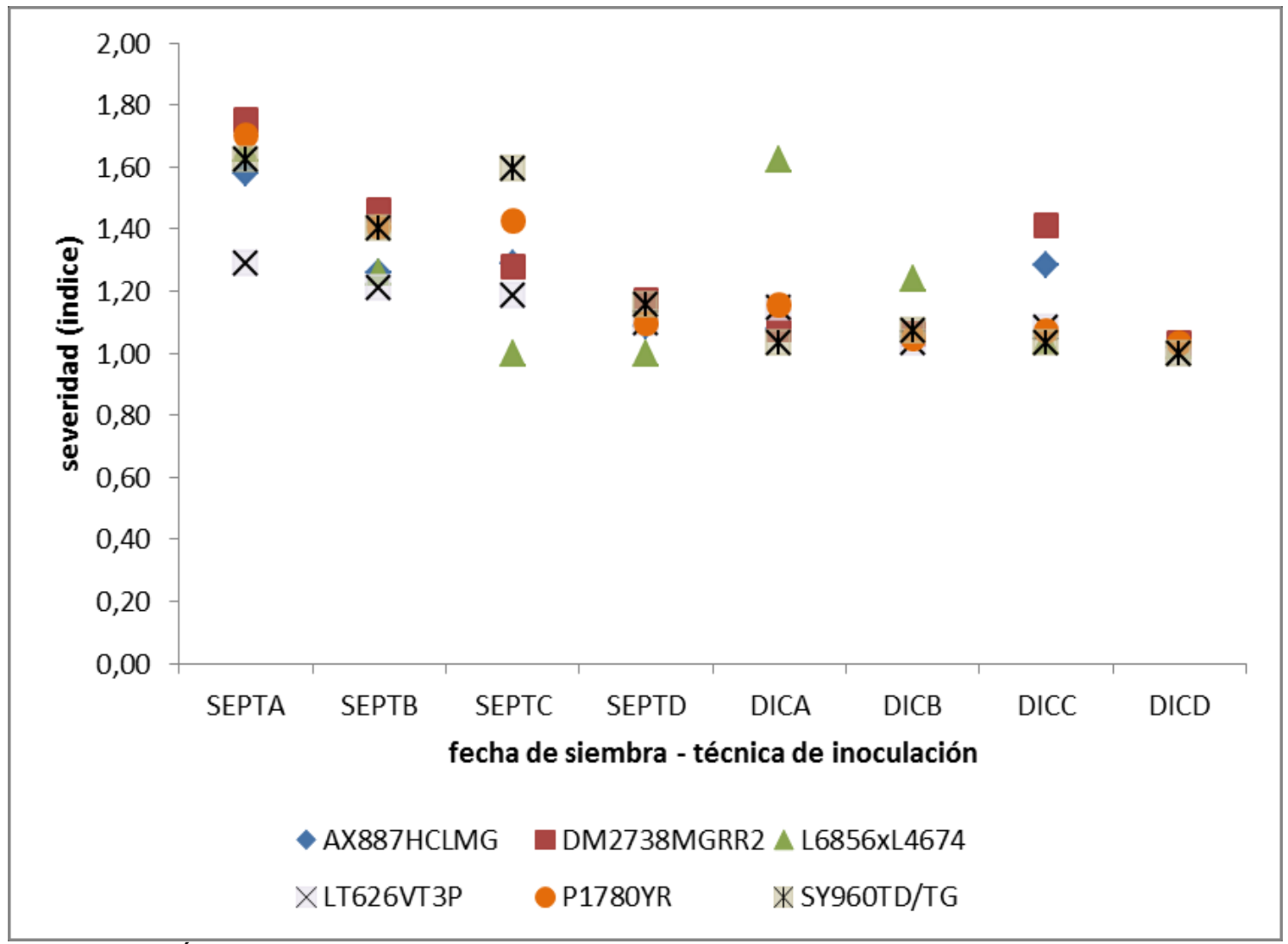

Figura 19: Índice de severidad de Aspergillus flavus en los híbridos evaluados utilizando dos técnicas de inoculación (A: inoculación en el canal de estigmas; B: testigo de técnica A; C: inoculación en grano; D: testigo de técnica $\mathrm{C}$ ) en dos fecha de siembra (sept: septiembre; dic: diciembre).

El análisis arrojó bajos IS que oscilaron entre 1 y 1,75, hallándose diferencias significativas entre los híbridos en algunos casos (Figura 19) (Tabla 13 ANEXO). Presello et al., (2009) obtuvieron valores bajos de severidad, estableciendo algunas diferencias entre híbridos pero de escasa magnitud y en la mayoría de los casos no consistentes entre años. También, Presello et al., (2014), evaluaron la mayor parte de los híbridos recomendados para la región templada en experimentos inoculados con especies de Fusarium y los resultados pusieron en evidencia diferencias entre cultivares para la resistencia a la enfermedad y acumulación de micotoxinas. Como la resistencia a hongos de los géneros Fusarium y Aspergillus parece estar controlada por la misma 
base genética (Robertson-Hoyt et al., 2007), es posible que los híbridos resistentes a Fusarium sean resistentes además a Aspergillus (Presello et al., 2016).

En cuanto a la técnica de inoculación, en el presente estudio solo se encontraron diferencias significativas en dos de los seis híbridos estudiados (Tabla 7), en el híbrido DM2738MGRR2 y en L6854xL4674 para ambas fechas de siembra. En cambio, cuando se analizó cada técnica con respecto a su testigo, para la técnica de inoculación en el canal de estigmas vs. su testigo (técnica B) solo se registraron diferencias significativas en el híbrido L6854xL4674 en la fecha de siembra diciembre, mientras que para la técnica de inoculación en los granos vs. su testigo (técnica D) se registró diferencia en el híbrido SY960TD/TG para la fecha de siembra septiembre y en el híbrido DM2738MGRR2 para la fecha de siembra diciembre. Estos resultados de severidad no permiten confirmar por sí solos las vías de entrada del hongo a campo y ni discriminar la mejor técnica de inoculación, a diferencia de Balestrasse (2008) que también obtuvo bajos valores de severidad pero con diferencias entre los híbridos y el testigo susceptible, lo que le permitió afirmar que la técnica de inoculación que utilizó (el canal de estigmas) fue efectiva para simular la enfermedad.

Sintetizando, los resultados del análisis de severidad permitieron diferenciar que las fechas de siembra de septiembre son más susceptibles a ataques de A. flavus y hay algunos cultivares que tienen mejor comportamiento que otros frente a este patógeno pero no se pudo establecer diferencias entre técnica de inoculación forzada. 
Tabla 7: Diferencia de medias del índice de severidad para la interacción "técnica de inoculación x híbrido" en dos fechas de siembra. Media de mínimos cuadrados.

\begin{tabular}{|c|c|c|c|c|c|}
\hline Híbrido & \begin{tabular}{|l|} 
Fecha de \\
siembra*
\end{tabular} & \begin{tabular}{|c|} 
Técnica de \\
inoculación ${ }^{* *}$
\end{tabular} & \begin{tabular}{|c|} 
Fecha de \\
siembra \\
\end{tabular} & $\begin{array}{l}\text { Técnica de } \\
\text { inoculación }\end{array}$ & $\begin{array}{c}\operatorname{Pr}>|\mathbf{t}| \\
* * *\end{array}$ \\
\hline AX887HCLMG & DIC & $\mathrm{A}$ & DIC & $\mathrm{B}$ & 0.8767 \\
\hline AX887HCLMG & DIC & $\mathrm{A}$ & DIC & $\mathrm{C}$ & 0.1686 \\
\hline AX887HCLMG & DIC & $\mathrm{C}$ & DIC & $\mathrm{D}$ & 0.0883 \\
\hline AX887HCLMG & SEPT & $\mathrm{A}$ & SEPT & $\mathrm{B}$ & 0.0884 \\
\hline AX887HCLMG & SEPT & $\mathrm{A}$ & SEPT & $\mathrm{C}$ & 0.1123 \\
\hline AX887HCLMG & SEPT & $\mathrm{C}$ & SEPT & $\mathrm{D}$ & 0.1859 \\
\hline DM2738MGRR2 & DIC & $\mathrm{A}$ & DIC & $\mathrm{B}$ & 0.9388 \\
\hline DM2738MGRR2 & DIC & $\mathrm{A}$ & DIC & $\mathrm{C}$ & 0.0327 \\
\hline DM2738MGRR2 & DIC & $\mathrm{C}$ & DIC & $\mathrm{D}$ & 0.0145 \\
\hline DM2738MGRR2 & SEPT & $\mathrm{A}$ & SEPT & $\mathrm{B}$ & 0.1513 \\
\hline DM2738MGRR2 & SEPT & $\mathrm{A}$ & SEPT & $\mathrm{C}$ & 0.0139 \\
\hline DM2738MGRR2 & SEPT & $\mathrm{C}$ & SEPT & $\mathrm{D}$ & 0.4945 \\
\hline L6856xL4674 & DIC & $\mathrm{A}$ & DIC & $\mathrm{B}$ & 0.0338 \\
\hline L6856xL4674 & DIC & $\mathrm{A}$ & DIC & $\mathrm{C}$ & 0.0005 \\
\hline \begin{tabular}{|l|} 
L6856xL4674 \\
\end{tabular} & DIC & $\mathrm{C}$ & DIC & $\mathrm{D}$ & 0.9011 \\
\hline \begin{tabular}{|l} 
L6856xL4674 \\
\end{tabular} & SEPT & $\mathrm{A}$ & SEPT & $\mathrm{B}$ & 0.1036 \\
\hline L6856xL4674 & SEPT & $\mathrm{A}$ & SEPT & $\mathrm{C}$ & 0.0056 \\
\hline L6856xL4674 & SEPT & $\mathrm{C}$ & SEPT & $\mathrm{D}$ & 0.1000 \\
\hline LT626VT3P & DIC & $\mathrm{A}$ & DIC & $\mathrm{B}$ & 0.4240 \\
\hline LT626VT3P & DIC & $\mathrm{A}$ & DIC & $\mathrm{C}$ & 0.6609 \\
\hline LT626VT3P & DIC & $\mathrm{C}$ & DIC & $\mathrm{D}$ & 0.5351 \\
\hline LT626VT3P & SEPT & $\mathrm{A}$ & SEPT & $\mathrm{B}$ & 0.6418 \\
\hline LT626VT3P & SEPT & $\mathrm{A}$ & SEPT & $\mathrm{C}$ & 0.5019 \\
\hline LT626VT3P & SEPT & $\mathrm{C}$ & SEPT & $\mathrm{D}$ & 0.5472 \\
\hline P1780YR & DIC & $\mathrm{A}$ & DIC & $\mathrm{B}$ & 0.4521 \\
\hline \begin{tabular}{|l}
$\mathrm{P} 1780 \mathrm{YR}$ \\
\end{tabular} & DIC & $\mathrm{A}$ & DIC & $\mathrm{C}$ & 0.5611 \\
\hline \begin{tabular}{|l} 
P1780YR \\
\end{tabular} & DIC & $\mathrm{C}$ & DIC & $\mathrm{D}$ & 0.7589 \\
\hline P1780YR & SEPT & $\mathrm{A}$ & SEPT & $\mathrm{B}$ & 0.1377 \\
\hline P1780YR & SEPT & $\mathrm{A}$ & SEPT & $\mathrm{C}$ & 0.1669 \\
\hline P1780YR & SEPT & $\mathrm{C}$ & SEPT & $\mathrm{D}$ & 0.0680 \\
\hline SY960TD/TG & DIC & $\mathrm{A}$ & DIC & $\mathrm{B}$ & 0.7801 \\
\hline SY960TD/TG & DIC & $\mathrm{A}$ & DIC & $\mathrm{C}$ & 0.9991 \\
\hline SY960TD/TG & DIC & $\mathrm{C}$ & DIC & $\mathrm{D}$ & 0.7954 \\
\hline SY960TD/TG & SEPT & $\mathrm{A}$ & SEPT & $\mathrm{B}$ & 0.2573 \\
\hline SY960TD/TG & SEPT & $\mathrm{A}$ & SEPT & $\mathrm{C}$ & 0.8919 \\
\hline SY960TD/TG & SEPT & $\mathrm{C}$ & SEPT & $\mathrm{D}$ & 0.0125 \\
\hline
\end{tabular}

*Fecha de siembra: DIC: diciembre; SEPT: septiembre - **Técnica de inoculación: A: inoculación en el canal de estigmas; B: testigo de técnica A; C: inoculación en grano; D: testigo de técnica C. $* * * \operatorname{Pr}>|\mathrm{t}|$ : Comparación de a pares sobre escala Logit para Tukey-Kramer, valores de $\mathrm{p}<0.05$ indican diferencias significativas en la interacción. 


\section{C.2.b. Incidencia de granos infectados}

La incidencia de $A$. flavus en grano fue variable, los datos registrados se presentan en la Tabla 12 del ANEXO. Los resultados estadísticos mostraron una clara diferencia significativa entre las fechas de siembra, registrándose la mayor incidencia para la siembra del mes de septiembre (Figura 20) (Tabla 14 ANEXO), aproximadamente el doble que en siembras de diciembre, $80,4 \%$ y $42,5 \%$ respectivamente. Los híbridos sembrados en septiembre sufrieron mayor estrés, dado por las condiciones ambientales ocurridas durante la etapa de floración y polinización. En este sentido esos híbridos alcanzaron el estado R1 en la segunda quincena de diciembre y R3 en la primera quincena de enero, siendo un periodo de baja precipitaciones y alta temperatura para la zona de Manfredi. Cabe recordar que Aspergillus invade con mayor facilidad plantas sometidas a condiciones de estrés como sequía, altas temperaturas, ataque de insectos, tormentas y daños mecánicos (Mazzani et al. 2004). Por el contrario, cuando se realizó la siembra en diciembre, los híbridos alcanzaron el estado R1 y R3 en la primera y segunda quincena de febrero respectivamente, mes que en las dos campañas de ensayo registró altas precipitaciones y temperaturas medias (Figuras 16 y 17). Estos resultados confirman lo establecido por Reyes y Cantú (2006), quienes proponen que una medida preventiva que desfavorece la infección consiste en la modificación de la fecha de siembra de modo que la fase sensible del ciclo biológico del maíz, el inicio de la etapa reproductiva, no coincida con condiciones ambientales favorables o estrés ambiental, a lo que se asocian alta incidencia e infección de hongos aflatoxigénicos. Esta medida se aplica en conjunto con el uso de híbridos con tolerancia a factores de estrés como las altas temperaturas y el déficit hídrico. 


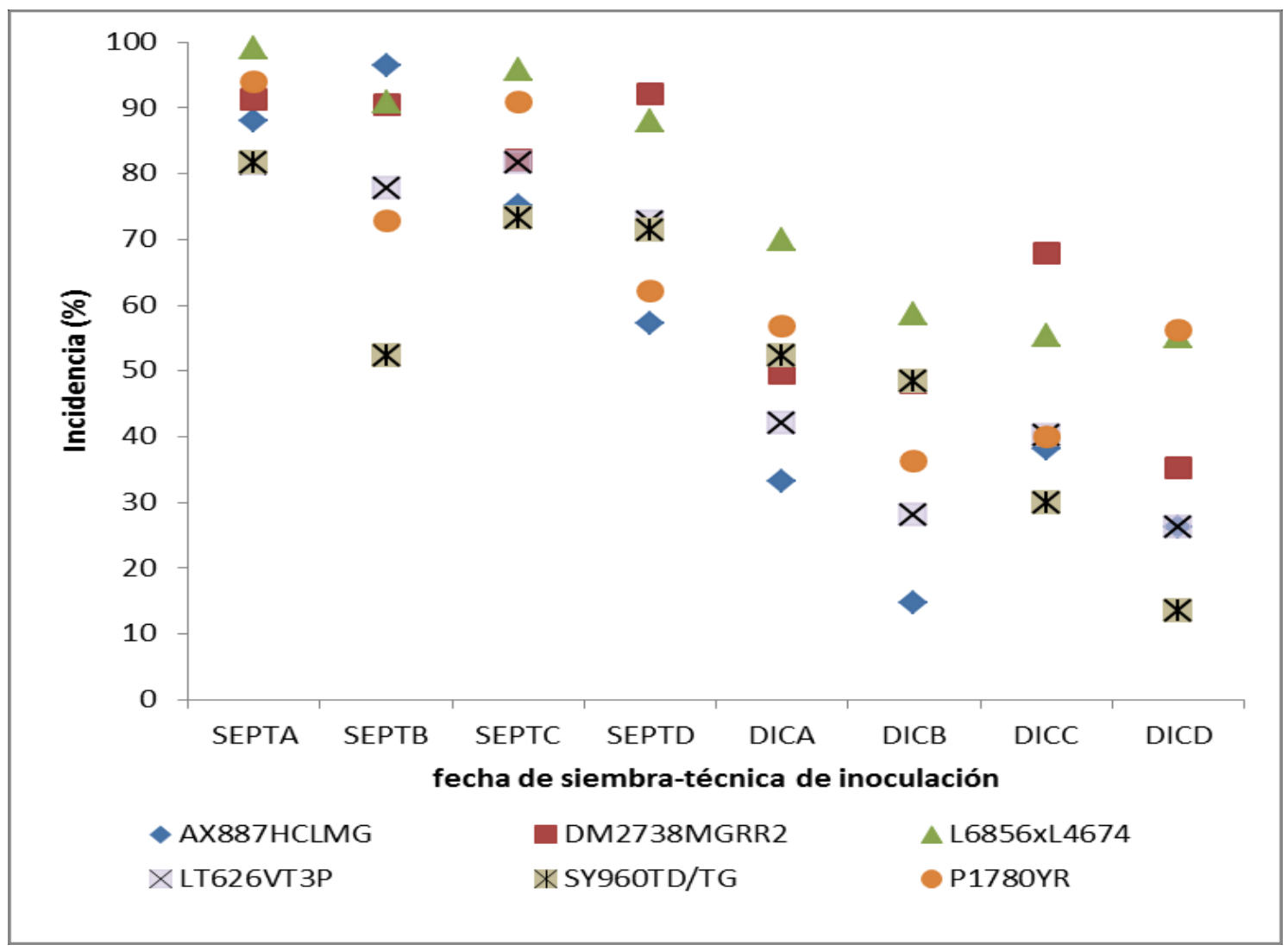

Figura 20: Incidencia de Aspergillus flavus en los híbridos evaluados bajo dos técnicas de inoculación (A: inoculación ene le canal de estigmas; B: testigo de técnica A; C: inoculación en grano; D: testigo de técnica C) en dos fecha de siembra (sept: septiembre; dic: diciembre).

Pudieron confirmarse diferencias significativas entre la técnica de inoculación en el canal de estigmas (inoculación A) y su respectivo testigo (técnica de inoculación B) en los híbridos AX887HCLMG, L6856X14674, LT626VT3P y P1780YR para la fecha de siembra diciembre, en cambio AX887HCLMG y SYN960TD/TG para la fecha de siembra septiembre (Tabla 8). Para la inoculación del grano (técnica de inoculación C) todos los híbridos presentaron diferencias significativas con respecto a su testigo (técnica de inoculación D) en ambas fechas de siembra, a excepción del híbrido L6856xL4674 que no presentó diferencias significativas. 
Tabla 8: Diferencia de medias de la incidencia en la interacción "técnica de inoculación x híbrido" en dos fechas de siembra. Medias de mínimos cuadrados.

\begin{tabular}{|c|c|c|c|c|c|}
\hline Híbridos & $\begin{array}{l}\text { Fecha de } \\
\text { siembra* } \\
\end{array}$ & \begin{tabular}{|c|} 
Técnica de \\
inoculación $* *$
\end{tabular} & \begin{tabular}{|c|} 
Fecha de \\
siembra \\
\end{tabular} & $\begin{array}{l}\text { Técnica de } \\
\text { inoculación } \\
\end{array}$ & $\begin{array}{c}\operatorname{Pr}>|\mathbf{t}| \\
* * * \\
\end{array}$ \\
\hline AX887HCLMG & DIC & A & DIC & $\mathrm{B}$ & $<.0001$ \\
\hline AX887HCLMG & DIC & $\mathrm{A}$ & DIC & $\mathrm{C}$ & $<.0001$ \\
\hline AX887HCLMG & DIC & $\mathrm{C}$ & DIC & $\mathrm{D}$ & $<.0001$ \\
\hline DM2738MGRR2 & $\mathrm{DIC}$ & $\mathrm{A}$ & DIC & $\mathrm{B}$ & 0.7783 \\
\hline DM2738MGRR2 & DIC & $\mathrm{A}$ & DIC & $\mathrm{C}$ & 0.0607 \\
\hline DM2738MGRR2 & DIC & $\mathrm{C}$ & DIC & $\mathrm{D}$ & 0.0081 \\
\hline L6856xL4674 & DIC & $\mathrm{A}$ & DIC & $\mathrm{B}$ & $<.0001$ \\
\hline L6856xL4674 & $\mathrm{DIC}$ & $\mathrm{A}$ & DIC & $\mathrm{C}$ & $<.0001$ \\
\hline L6856xL4674 & DIC & $\mathrm{C}$ & DIC & $\mathrm{D}$ & 0.9895 \\
\hline LT626VT3P & DIC & $\mathrm{A}$ & DIC & $\mathrm{B}$ & $<.0001$ \\
\hline LT626VT3P & DIC & $\mathrm{A}$ & DIC & $\mathrm{C}$ & 0.3581 \\
\hline LT626VT3P & DIC & $\mathrm{C}$ & DIC & $\mathrm{D}$ & $<.0001$ \\
\hline P1780YR & DIC & $\mathrm{A}$ & $\mathrm{DIC}$ & $\mathrm{B}$ & 0.0038 \\
\hline P1780YR & DIC & $\mathrm{A}$ & DIC & $\mathrm{C}$ & 0.0447 \\
\hline P1780YR & DIC & $\mathrm{C}$ & DIC & $\mathrm{D}$ & $<.0001$ \\
\hline SY960TD/TG & DIC & $\mathrm{A}$ & $\mathrm{DIC}$ & $\mathrm{B}$ & 0.1591 \\
\hline SY960TD/TG & DIC & $\mathrm{A}$ & DIC & $\mathrm{C}$ & 0.0009 \\
\hline SY960TD/TG & DIC & $\mathrm{C}$ & DIC & $\mathrm{D}$ & $<.0001$ \\
\hline AX887HCLMG & SEPT & $\mathrm{A}$ & SEPT & $\mathrm{B}$ & 0.0302 \\
\hline AX887HCLMG & SEPT & $\mathrm{A}$ & SEPT & $\mathrm{C}$ & 0.1334 \\
\hline AX887HCLMG & SEPT & $\mathrm{C}$ & SEPT & $\mathrm{D}$ & $<.0001$ \\
\hline DM2738MGRR2 & SEPT & $\mathrm{A}$ & SEPT & $\mathrm{B}$ & 0.9195 \\
\hline DM2738MGRR2 & SEPT & $\mathrm{A}$ & SEPT & $\mathrm{C}$ & 0.3530 \\
\hline DM2738MGRR2 & SEPT & $\mathrm{C}$ & SEPT & $\mathrm{D}$ & $<.0001$ \\
\hline L6856xL4674 & SEPT & $\mathrm{A}$ & SEPT & $\mathrm{B}$ & 0.3821 \\
\hline L6856xL4674 & SEPT & $\mathrm{A}$ & SEPT & $\mathrm{C}$ & 0.5676 \\
\hline L6856xL4675 & SEPT & $\mathrm{C}$ & SEPT & $\mathrm{D}$ & 0.6458 \\
\hline LT626VT3P & SEPT & $\mathrm{A}$ & SEPT & $\mathrm{B}$ & 0.7361 \\
\hline LT626VT3P & SEPT & $\mathrm{A}$ & SEPT & $\mathrm{C}$ & 0.9826 \\
\hline LT626VT3P & SEPT & $\mathrm{C}$ & SEPT & $\mathrm{D}$ & $<.0001$ \\
\hline P1780YR & SEPT & $\mathrm{A}$ & SEPT & $\mathrm{B}$ & 0.2869 \\
\hline P1780YR & SEPT & $\mathrm{A}$ & SEPT & $\mathrm{C}$ & 0.7771 \\
\hline P1780YR & SEPT & $\mathrm{C}$ & SEPT & $\mathrm{D}$ & $<.0001$ \\
\hline SY960TD/TG & SEPT & $\mathrm{A}$ & SEPT & $\mathrm{B}$ & $<.0001$ \\
\hline SY960TD/TG & SEPT & $\mathrm{A}$ & SEPT & $\mathrm{C}$ & $<.0001$ \\
\hline SY960TD/TG & SEPT & $\mathrm{C}$ & SEPT & $\mathrm{D}$ & $<.0001$ \\
\hline
\end{tabular}

*Fecha de siembra: DIC: diciembre; SEPT: septiembre - **Técnica de inoculación: A: inoculación en el canal de estigmas; B: testigo de técnica A; C: inoculación en grano; D: testigo de técnica C. $* * * \operatorname{Pr}>|t|$ : Comparación de a pares sobre escala Logit para TukeyKramer, valores de $\mathrm{p}<0.05$ indican diferencias significativas en la interacción. 
En ambos métodos, a pesar que la incidencia fue mayor cuando el hongo fue inoculado (técnica A y C), los testigos (técnicas B y D) tuvieron un alto valor, por ejemplo mayor al 50\% cuando se siembra en el mes de septiembre (Figura 20) (Tabla 14 ANEXO), corroborando lo encontrado por Mazzani et al., (2000), Pascale et al., (1997) y Widstrom, (1996) que establecieron que la colonización natural de los granos de maíz con A. flavus ocurre desde el campo haciendo improbable un almacenamiento seguro. En este sentido el control de hongos productores de toxinas es de gran importancia para la industria del maíz, por lo que se han ensayado métodos basados en la prevención, remoción e inactivación de los cuales la prevención es la alternativa más lógica y económica.

Entre las técnicas de inoculación, en la fecha de siembra septiembre se dan valores muy altos de incidencia siendo mayor en cada híbrido cuando se usó la técnica de inoculación en el canal de estigmas (técnica A), entre un 5 a 10\% aproximadamente más que cuando se usó la técnica de inoculación en grano (técnica $\mathrm{C}$ ). En cambio en la fecha de siembra diciembre esto se ve en los híbridos L6854xL4674, SY960TD/TG y P1780YR, estos presentan casi el doble de incidencia de A. flavus cuando se los inocula con la técnica de inoculación en el canal de estigmas, mientras que en el híbrido DM2738MGRR2 se registra mayor incidencia cuando se inocula con la técnica de inoculación en el grano.

Entre los híbridos evaluados también hubo diferencias significativas (Figura 20) (Tabla 14 ANEXO), lo que permite detectar la resistencia de algunos materiales hacia el patógeno evaluado. En la fecha de siembra septiembre se ve que en las técnicas de inoculación testigo todos los híbridos superan el 50\% de incidencia, mientras que en la fecha de siembra diciembre solo el híbrido usado como testigo y para la técnica testigo de inoculación de grano el P1780YR. También se observa que para ambas fechas de siembra el híbrido LT626VT3P no presento diferencias significativas entre técnicas de inoculación, el AX887HCLMG presenta este comportamiento pero solo en la fecha de siembra diciembre.

Diferencias observadas en la susceptibilidad de genotipos de maíz a la colonización de sus granos por hongos y a la consecuente contaminación con micotoxinas dirigen las investigaciones hacia la selección de híbridos resistentes como una alternativa económica y segura para minimizar el problema (Mazzani et al., 1999, Widstrom, 
1996). Presello et al., (2016) indica la importancia de prevenir las podredumbres de espiga en maíz a través del uso de híbridos menos susceptibles. La resistencia genética a estas enfermedades debería ser incluida como criterio en la elección del híbrido a fin de reducir pérdidas en rendimiento y minimizar el riesgo de contaminación con micotoxinas en grano.

En síntesis, el análisis de la incidencia de granos infectados permitió establecer qyue fechas de siembra de septiembre son más susceptibles a ataques del hongo, que la mejor técnica de inoculación es en el canal de estigmas y que hay cultivares de mejor comportamiento que otros.

\section{C.2.c. Fluorescencia bajo luz UV}

La metodología de detección de $A$. flavus con fluorescencia bajo luz UV ( $\lambda: 360 \mathrm{~nm})$ reveló un $95,8 \%$ de positivos totales cuando se analizó estadísticamente. No se encontraron diferencias significativas entre tratamientos, híbridos y fecha de siembra (Tablas 9, 10 y 11). Muchos fueron falsos positivos por lo expuesto de la evaluación de las variables anteriormente explicadas (Tabla 12 - ANEXO).

Tabla 9: Tabla general de los resultados del modelo usado para la detección de Aspergillus flavus por fluorescencia bajo luz UV.

\begin{tabular}{|c|c|c|c|}
\hline Familia & Enlace & Convergencia & Escala \\
\hline binomial & logit & Alcanzada & 1 \\
\hline
\end{tabular}

Tabla 10: Medidas de ajuste del modelo para la detección de Aspergillus flavus por fluorescencia bajo luz UV.

\begin{tabular}{|c|c|c|c|c|}
\hline $\mathbf{N}$ & AIC & BIC & logLik & Deviación \\
\hline 288 & 108,16 & 155,78 & $-41,08$ & 82,16 \\
\hline
\end{tabular}

AIC y BIC menores implica mejor

Tabla 11: Prueba de hipótesis marginales para los efectos fijos en la detección de Aspergillus flavus por fluorescencia bajo luz UV

\begin{tabular}{|l|c|c|c|c|}
\hline Fuente & numDF & denDF & F-valor & p-valor \\
\hline Campaña & 1 & 275 & 0,37 & 0,5443 \\
\hline Fecha de siembra & 1 & 275 & 0,37 & 0,5443 \\
\hline Repetición & 2 & 275 & 0,27 & 0,7605 \\
\hline Híbridos & 5 & 275 & 0 & $>0,9999$ \\
\hline $\begin{array}{l}\text { Técnica de } \\
\text { inoculación }\end{array}$ & 3 & 275 & 0,64 & 0,5896 \\
\hline
\end{tabular}

Resultados similares obtuvieron De Rossi et al. (2014), quienes evaluaron la presencia de micotoxinas en maíz en muestras de granos provenientes de 14 híbridos sembrados 
en 2 localidades de la provincia de Córdoba. El método de detección por fluorescencia bajo luz negra no fue adecuado ya que presentó falsos positivos y falsos negativos.

Dichos resultados contradicen lo dicho por Munkvold et al. (2012) en que es una prueba de detección inicial para determinar la presencia del hongo, pero si concuerdan en que los resultados deben ser verificados por un análisis de laboratorio, necesitando las muestras más pruebas de determinación. 


\section{CONCLUSIONES}

El hongo A. flavus es un patógeno que afecta al maíz en condiciones de campo produciendo la podredumbre de la espiga, para el área de estudio y los híbridos de maíz analizados. Sabiendo que la vía de entrada de A. flavus en el campo es a través de la mazorca, ya sea por el canal de estigmas, en polinización, o por granos en formación que han sufrido algún daño, se determinó que la mejor de las técnicas de inoculación artificial empleadas para infectar A. flavus en mazorca de maíz fue el uso de jeringa automática inoculando en el canal de estigmas. Por esto, se acepta la hipótesis 1 que plantea que la eficiencia de infección es diferente según los métodos de inoculación experimental utilizados.

Este estudio es el primero realizado en condiciones de campo en la provincia de Córdoba. Permitió definir que las fechas de siembra tardía, en diciembre, son menos favorables a la presencia de $A$. flavus, información útil como técnica de manejo de la enfermedad. Se acepta la hipótesis 2 de acuerdo a la que A. flavus presenta un comportamiento distinto según la fecha de siembra de los híbridos de maíz.

La técnica de detección de $A$. flavus por fluorescencia bajo luz UV es una técnica presuntiva que dio falsos positivos por lo que no se considera confiable para la detección de A. flavus en grano. La determinación de la incidencia del hongo en granos de maíz sembrados en medio de cultivo es más confiable que la severidad del patógeno en mazorcas de maíz, ya que estas pueden o no presentar síntomas, lo cual puede llevar a una errónea caracterización de híbridos a partir de la severidad. La evaluación de la incidencia permitió ver un comportamiento diferencial de los híbridos frente a A. flavus. Por estos resultados se acepta la hipótesis 3, según la cual los híbridos de maíz tienen un comportamiento diferencial a un aislado de $A$. flavus. El parámetro incidencia de granos infectados permitió demostrarlo

Estas conclusiones surgen de dos años de evaluación y de inoculaciones experimentales con una cepa de A. flavus. Sería adecuado continuar los estudios relacionados a la podredumbre de espigas en maíz, ensayar otras técnicas para detectar la presencia de $A$. flavus, como por ejemplo aspersión de los estigmas de las mazorcas con una suspensión conidial en la etapa posterior a la polinización. Además probar más cepas de este patógeno que sean representativas de la zona incluyendo productoras y no productoras 
de micotoxinas, ya que es necesario disponer de aislados toxicogénicos, agresivos y representativos de la población del patógeno en la región para que se desarrollen cultivares resistentes a este patógeno y a la producción de micotoxinas. 


\section{E. BIBLIOGRAFIA}

Abarca, M. 2000. Taxonomía e identificación de especies implicadas en la argiospilosis nosocomial. Revista Iberoamericana de Micología. 17: 579-584.

Abbas, H.K., Weaver, M.A., Zablotowicz, R.M., Horn, B.W. and Shier, W.T. 2005. Relationships between aflatoxin production and sclerotia formation among isolates of Aspergillus section Flavi from the Mississippi Delta. European Journal of Plant Pathology 112: 283-287.

Abbas, H.K., Zablotowicz, R.M., Horn, B.W., Phillips, N.A., Johnson, B.J., Jin, X., and Abel, C.A. 2011. Comparison of major biocontrol strains of non-aflatoxigenic Aspergillus flavus for the reduction of aflatoxins and cyclopiazonic acid in maize. Food Additives and Contaminants 28:198-208.

Acosta, S. 1994. Memoria de 1er Curso-Taller sobre aflatoxinas en maíz. Antecedentes históricos e importancia de la contaminación con aflatoxinas. Tamaulipas, México. 3-8 pp.

Alcalá, L., Muñoz, P., Peláz, T y Bauza, E. 1997. Aspergillus y aspergilosis. Servicio de Microbiología Clínica. Hospital General Universitario Gregorio Marañon. Madrid. 7 p.

Amaike, S. and Keller, N.P. 2011. Aspergillus flavus. Annual Review of Phytopathology 49:107-133.

Andrade, F.H. 1992. Radiación y temperatura determinan los rendimientos máximos de maíz. Balcarce. Estación Experimental Agropecuaria. Informe Técnico No 106. 16 p.

Ayres, J., Mundt, J. and Sandine, W. 1980. Microbiology of foods. San Francisco: Freeman. $708 \mathrm{p}$.

Balestrasse, J.P. 2008. Evaluación de cultivares de maíz por su comportamiento frente a Aspergillus flavus Link: Fr. Trabajo de Intensificación. Facultad de Agronomía. UBA.

Bellini Saibene, Y., Schaab, L., Ramos, L., Belmonte, L. y Fuentes, E.M. (Eds.). 2011. Anuario RIAN - RIAP, 2006-2007. Buenos Aires. Ediciones INTA. 39 p. Disponible en: http://inta.gob.ar/documentos/anuario-rian-riap-2006-2007 
Bonifaz, A. 2012. Capítulo 5: Hongos contaminantes, Capitulo 27 Aspergilosis. En: Micología Médica Básica (600p.) 4 Edición, McGrawHill. México. 67-71 pp., 381-396 pp.

Borgantes- Ledezma P., Borgantes- Ledezma D y Borgantes- Ledezma S. 2004. Acta Médica Costarricense. Vol. 46 N4 San José. ISSN 0001-6012

Botta, G. y Gonzalez, M. 2012. Capítulo 6: Enfermedades fúngicas, bacterianas y abióticas del maíz. En: Bases para el manejo del cultivo de maíz. Guillermo Eyhérabide (Ed). Ediciones INTA. 125-150 pp.

Bucio Villalobos, C.M., Luna Olvera, H.A., Martínez Jaime, O.A. y Guzmán de Peña, D. 2007 Efecto del extracto de estigma de maíz sobre Aspergillus spp. En: Acta Universitaria, enero-abril, año/Vol. 17, numero 001. Universidad de Guanajuato, México. 59-62 pp.

Buntig, M.B., Cardwell, K.F. and Coty, P.J. 1982. Distribution of Aspergillus section Flavi among field soils from the four agroecological zones of the Republic of Bénin. Climate and crop distribution. In: Food Nutrition and Climate. Blaxter, K.L. and Fowden, L. (Ed). Applied Science Publishers. $43-78$ pp.

Calvo, A.M., Wilson, R.A., Bok, J.W. and Keller, N.P. 2002. Relationship between secondary metabolism and fungal development. Microbiology and Molecular Biology Reviews 66: 447-459.

Camiletti, B.X., Moral, J., Asensio, C.M., Torrico, A.K., Lucini, E.I., Giménez-Pecci, M.P. and Michailides, T.J. 2018. Characterization of Argentinian endemic Aspergillus flavus isolates and their potential use as biocontrol agents for mycotoxins in maize. Phytopathology, DOI: 10.1094/PHYTO-07-17-0255-R

Camiletti, B.X., Torrico, A.K., Maurino, M., Cristos, D., Magnoli, C., Lucini, E. y Giménez Pecci, M.P. 2017. Fungal screening and aflatoxin production by Aspergillus section Flavi isolated from pre-harvest maize ears grown in two Argentine regions. Crop Protection 92:41-48.

Cardwell, K.F. and Coty, P.J. 2002. Distribution of Aspergillus section Flavi among field soils from the four agroecological zones of the Republic of Bénin, West Africa. 86 (4): 434439. 
Carmona, M.; Reis, E.M. y Gally, M. 2006. Pudriciones de tallos y raíces en el cultivo de maíz. Revista maíz en siembra directa AAPRESID. 86-89 pp.

Carnaghan, R. and Sargeant, K. 1961. The toxicity of certain groundnut meal to poultry. Veterinary Record 73: 726-27.

Carrillo, L. 2003. Capítulo 4: Aspergillus. En: Los hongos de los alimentos y forrajes. Universidad Nacional de Salta. 44-60 pp.

Carvajal, M. 2013. Transformación de la aflatoxina B de alimentos, en el cancerígeno humano adulto AFB -ADN. 1 TIP Revista Especializada en Ciencias Químico- Biológicas UNAM 16:109-120.

Carvajal, M. 2010. Investigación sobre aflatoxinas ¿Para qué?. Departamento de Botánica, Instituto de Biología. UNAM. 5 p.

Chang, P.K. and Ehrlich, K.C. 2010. What does genetic diversity of Aspergillus flavus tell us about Aspergillus oryzae? International Journal of Food Microbiology 138:189-199.

Cirilo, A.G. y Andrade, F.H. 1998. Maíz. En: Calidad de Productos Agrícolas. Bases ecofisiológicas, genéticas y de manejo agronómico. Aguirrezábal, L.A.N. y Andrade, F.H. (Ed). Unidad Integrada Balcarce. 76-136 pp.

Cleveland, T.E. and Bhatnagar D. 1992. Molecular strategies for reducing aflatoxin levels in crops before harvest. In: Molecular Approaches to Improving Food Quality and Safety. Bhatnagar, D. and Cleveland, T.E. (Ed). Van Nostrand Reinhold, New York. 205-228 pp.

Cleveland, T.E., Yu J., Fedorova N., Bhatnagar D., Payne G.A., Nierman W.C. and Bennett J.W. 2009. Potential of Aspergillus flavus genomics for applications in biotechnology. Trends in Biotechnology 27:151-157.

CNPAMM, La Confederación Nacional de Productores Agrícolas de Maíz de México. 2017. www.cnpamm.org.mx

Codex Alimentarius Commission. 2001. Comments submitted on the draft maximum level for aflatoxin M1 in milk. Codex Committee on Food Additives and Contaminants, Session 33, La Haya, Paises Bajos. 
Cotty. J.W. 1989. Virulence and cultural characteristics of two Aspergillus flavus strains pathogenic on cotton. Phytopathology 79:808-814.

Couretot, L., Parisi, L., Magnone, G, De Rossi, R., Guerra, F., Plaza, M.C., Vuletic, E., Brücher, E. y Guerra, G. 2016. Enfermedades del maíz en las últimas cinco campañas. Disponible en: https://inta.gob.ar/sites/default/files/inta_mj_actualizacion_maiz2016.pdf

D'Mello, J.P.F. and McDonald, A.M.C. 1997. Setting maximum levels for certain contaminants in foodstuffs. European commission's 2002.

De Rossi, R.L., Guerra, F.A., Brücher, E., Torrico, A.K., Maurino, M.F., Leucini, E., Gimenez Pecci, M.P., Plaza, M.C., Guerra, G.D., Camiletti, B.X., Ferrer, M. y Laguna, I.G. 2017. Capítulo 9: Enfermedades del maíz de seimbra tardía causada por hongos. En: El mismo maíz, un nuevo desafío: Compendio primer congreso de maíz tardío. Borras, L. y Uhart, S. (Eds). 1a edición compendiada. - San Isidro : Dow Agrosciences. Argentina. 250 p. ISBN 978-987-98384-3- 3

De Rossi, R.L., Guerra, F.A., Plazas, M.C. y Guerra, G.D. 2014. Determinación de fumonisinas y aflatoxinas en granos de maíz, de catorce híbridos con y sin fungicidas en dos localidades. En: Libro de resúmenes del $3^{\circ}$ Congreso Argentino de Fitopatología. Ploper, D. L. (Ed). Tucumán. Pág. 353.

Detroy, R.W. 1971. Aflatoxin and related compounds. In: Microbial Toxins vol. 6. Ciegler (Ed). Academic Press, New York. 4-178 pp.

Devi, Q.R. and Polasa, H. 1987. Interference in toxin production among toxigenic Aspergillus species. Journal of Stored Products Research 23: 149-150.

Diaz, C. 2011. Performance de híbridos de maíz frente a stress biótico, tratados con opera. Trabajo Top Ciencia. Basf. Edición 2011. Buenos Aires, Argentina.

Di Rienzo J.A., Casanoves F., Balzarini M.G., Gonzalez L., Tablada M. y Robledo C.W. InfoStat versión 2015. Grupo InfoStat, FCA, Universidad Nacional de Córdoba, Argentina. URL http://www.infostat.com.ar

Díaz, G. 1996. Micotoxinas y mocotoxicosis. En: Salud humana y animal. Primera parte. Veterinaria al día 2: 28-34 pp. 
Etcheverry, M., Nesci, A., Barros, G., Torres, A. and Chulze, S. 1999. Occurrence of Aspergillus sección Flavi and aflatoxin B1 in corn genotypes and corn meal in Argentina. Mycopathologia 147: 37-41.

Eyhérabide, G., F. Borrás, M. Percilbaldi, A. Farroni, J. Robutti, A. Di Martino, D. Presello and Lorea R. 2007. Physical and biochemical grain quality characterization in maize cultivars from Argentina. First Latinoamerican Conference of ICC. Rosario, Argentina.

Eyhérabide, G.H. 2012. Capítulo 1: El maíz y su cultivo en Argentina. Contexto general y tecnológico. En: Enfermedades del maíz producidas por virus y mollicutes en Argentina. Giménez Pecci, M.P; Laguna, I.G. y Lenardon, S. (Ed). $1^{\mathrm{a}}$ edición, Buenos Aires: Ediciones INTA. ISBN 978-987-679-116-8.

FADA. Fundación Agropecuaria para el Desarrollo de Argentina. 2016. www.fundacionfada.org .

Fernández M., Oviedo M.S., Iglesias J., Giomi G.M., Fauguel C.M. y Presello D.A. 2014. Resistencia a la contaminación con deoxinivalenol y zearalenona en cultivares de maíz. Congreso Nacional de Maíz. Rosario.

Fokunang, C.N., Tembe, E.A., Tamkins, P. and Barkwan, S. 2006. Global impact of mycotoxins on human and animal health management. Agriculture 35: 247-253.

Food and Agriculture Organization (FAO) 2004. Worldwide Regulations for Mycotoxins in Food and Feed in 2003. Available at: http://www.fao.org/docrep/007/y5499e/y5499e00.htm.

Garcia, S. and Heredia, N. 2006. Mycotoxins in Mexico: Epidemiology, management, and control strategies. Mycophatologia 162: 255-264.

Garzón, J.M. y Rossetti, V. 2013. Una Argentina Competitiva, Productiva y Federal. Actualidad y desafíos en la cadena del maíz y sus derivados industriales. IERAL Documento de Trabajo. Edición $\mathrm{N}^{\circ} 125$. Año 19.39 p.

Garzón, J.M., Moncarz, P., Rossetti, V., Torre, N., Bullano, F., Fiant, S. y Agusto, G. 2015. E1 Aporte del Campo a la Economía de Córdoba. 1a ed. Instituto de Estudios sobre la Realidad Argentina y Latinoamericana - IERAL; Bolsa de Cereales de Córdoba. 164 p. 
Ghida Daza, C. 2016. Capítulo: Resultados económicos de maíz. Campaña 2016/17. En: Maíz. Actualización 2016. Informe de Actualización Técnica en línea $\mathrm{N}^{\mathrm{o}}$ 5. Estación Experimental Agropecuaria Marcos Juarez. Ediciones INTA. 57-63 pp.

Ghida Daza, C. y Sánchez, C. 2009. Zonas Agroeconómicas Homogéneas. Córdoba. Serie Estudios socioeconómicos de la sustentabilidad de los sistemas de producción y recursos naturales $\mathrm{N}^{\circ}$ 10. ISSN 1851-6955. Buenos Aires. Ediciones INTA. 257 p.

Giorni, P., Mazan, N., Pietri, A. Bertuzzi, T. and Battiloni, P. 2007. Studies de Aspergillus section Flavi isolated in northen Italy from maize. International Journal of Food Microbiology. 113:330-338.

GIPSA. Grain Inspection Packers and Stockyards Administration 1998. Aflatoxin. Washington, DC, USA. Disponible en: http://www.usda.gov/gipsa/newsroom/backgrounders/baflatox.htm

Goizueta, M.E. 2014 Conducta, dinámica y patrones tecnológicos de la cadena del maíz. 1a ed. Buenos Aires: Ministerio de Ciencia, Tecnología e Innovación Productiva. ISBN 978987-1632-21-3.

Disponible

en: http://www.mincyt.gob.ar/adjuntos/archivos/000/036/0000036195.pdf

Google Earth. 2013. Image Landsat, US Dept of State Geographer. C2013 Google.

Gorgas, J. 2006. Red de información agroeconómica de la región pampeana (RIAP). INTA Centro Regional Córdoba. Boletín informativo de la provincia de Córdoba. Año $1, \mathrm{n}^{\mathrm{o}} 1$, $21 \mathrm{p}$.

Gqaleni, N., Smith, J.E., Lacey, J. and Gettinby, G. 1997. Effects of temperature, water activity, and incubation time on production of aflatoxins and cyclopiazonic acid by an isolate of Aspergillus flavus in surface agar culture. Applied and Environmental Microbiology 63: 1048-1053.

Guevara, E. 1991. Role des caracteres d'enracinement dans la tolerance au deficit hydrique du mais (Zea mays L.) en Argentine. Thèse Docteur Ingénieur, Montpellier. Ecole Nationale Superieure Agronomique. 87 p.

Guzmán de Peña, D., Aguirre, J. and Ruiz-Herrera, J. 1998. Regulation of mycotoxins biosynthesis during sporulation of Aspergelli. En: Miraglia M, Van Equmond H, Berna 
C, Gilbert J, ed. Mycotoxins and phycotoxin Development in Chemistry, Toxicology and Food Safety. USA, 321-326 pp.

Henry, S., Bosch, F.X., Bowers, J.C., Partier, C.J. Petersen, B.J. and Borraj, L. 1998. Safety evaluation of certain food additives and contaminants: Aflatoxinas. Series 40. World Health Organization, Ginebra.

Hernández, D.S., Reyes, L.A., Reyes, M.C.A., García, O.J.G. y Mayek, P.N. 2007. Incidencia de hongos potencialmente toxígenos en maíz (Zea mays L.) almacenado y cultivado en el norte de Tamaulipas, México. Revista Mexicana de Fitopatología 25:127-133.

Hussein, H.S. and Brasel, J.M. 2001. Toxicity, metabolism, and impact of mycotoxins on humans and animals. Toxicology 167: 101-34.

INTA, 1980. El cultivo de maíz. Colección principales cultivos de Argentina. Buenos Aires, Argentina. $163 \mathrm{p}$.

INTA, 2012. Evolución del sistema productivo agropecuario argentino. Actualización Técnica $\mathrm{N}^{\circ}$ 69. Ediciones INTA. Buenos Aires, Argentina. 36 p.

Juan, C., Soriano, J.M. y Burdasapal, P. 2007. Aflatoxinas del grupo B y G. En: Micotoxinas en alimentos. Coord. José Miguel Soriano del Castillo. Díaz de Santos. España. 91-117 pp.

Juchems, A.M., Selim, M.I. and Papendorf, W. 2002. Levels and distribution of aflatoxinas B1 in grain dust. NASD. Disponible en: http://nasdonline.org/1387/d001376/levels-anddistribution-of-aflatoxin-b1-in-grain.html

Klich, M.A and Pitt, J.I. 1992. A laboratory guide to common Aspergillus species and their teleomorphs. CSIRO Division of Food Processing, North Ryde, Australia.

Klich, M.A. 2002. Identification of Common Aspergillus Species. First edition. Centraalbureau voor Shimmelcultures, Utrecht. The Netherlands. 166p.

Kozakiewicz, Z. 1989. Aspergillus species on stored products. CAB International Mycological Institute, Kew, Surrey.

Lacey, J. 1989. Prevention of mould growth and mycotoxin production through control of environmental factors. In: Mycotoxins and Phycotoxins '88. Natori, S.; Hashimoto, K. and Ueno, Y. (Eds). Elsevir, Amsterdam. 161-169 pp. 
Larone, D. 2011. Capitulo Hyaline Hyphomycetes. In: Medically Important Fungi: A Guide To Identification. ASM Press: Washington, 282-293 pp.

Lieutier, J. 2002. Criterios para la elección de híbridos de maíz. En guía Dekalb del cultivo de maíz. Satorre, E. Dekalb. 24-33 pp.

Lillehoj, E.B. 1992. Aflatoxin: genetic mobilization agent. In: Mycotoxins in Ecological Systems. Bhatnagar D et al., (Eds). Marcel Dekker, New York. 1-22 pp.

López, G., Park, D. y Phillips, T. 1999. Sistema integrado de gestión de micotoxinas. Tercer conferencia internacional sobre micotoxinas. FAO/OMS/PMA sobre micotoxinas. Túnez.

M.A.F.F. (Dept. of Health Scottish Executive). 1999. Food Safety. Information Bulletin No 115.

Machado, J da C. 1988. Patología de sementes: fundamentos e aplicaçoes. Brasilia. Ministério da Educaçao; Lavras: ESAL/FAEPE. 107 p.

MAGyP, Ministerio de Agricultura, Ganadería y Pesca de la Nación. 2017. www.magyp.gob.ar MAGyP, Ministerio de Agricultura, Ganadería y Pesca de la Nación. 2011. Informe mensual al 17/08/2011. Campaña 2009/2010 Disponible en http://www.agroindustria.gob.ar/sitio/areas/estimaciones/ archivos/estimaciones/11000 0_2011/000800_Agosto/110818_Informe $\% 20$ Mensual\%20de $\% 20$ Estimaciones $\% 20 \mathrm{Ag}$ osto\%202011.pdf

MAIZAR, Asociación Maíz y Sorgo Argentino. 2012. Proyecto calidad de maíz. www.maizar.org.ar

MAIZAR, Asociación Maíz y Sorgo Argentino. 2008. Desafíos y Oportunidades para las Cadena de Valor del Maíz y Sorgo Argentinos 2008/2017. 27 p.

Marinelli, A.; Oddino, C.; García, J.; Tarditi, L.; Ferrari, S.; D`Eramo, L.; Lenardon, J.; Palacios, S., Chulze, S. y March, G.J. 2010. Podredumbre del tallo y raíz del maíz en la región centro sur de Córdoba. Acta IX Congreso Nacional de Maíz, Rosario, Argentina.

Marsh, S.F. and Payne, G.A., 1984a. Scanning EM studies on the colonization of dent corn by Aspergillus flavus. Phytopathology 74: 557-561. 
Marsh, S.F. and Payne, G.A., 1984b. Preharvest infection of corn silks and kernels by Aspergillus flavus. Phytopathology 74: 1284-1289.

Martinez, A.J., Weng, C.Y. and Park, D.L. 1994. Distribution of ammonia/aflatoxis reaction products in corn following exposure to ammonia decontamination procedure. Food Additives and Contaminants 11: 659-667.

Mazzani, C., Borges, O., Luzón, O., Barrientos, V. y Quijada, P. 2000. Fusarium moniliforme, fumonisinas y Aspergillus flavus en granos de híbridos de maíz en el Estado Guárico, Venezuela. Rev. Fac. Agron. (LUZ) 17: 185-195.

Mazzani, C., Borges, O., Luzón, O., Barrientos, V. y Quijada, P. 1999. Incidencia de Aspergillus flavus, Fusarium moniliforme, aflatoxinas y fumonisinas en ensayos de híbridos de maíz en Venezuela. Fitopatología. Venezuela 12: 9-13.

Mazzani, C., Luzón, O. y Chavarry, M. 2004. Aspergillus flavus asociado a Epigratus sp (Coleoptera: Tenebrionidae) en maíz bajo riego en Turén, estado Portuguesa, Venezuela. Entomotropica 19: 157-159.

McGee, D.C., Olanya, O. M., and Hoyos, G. M., 1996. Populations of Aspergillus flavus in the Iowa cornfield ecosystem in years not favorable for aflatoxin contamination of corn grain. Plant Disease 80: 742-746.

MERCOSUR/GMC. 2002. Resolución $\mathrm{N}^{\circ}$ 25/02. Reglamento técnico MERCOSUR sobre límites máximos de aflatoxinas admisibles en leche, maní y maíz. (Derogación de la Resolución GMC N 56/94) MERCOSUR 2002. 7 p.

Montes, G.N., Reyes, M.C.A., Montes, R.N., y Cantú, A.M.A. 2009. Incidence of potentially toxigenic fungi in maize (Zea mays L.) grain used as food and animal feed. Journal of Food 7:119-125.

Moss, M.O. 1991. The environmental factors controlling mycotoxin formation. In: Mycotoxins and Animal Foods. Smith, J.E. and Henderson, R.S. (Eds). CRC Press, Boca Ratón, Florida. 37-56 pp.

Munkvold, G.P. and White, D.G. 2016. Compendium of Corn Diseases. Fourth Edition. The American Phytopathological Society, APS Press. 
Munkvold, G., Hurburgh, C., Meyer, J., Loy, D. and Robertson, A. 2012. Afltoxins in Corn. Iowa State University. Iowa, EE. UU. 4 p.

Muñoz, R. 2016. Informe de coyuntura del mercado de granos $\mathrm{N}^{\circ} 460.11$ p.

Nesci, A. and Etcheverry, M. 2002. Aspergillus section Flavi populations from field maize in Argentina. Applied Microbiology 34: 343-348.

Oddino, C., Soave, J., Soave, S., Moresi, A. y Buteler, M. 2006. Comportamiento de maníes silvestres frente a la Podredumbre parda de la raíz del maní causada por Fusarium solani. Criadero del Carmen. V encuentro Internacional de Especialistas en Arachis. Río Cuarto, Córdoba. 21-26 pp.

Official Journal of the European Union (OJ) 2003. "Amending Regulation (EC) 466/2001 as regard aflatoxins". Commision Regulation (EC). No. 2174/2003:L326/12.

Oviedo, M.S., Fernández, M., Iglesias, J., Giomi, G.M., Fauguel, C.M. y Presello, D.A. 2014. Resistencia genética a Fusarium verticillioides y acumulación de fumonisinas en cultivares de maíz. Congreso Nacional de Maíz. Rosario.

Pascale, M., A. Visconti, M. Pronezuk, H. Wisniewska and J. Chelkowski. 1997. Accumulation of fumonisins in maize hybrids inoculated under field conditions with Fusarium moniliforme Sheldon. J. Sci. Food Agric. 74: 1-6.

Parisi, L.; Couretot, L.; Fernández, M.; Hirsch, M.; Magnone, G. y Ferraris, G. 2014. Caracterización de enfermedades foliares y podredumbres de tallo en un ensayo comparativo de rendimiento de maíz de segunda. Disponible en: https://inta.gob.ar/sites/default/files/script-tmpinta_pergamino_enfermedades_foliares_y_podredumbre_de.pdf

Parisi, L. y Couretot, L. 2012. Aspectos fitosanitarios y comportamiento de cultivares de m aíz en siembra tardía. Campaña 2011/12. Actas de VII Jornada de Actualización Técnica de Maíz.

Payne G.A. and Yu J. 2010. Ecology, development and gene regulation in Aspergillus flavus. In: Aspergillus: Molecular Biology and Genomics. Machida, M. and Gomi, K. (Eds) Caister Academic Press. Norwich, United Kingdom. 157-171 pp.

Payne, G.A. 1992. Aflatoxins in maize. Crit. Rev. Plant Sci. 10: 423-440 
Presello, D.A., Iglesias, J., Fernández, M., Fauguel, C.M., Giomi, G.M. y Oviedo, M.S. 2014. Uso de resistencia genética para reducir los niveles de contaminación con micotoxinas en maíz. Disponible en: https://www.engormix.com/micotoxinas/articulos/usoresistencia-genetica-reducir-t40563.htm

Presello, D.A., Botta G. e Iglesias J. 2004. Podredumbres de espiga de maíz y micotoxinas asociadas. IDIA XXI: 152-157.

Presello, D.A., Iglesias, J., Fernández, M., Fauguel, C., Eyhérabide, G. y Lorea, R. 2009. Reacción de cultivares a hongos productores de micotoxinas en maíz. Disponible en https://inta.gob.ar/sites/default/files/inta-reacc_cultimaiz_micotoxinas 2009.pdf

Presello, D.A., Lorea, R.D. y Eyhérabide, G.H. 2016. Rendimiento de cultivares de maíz en ensayos de siembra temprana y tardía. RTA / Vol. 10 / No $31-7-10$ pp.

Presello, D.A., Oviedo, M.S., Fernández, M., Iglesias, J. y Copia, P.A. 2016. Resistencia a podredumbres de espiga y acumulación de micotoxinas en maíz. RTA / Vol. 10 / No 32 $-29-32 \mathrm{pp}$.

Probst, C., Schulthess, F., and Cotty, P.J. 2010. Impact of Aspergillus section Flavi community structure on the development of lethal levels of aflatoxins in Kenyan maize (Zea mays). Journal of Applied Microbiology 108:600-610.

Quezada-Viay, M.Y., Flores-Olivas, A., Arrúa-Alvarenga, A.A., Vázques-Badillo, M.E. y Moreno-Martinez, E. 2011. Resistencia de plantas de maíz a la infección por Aspergillus flavus Link en invernadero. Revista Agraria - Nueva Época- Año VIII. Vol. 8. $\mathrm{N}^{\circ} 2$.

Reid, L.M., Mather, D.E. and Hamilton, R.I. 1996. Distribution of deoxynivalenol in Fusarium graminearum-infected maize ears. Phytopathology 86: 110-114.

Reis, E.M.; Trezzi Casa, R. and Bresolin, A.C. 2004. Manual de diagnose e controle de doenças do milho.2 ed. Rev. Atual. Lages, Santa Catarina, Brasil. Ed. Graphel. 144 p. ISBN 8598548-02-2.

Resnik, S.L. 1997. Micotoxinas. Conferencia en el Primer Congreso Binacional de Producción Animal. $21^{\circ}$ Congreso Argentino (AAPA) y $2^{\circ}$ Congreso Uruguayo (AUPA). Revista Argentina de Producción Animal. 17: 221-225. 
Reyes, M.C.A. y Cantú, A.M.A. 2006. Maíz. En: Campo Experimental Río Bravo: 50 años de Investigación Agropecuaria en el Norte de Tamaulipas. Historia, Logros y Retos. Rodríguez del Bosque (Ed.). Libro Técnico $\mathrm{N}^{\circ} 1$. Campo Experimental Río Bravo, INIFAPSAGARPA. Río Bravo, México. 55-74 pp.

Rheeder, J.P., Marasas, W.F., Thiel P.G., Syndenham, E.W., Shepard, G.S. and Van Schalkwyk D.J. 1992. Fusarium moniliforme and fumonisins in corn in relation to human esophageal cancer in Transkei. Phytopathology 82: 353 - 357.

Ritchie, S. and Hanway, J.J. 1982. How a corn plant develops. Iowa State Univ. Technol. Spec. Rep., 48 p.

Robertson-Hoyt, L.A.; Betrán, J.; Payne, G.A.; White, D.G.; Isakeit, T.; Maragos, C.M.; Molnár, T.L and Holland, J.B. 2007. Relationships among resistances to Fusarium and Aspergillus ear rots and contamination by fumonisin and aflatoxin in maize. Phytopathology 97: 311-317.

Rodríguez, A.V. 2015. Importancia de Aspergillus flavus en maíz. En: Recopilación de presentaciones técnicas, 6ta Jornada Nacional de Forrajes Conservados. 1ª Edición. Ediciones INTA. 105-107 pp.

Rodríguez, J.; Patterson C.; Potts M.; Poneleit C. and Beine R. 1993. Role of selected arthropods in the contamination of corn by as Aspergillus flavus measured by aflatoxin production. Alabama: Craftmaster Printers, 23-26 pp.

Sánchez, C. y Barberis, N.A. 2013. Caracterización del territorio Centro de la provincia de Córdoba. $1^{\mathrm{a}}$ ed. Manfredi, Córdoba. Ediciones INTA. Estación Experimental Agropecuaria Manfredi. 97 p. ISBN 978-987-521-450-7.

Sargeant, K., Carnaghan, R.B.A. and Allcroft, R. 1963. Toxic products in groundnuts. Chemistry and origin. Chemistry and Industry, 53-55 pp.

Sargeant, K., Sheridan, A., O'Kelly, J. and Carnaghan, R.B.A. 1961. Toxicity associated with certain samples of groundnuts. Nature 192: 1096-1097.

SAS. 2018. University Edition, version SAS Studio 3.71. 
Scheidegger, K.A. and Payne, G.A. 2003. Unlocking the secrets behind secondary metabolism: a review of Aspergillus flavus from pathogenicity to functional genomics. J. Toxicol. 22: 423-429.

Servicio Meteorológico Nacional. 2018. Disponible en: https://www.smn.gob.ar/caracterizaci\%C3\%B3n-estad\%C3\%ADsticas-de-largo-plazo

Smith, J. and Hacking, A. 1983. Fungal toxicity. The filamentous fungi. London: Arnold EV, 238-264 pp.

Smith, J.E. and Ross, K. 1991. The toxigenic Aspergillus. In: Mycotoxins and Animal Foods. Smith, J.E. and Henderson, R.S. (Eds). CRC Press, Boca Ratón, Florida. 101-108 pp.

Soriano, J.M. 2007. Micotoxinas en alimentos. Díaz de Santos. España. 396 p.

Tabata, Setsuko, Kaminura, Hisashi, Ibe, Akihiro, Hashimato, Hideki, Tamura and Yukihiro. 1994. Degradation of aflatoxins by food additives. Journal of Food Protection 57: 4247.

Tangarife, V. 2011. Aspergillus spp. Universidad de Antioquia. Disponible en: http://aprendeenlinea.udea.edu.co/lms/moodle/mod/page/view.php?id=100812

Torrico, A.K., Camiletti, B.X., Maurino, M., Barontini, J., Ferrer Lanfranchi, M., Rodriguez, A., Cristos, D., Magnoli, C., Lucini, E. y Gimenez Pecci, M.P. 2016. Hongos causales de pudrición de la espiga de maíz en la región agrícola central de Argentina. Congreso de Maíz Tardío. Rincón de Pilar. Argentina.

Totis de Zeljkovich, L.E. 2012. Capítulo: Requerimientos agroclimáticos del cultivo de maíz. En: Bases para el manejo del cultivo de maíz. Eyhérabide, G.H. (Ed). Ediciones INTA. 7-24 pp.

Totis de Zeljkovich, L.E; Zeljkovich, V.J.; Blotta, L.A. y Hansen, O.M. 1992. Evaluación de sistemas de manejo continuados. I. Efecto sobre los rendimientos del cultivo de maíz integrando la secuencia maíz-trigo/soja en Pergamino. In: $5^{\circ}$ Congreso Nacional de Maíz, $2^{\circ}$ Reunión Suramericana. Pergamino. Actas. Pergamino, A.I.A.N.B.A. t.2. 195$206 \mathrm{pp}$. 
USDA: United States Department of Agriculture, Statistics information. 2011. Web Page: www.usda.gov.

Watson, S. A. 1988. Corn marketing, processing and utilization. In: Corn and Corn Improvement. Sprague, G.F. and Dudley, J.W. (Eds). American Society of America, Inc., Crop Science Society of America, Inc., Soil Society of America, Inc. Madison, Wisconsin, USA. 881-940 pp.

Widstrom, N.W. 1996. The aflatoxin problem with corn grain. Advances in Agronomy 56: 219280.

Widstrom, N.W. 1992. Aflatoxin in developing maize: interactions among involved biota and pertinent econiche factors. In: Mycotoxins in Ecological Systems. Bhatnagar, D.; Lillehoj, E.B. and Arora, D.K. (Eds). Marcel Dekker, New York. 23-58 pp.

Wu, F.; Stacy, S. and Kensler, T. 2013. Global Risk Assessment of Aflatoxins in Maize and Peanuts: Are Regulatory Standards Adequately Protective? Toxicological Sciences.

Zummo N. and Scott G. E. 1992. Interaction of Fusarium moniliforme and Aspergillus flavus on kernel infection and aflatoxin contamination in maize ears. Plant Disease 76: 771773. 


\section{F. ANEXO}

\section{F1. Base de datos para la determinación de $A$. flavus en maíz}

Tabla 12: Resumen de la base de datos para determinar el comportamiento de Aspergillus flavus en híbridos de maíz en dos fecha de siembra con dos técnicas de inoculación.

\begin{tabular}{|c|c|c|c|c|c|c|}
\hline Campaña & $\begin{array}{c}\text { Fecha de } \\
\text { siembra }\end{array}$ & Híbrido & \begin{tabular}{|c|} 
Técnica de \\
inoculación*
\end{tabular} & $\begin{array}{l}\text { Índice de } \\
\text { severidad }\end{array}$ & $\begin{array}{c}\text { Incidencia } \\
(\%)\end{array}$ & $\begin{array}{l}\text { Fluorescencia } \\
\text { bajo luz UV** }\end{array}$ \\
\hline $2014 / 15$ & septiembre & AX887HCLMG & A & 1,9 & 75,4 & 1 \\
\hline $2014 / 15$ & septiembre & AX887HCLMG & $\mathrm{B}$ & 1,0 & 64,0 & 1 \\
\hline $2014 / 15$ & septiembre & AX887HCLMG & $\mathrm{C}$ & 1,0 & 51,8 & 1 \\
\hline $2014 / 15$ & septiembre & AX887HCLMG & $\mathrm{D}$ & 1,0 & 52,1 & 1 \\
\hline $2014 / 15$ & diciembre & AX887HCLMG & A & 1,1 & 34,2 & 1 \\
\hline $2014 / 15$ & diciembre & AX887HCLMG & B & 1,0 & 10,5 & 1 \\
\hline $2014 / 15$ & diciembre & AX887HCLMG & $\mathrm{C}$ & 1,1 & 26,5 & 1 \\
\hline $2014 / 15$ & diciembre & AX887HCLMG & $\mathrm{D}$ & 1,0 & 21,7 & 1 \\
\hline $2015 / 16$ & septiembre & AX887HCLMG & A & 1,5 & 92,6 & 1 \\
\hline $2015 / 16$ & septiembre & AX887HCLMG & B & 1,5 & 96,2 & 1 \\
\hline $2015 / 16$ & septiembre & AX887HCLMG & $\mathrm{C}$ & 1,7 & 86,2 & 1 \\
\hline $2015 / 16$ & septiembre & AX887HCLMG & $\mathrm{D}$ & 1,2 & 60,1 & 1 \\
\hline $2015 / 16$ & diciembre & AX887HCLMG & A & 1,0 & 23,1 & 1 \\
\hline $2015 / 16$ & diciembre & AX887HCLMG & B & 1,1 & 26,3 & 1 \\
\hline $2015 / 16$ & diciembre & AX887HCLMG & $\mathrm{C}$ & 1,6 & 54,9 & 1 \\
\hline $2015 / 16$ & diciembre & AX887HCLMG & $\mathrm{D}$ & 1,0 & 31,9 & 1 \\
\hline $2014 / 15$ & septiembre & DM2738MGRR2 & A & 1,4 & 84,1 & 1 \\
\hline $2014 / 15$ & septiembre & DM2738MGRR2 & $\mathrm{B}$ & 1,3 & 82,5 & 1 \\
\hline $2014 / 15$ & septiembre & DM2738MGRR2 & $\mathrm{C}$ & 1,2 & 58,7 & 1 \\
\hline $2014 / 15$ & septiembre & DM2738MGRR2 & $\mathrm{D}$ & 1,1 & 77,4 & 1 \\
\hline $2014 / 15$ & diciembre & DM2738MGRR2 & A & 1,0 & 59,6 & 1 \\
\hline $2014 / 15$ & diciembre & DM2738MGRR2 & B & 1,1 & 44,8 & 1 \\
\hline $2014 / 15$ & diciembre & DM2738MGRR2 & $\mathrm{C}$ & 1,4 & 60,2 & 1 \\
\hline $2014 / 15$ & diciembre & DM2738MGRR2 & $\mathrm{D}$ & 1,0 & 21,8 & 1 \\
\hline $2015 / 16$ & septiembre & DM2738MGRR2 & A & 2,3 & 98,5 & 1 \\
\hline $2015 / 16$ & septiembre & DM2738MGRR2 & $\mathrm{B}$ & 1,7 & 100,0 & 1 \\
\hline $2015 / 16$ & septiembre & DM2738MGRR2 & $\mathrm{C}$ & 1,4 & 100,0 & 1 \\
\hline $2015 / 16$ & septiembre & DM2738MGRR2 & $\mathrm{D}$ & 1,3 & 98,8 & 1 \\
\hline $2015 / 16$ & diciembre & DM2738MGRR2 & A & 1,2 & 42,9 & 1 \\
\hline $2015 / 16$ & diciembre & DM2738MGRR2 & $\mathrm{B}$ & 1,0 & 54,8 & 1 \\
\hline $2015 / 16$ & diciembre & DM2738MGRR2 & $\mathrm{C}$ & 1,5 & 79,9 & 1 \\
\hline $2015 / 16$ & diciembre & DM2738MGRR2 & $\mathrm{D}$ & 1,0 & 52,8 & 1 \\
\hline $2014 / 15$ & septiembre & L6854xL4674 & A & 1,1 & 98,8 & 1 \\
\hline $2014 / 15$ & septiembre & L6854xL4674 & $\mathrm{B}$ & 1,0 & 84,9 & 1 \\
\hline $2014 / 15$ & septiembre & L6854xL4674 & $\mathrm{C}$ & 1,0 & 94,1 & 1 \\
\hline $2014 / 15$ & septiembre & L6854xL4674 & $\mathrm{D}$ & 1,0 & 0,0 & 1 \\
\hline $2014 / 15$ & diciembre & L6854xL4674 & A & 2,5 & 92,6 & 1 \\
\hline
\end{tabular}




\begin{tabular}{|c|c|c|c|c|c|c|}
\hline $2014 / 15$ & diciembre & L6854xL4674 & B & 1,6 & 65,3 & 1 \\
\hline $2014 / 15$ & diciembre & L6854xL4674 & $\mathrm{C}$ & 1,1 & 57,2 & 1 \\
\hline $2014 / 15$ & diciembre & L6854xL4674 & $\mathrm{D}$ & 1,0 & 68,3 & 1 \\
\hline $2015 / 16$ & septiembre & L6854xL4674 & $\mathrm{A}$ & 3,5 & 33,3 & 1 \\
\hline $2015 / 16$ & septiembre & L6854xL4674 & B & 2,5 & 33,3 & 1 \\
\hline $2015 / 16$ & septiembre & L6854xL4674 & $\mathrm{C}$ & 2,0 & 33,3 & 1 \\
\hline $2015 / 16$ & septiembre & L6854xL4674 & $\mathrm{D}$ & 1,5 & 52,0 & 1 \\
\hline $2015 / 16$ & diciembre & L6854xL4674 & A & 1,1 & 45,2 & 1 \\
\hline $2015 / 16$ & diciembre & L6854xL4674 & $\mathrm{B}$ & 1,0 & 46,7 & 1 \\
\hline $2015 / 16$ & diciembre & L6854xL4674 & $\mathrm{C}$ & 1,0 & 59,7 & 1 \\
\hline $2015 / 16$ & diciembre & L6854xL4674 & $\mathrm{D}$ & 1,0 & 54,6 & 1 \\
\hline $2014 / 15$ & septiembre & LT626VT3P & A & 1,1 & 69,2 & 1 \\
\hline $2014 / 15$ & septiembre & LT626VT3P & $\mathrm{B}$ & 1,1 & 82,6 & 0 \\
\hline $2014 / 15$ & septiembre & LT626VT3P & $\mathrm{C}$ & 1,1 & 86,3 & 1 \\
\hline $2014 / 15$ & septiembre & LT626VT3P & $\mathrm{D}$ & 1,1 & 57,7 & 1 \\
\hline $2014 / 15$ & diciembre & LT626VT3P & A & 1,1 & 37,0 & 1 \\
\hline $2014 / 15$ & diciembre & LT626VT3P & $\mathrm{B}$ & 1,0 & 27,3 & 1 \\
\hline $2014 / 15$ & diciembre & LT626VT3P & $\mathrm{C}$ & 1,0 & 42,3 & 1 \\
\hline $2014 / 15$ & diciembre & LT626VT3P & $\mathrm{D}$ & 1,0 & 22,7 & 1 \\
\hline $2015 / 16$ & septiembre & LT626VT3P & $\mathrm{A}$ & 1,7 & 56,7 & 1 \\
\hline $2015 / 16$ & septiembre & LT626VT3P & B & 1,4 & 63,5 & 1 \\
\hline $2015 / 16$ & septiembre & LT626VT3P & $\mathrm{C}$ & 1,3 & 75,2 & 1 \\
\hline $2015 / 16$ & septiembre & LT626VT3P & $\mathrm{D}$ & 1,1 & 84,2 & 1 \\
\hline $2015 / 16$ & diciembre & LT626VT3P & $\mathrm{A}$ & 1,2 & 47,3 & 1 \\
\hline $2015 / 16$ & diciembre & LT626VT3P & $\mathrm{B}$ & 1,1 & 28,7 & 1 \\
\hline $2015 / 16$ & diciembre & LT626VT3P & $\mathrm{C}$ & 1,1 & 42,1 & 1 \\
\hline $2015 / 16$ & diciembre & LT626VT3P & $\mathrm{D}$ & 1,0 & 29,3 & 1 \\
\hline $2014 / 15$ & septiembre & P1780Y & $\mathrm{A}$ & 1,5 & 86,1 & 1 \\
\hline $2014 / 15$ & septiembre & $\mathrm{P} 1780 \mathrm{Y}$ & $\mathrm{B}$ & 1,1 & 67,3 & 1 \\
\hline $2014 / 15$ & septiembre & $\mathrm{P} 1780 \mathrm{Y}$ & $\mathrm{C}$ & 1,2 & 79,6 & 1 \\
\hline $2014 / 15$ & septiembre & P1780Y & $\mathrm{D}$ & 1,0 & 27,1 & 1 \\
\hline $2014 / 15$ & diciembre & $\mathrm{P} 1780 \mathrm{Y}$ & A & 1,2 & 52,3 & 1 \\
\hline $2014 / 15$ & diciembre & $\mathrm{P} 1780 \mathrm{Y}$ & $\mathrm{B}$ & 1,0 & 28,3 & 1 \\
\hline $2014 / 15$ & diciembre & P1780Y & $\mathrm{C}$ & 1,0 & 39,2 & 1 \\
\hline $2014 / 15$ & diciembre & $\mathrm{P} 1780 \mathrm{Y}$ & $\mathrm{D}$ & 1,1 & 54,2 & 1 \\
\hline $2015 / 16$ & septiembre & $\mathrm{P} 1780 \mathrm{Y}$ & A & 2,0 & 99,3 & 1 \\
\hline $2015 / 16$ & septiembre & P1780Y & B & 1,9 & 88,5 & 1 \\
\hline $2015 / 16$ & septiembre & P1780Y & $\mathrm{C}$ & 1,7 & 93,0 & 1 \\
\hline $2015 / 16$ & septiembre & $\mathrm{P} 1780 \mathrm{Y}$ & $\mathrm{D}$ & 1,2 & 51,9 & 1 \\
\hline $2015 / 16$ & diciembre & P1780Y & A & 1,2 & 59,1 & 1 \\
\hline $2015 / 16$ & diciembre & P1780Y & B & 1,1 & 38,1 & 1 \\
\hline $2015 / 16$ & diciembre & $\mathrm{P} 1780 \mathrm{Y}$ & $\mathrm{C}$ & 1,2 & 37,6 & 1 \\
\hline $2015 / 16$ & diciembre & P1780Y & $\mathrm{D}$ & 1,0 & 53,8 & 1 \\
\hline $2014 / 15$ & septiembre & SY960TD/TG & A & 1,5 & 80,8 & 1 \\
\hline $2014 / 15$ & septiembre & SY960TD/TG & $\mathrm{B}$ & 1,4 & 56,4 & 1 \\
\hline
\end{tabular}




\begin{tabular}{|l|l|l|l|l|l|l|}
$2014 / 15$ & septiembre & SY960TD/TG & C & 1,4 & 76,7 & 1 \\
\hline $2014 / 15$ & septiembre & SY960TD/TG & D & 1,1 & 71,0 & 1 \\
\hline $2014 / 15$ & diciembre & SY960TD/TG & A & 1,0 & 46,6 & 1 \\
\hline $2014 / 15$ & diciembre & SY960TD/TG & B & 1,1 & 63,3 & 1 \\
\hline $2014 / 15$ & diciembre & SY960TD/TG & C & 1,0 & 30,2 & 1 \\
\hline $2014 / 15$ & diciembre & SY960TD/TG & D & 1,0 & 14,3 & 1 \\
\hline $2015 / 16$ & septiembre & SY960TD/TG & A & 1,8 & 77,6 & 1 \\
\hline $2015 / 16$ & septiembre & SY960TD/TG & B & 1,5 & 52,6 & 1 \\
\hline $2015 / 16$ & septiembre & SY960TD/TG & C & 1,9 & 66,7 & 1 \\
\hline $2015 / 16$ & septiembre & SY960TD/TG & D & 1,2 & 58,6 & 1 \\
\hline $2015 / 16$ & diciembre & SY960TD/TG & A & 1,0 & 44,3 & 1 \\
\hline $2015 / 16$ & diciembre & SY960TD/TG & B & 1,0 & 27,0 & 1 \\
\hline $2015 / 16$ & diciembre & SY960TD/TG & C & 1,1 & 24,0 & 1 \\
\hline $2015 / 16$ & diciembre & SY960TD/TG & D & 1,0 & 13,1 & 1 \\
\hline
\end{tabular}

*Técnica de inoculación: A: inoculación en el canal de estigmas; B: testigo de técnica A; C: inoculación en grano; D: testigo de técnica C. **UV: valor 1:positivo, valor 0: negativo

\section{F2. Resultados del análisis estadístico}

\section{F.2.a. Severidad}

Tabla 13: Media de Mínimos Cuadrados para la interacción técnica de inoculación*híbrido (fecha de siembra) para la variable índice de severidad de Aspergillus flavus en maíz.

\begin{tabular}{|c|c|c|c|c|c|c|}
\hline \multicolumn{6}{|c|}{ Técnica de inoculación*híbrido(Fecha de siembra) Media de Mínimos Cuadrados } \\
\hline $\begin{array}{c}\text { Fecha de } \\
\text { siembra }\end{array}$ & $\begin{array}{c}\text { Técnica de } \\
\text { inoculación* }\end{array}$ & Híbrido & $\begin{array}{c}\text { Pr }> \\
|\mathbf{t}| * *\end{array}$ & Media & $\begin{array}{c}\text { Error } \\
\text { Estándar }\end{array}$ & $\begin{array}{c}\text { Media con } \\
\text { antilogaritmo }\end{array}$ \\
\hline diciembre & A & AX887HCLMG & 0.4261 & 0,072 & 0.09026 & 1,07 \\
\hline diciembre & B & AX887HCLMG & 0.5641 & 0,052 & 0.09026 & 1,05 \\
\hline diciembre & C & AX887HCLMG & 0.0064 & 0,248 & 0.09026 & 1,28 \\
\hline diciembre & D & AX887HCLMG & 0.8473 & 0,019 & 0.09888 & 1,02 \\
\hline septiembre & A & AX887HCLMG & $<.0001$ & 0,458 & 0.09026 & 1,58 \\
\hline septiembre & B & AX887HCLMG & 0.0215 & 0,229 & 0.09888 & 1,26 \\
\hline septiembre & C & AX887HCLMG & 0.0052 & 0,255 & 0.09026 & 1,29 \\
\hline septiembre & D & AX887HCLMG & 0.3459 & 0,085 & 0.09026 & 1,09 \\
\hline diciembre & A & DM2738MGRR2 & 0.4261 & 0,072 & 0.09026 & 1,07 \\
\hline diciembre & B & DM2738MGRR2 & 0.4918 & 0,062 & 0.09026 & 1,06 \\
\hline diciembre & C & DM2738MGRR2 & 0.0002 & 0,346 & 0.09026 & 1,41 \\
\hline diciembre & D & DM2738MGRR2 & 0.7252 & 0,032 & 0.09026 & 1,03 \\
\hline septiembre & A & DM2738MGRR2 & $<.0001$ & 0,562 & 0.09026 & 1,75 \\
\hline septiembre & B & DM2738MGRR2 & $<.0001$ & 0,378 & 0.09026 & 1,46 \\
\hline septiembre & C & DM2738MGRR2 & 0.0071 & 0,245 & 0.09026 & 1,28 \\
\hline septiembre & D & DM2738MGRR2 & 0.0819 & 0,158 & 0.09026 & 1,17 \\
\hline diciembre & A & L6856xL4674 & $<.0001$ & 0,486 & 0.09026 & 1,63 \\
\hline diciembre & B & L6856xL4674 & 0.0189 & 0,214 & 0.09026 & 1,24 \\
\hline diciembre & C & L6856xL4674 & 0.6764 & 0,038 & 0.09026 & 1,04 \\
\hline
\end{tabular}




\begin{tabular}{|c|c|c|c|c|c|c|}
\hline diciembre & $\mathrm{D}$ & L6856xL4674 & 0.8091 & 0,022 & 0.09026 & 1,02 \\
\hline septiembre & $\mathrm{A}$ & L6856xL4674 & 0.0001 & 0,505 & 0.1277 & 1,66 \\
\hline septiembre & $\mathrm{B}$ & L6856xL4674 & 0.0394 & 0,229 & 0.1105 & 1,26 \\
\hline septiembre & $\mathrm{C}$ & L6856xL4674 & 10.000 & 0,000 & 0.1277 & 1,00 \\
\hline septiembre & $\mathrm{D}$ & L6856xL4674 & 10.000 & 0,000 & 0.2211 & 1,00 \\
\hline diciembre & A & LT626VT3P & 0.1351 & 0,135 & 0.09026 & 1,14 \\
\hline diciembre & $\mathrm{B}$ & LT626VT3P & 0.7138 & 0,033 & 0.09026 & 1,03 \\
\hline diciembre & $\mathrm{C}$ & LT626VT3P & 0.3806 & 0,079 & 0.09026 & 1,08 \\
\hline diciembre & $\mathrm{D}$ & LT626VT3P & 10.000 & 0,000 & 0.09026 & 1,00 \\
\hline septiembre & $\mathrm{A}$ & LT626VT3P & 0.0053 & 0,254 & 0.09026 & 1,29 \\
\hline septiembre & $\mathrm{B}$ & LT626VT3P & 0.0539 & 0,192 & 0.09888 & 1,21 \\
\hline septiembre & $\mathrm{C}$ & LT626VT3P & 0.0638 & 0,168 & 0.09026 & 1,18 \\
\hline septiembre & $\mathrm{D}$ & LT626VT3P & 0.3136 & 0,091 & 0.09026 & 1,10 \\
\hline diciembre & A & P1780YR & 0.1122 & 0,144 & 0.09026 & 1,15 \\
\hline diciembre & $\mathrm{B}$ & P1780YR & 0.5971 & 0,048 & 0.09026 & 1,05 \\
\hline diciembre & $\mathrm{C}$ & P1780YR & 0.4414 & 0,070 & 0.09026 & 1,07 \\
\hline diciembre & $\mathrm{D}$ & P1780YR & 0.7367 & 0,030 & 0.09026 & 1,03 \\
\hline septiembre & A & P1780YR & $<.0001$ & 0,533 & 0.09026 & 1,70 \\
\hline septiembre & $\mathrm{B}$ & P1780YR & 0.0002 & 0,343 & 0.09026 & 1,41 \\
\hline septiembre & $\mathrm{C}$ & P1780YR & 0.0001 & 0,356 & 0.09026 & 1,43 \\
\hline septiembre & $\mathrm{D}$ & P1780YR & 0.3950 & 0,094 & 0.1105 & 1,10 \\
\hline diciembre & A & SY960TD/TG & 0.7127 & 0,033 & 0.09026 & 1,03 \\
\hline diciembre & $\mathrm{B}$ & SY960TD/TG & 0.4457 & 0,069 & 0.09026 & 1,07 \\
\hline diciembre & $\mathrm{C}$ & SY960TD/TG & 0.7138 & 0,033 & 0.09026 & 1,03 \\
\hline diciembre & $\mathrm{D}$ & SY960TD/TG & 10.000 & 0,000 & 0.09026 & 1,00 \\
\hline septiembre & A & SY960TD/TG & $<.0001$ & 0,484 & 0.09026 & 1,62 \\
\hline septiembre & $\mathrm{B}$ & SY960TD/TG & 0.0002 & 0,339 & 0.09026 & 1,40 \\
\hline septiembre & $\mathrm{C}$ & SY960TD/TG & $<.0001$ & 0,467 & 0.09026 & 1,60 \\
\hline septiembre & $\mathrm{D}$ & SY960TD/TG & 0.1084 & 0,146 & 0.09026 & 1,16 \\
\hline
\end{tabular}

*Técnica de inoculación: A: inoculación en el canal de estigmas; B: testigo de técnica A; $\mathrm{C}$ : inoculación en grano; D: testigo de técnica $\mathrm{C}$. $* *$ Valores de $\mathrm{p}<0.05$ indican diferencias significativas en la interacción. 


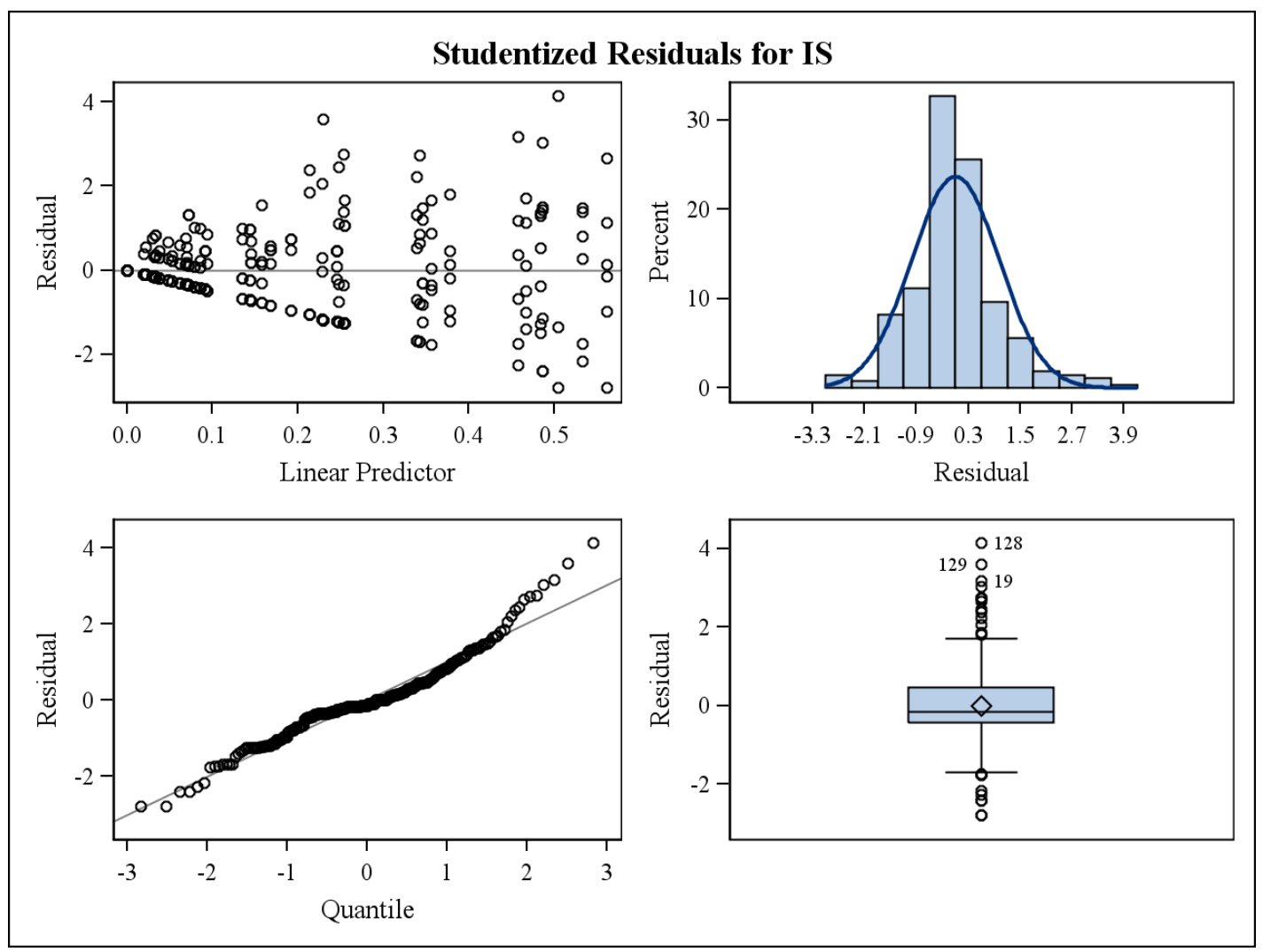

Figura 21: Supuestos de la variable índice de severidad para Aspergillus flavus en maíz.

\section{F.2.b. Incidencia de granos infectados}

Tabla 14: Media de Mínimos Cuadrados para la interacción técnica de inoculación*híbrido (fecha de siembra) para la variable incidencia de Aspergillus flavus en maíz.

\begin{tabular}{|c|c|c|c|c|c|}
\hline \multicolumn{5}{|c|}{ Técnica de inoculación*híbrido(Fecha de siembra) Media de Mínimos } \\
Cuadrados \\
\hline $\begin{array}{c}\text { Fecha de } \\
\text { siembra }\end{array}$ & $\begin{array}{c}\text { Técnica de } \\
\text { inoculación* }\end{array}$ & Híbridos & $\begin{array}{c}\text { Pr }> \\
|t|\end{array}$ & Medias & $\begin{array}{c}\text { Error } \\
\text { estándar }\end{array}$ \\
\hline diciembre & A & AX887HCLMG & 0.3308 & 0,3327 & 0.1585 \\
\hline diciembre & A & DM2738MGRR2 & 0.9857 & 0,4963 & 0.2043 \\
\hline diciembre & A & L6856xL4674 & 0.2381 & 0,6994 & 0.1501 \\
\hline diciembre & A & LT626VT3P & 0.6334 & 0,4214 & 0.1618 \\
\hline diciembre & A & P1780YR & 0.7922 & 0,569 & 0.2584 \\
\hline diciembre & A & SY960TD/TG & 0.9192 & 0,5229 & 0.2248 \\
\hline diciembre & B & AX887HCLMG & 0.0148 & 0,1476 & 0.08981 \\
\hline diciembre & B & DM2738MGRR2 & 0.9413 & 0,4816 & 0.2500 \\
\hline diciembre & B & L6856xL4674 & 0.5753 & 0,5873 & 0.1524 \\
\hline diciembre & B & LT626VT3P & 0.1885 & 0,2805 & 0.1441 \\
\hline diciembre & B & P1780YR & 0.4731 & 0,3627 & 0.1812 \\
\hline diciembre & B & SY960TD/TG & 0.9454 & 0,484 & 0.2327 \\
\hline diciembre & C & AX887HCLMG & 0.4991 & 0,3815 & 0.1684 \\
\hline diciembre & C & DM2738MGRR2 & 0.5338 & 0,6796 & 0.2627 \\
\hline diciembre & C & L6856xL4674 & 0.7154 & 0,553 & 0.1440 \\
\hline diciembre & C & LT626VT3P & 0.5783 & 0,4019 & 0.1716 \\
\hline
\end{tabular}




\begin{tabular}{|l|c|c|c|c|c|} 
diciembre & C & P1780YR & 0.5809 & 0,3996 & 0.1766 \\
\hline diciembre & C & SY960TD/TG & 0.1925 & 0,2996 & 0.1363 \\
\hline diciembre & D & AX887HCLMG & 0.1501 & 0,2629 & 0.1383 \\
\hline diciembre & D & DM2738MGRR2 & 0.3987 & 0,3535 & 0.1632 \\
\hline diciembre & D & L6856xL4674 & 0.7682 & 0,5525 & 0.1765 \\
\hline diciembre & D & LT626VT3P & 0.1503 & 0,263 & 0.1384 \\
\hline diciembre & D & P1780YR & 0.7300 & 0,5614 & 0.1758 \\
\hline diciembre & D & SY960TD/TG & 0.0101 & 0,1356 & 0.08366 \\
\hline septiembre & A & AX887HCLMG & 0.1233 & 0,8809 & 0.1357 \\
\hline septiembre & A & DM2738MGRR2 & 0.1423 & 0,9131 & 0.1267 \\
\hline septiembre & A & L6856xL4674 & 0.1741 & 0,991 & 0.03075 \\
\hline septiembre & A & LT626VT3P & 0.2774 & 0,8135 & 0.2052 \\
\hline septiembre & A & P1780YR & 0.2439 & 0,9405 & 0.1322 \\
\hline septiembre & A & SY960TD/TG & 0.0370 & 0,8173 & 0.1066 \\
\hline septiembre & B & AX887HCLMG & $<.0001$ & 0,9642 & 0.02466 \\
\hline septiembre & B & DM2738MGRR2 & 0.0018 & 0,9056 & 0.06101 \\
\hline septiembre & B & L6856xL4674 & 0.0015 & 0,9081 & 0.05957 \\
\hline septiembre & B & LT626VT3P & 0.0805 & 0,778 & 0.1233 \\
\hline septiembre & B & P1780YR & 0.1687 & 0,7283 & 0.1413 \\
\hline septiembre & B & SY960TD/TG & 0.8962 & 0,5233 & 0.1781 \\
\hline septiembre & C & AX887HCLMG & 0.1219 & 0,7519 & 0.1332 \\
\hline septiembre & C & DM2738MGRR2 & 0.0347 & 0,8201 & 0.1053 \\
\hline septiembre & C & L6856xL4674 & $<.0001$ & 0,9579 & 0.02876 \\
\hline septiembre & C & LT626VT3P & 0.0384 & 0,8156 & 0.1074 \\
\hline septiembre & C & P1780YR & 0.0015 & 0,908 & 0.05962 \\
\hline septiembre & C & SY960TD/TG & 0.1579 & 0,7333 & 0.1396 \\
\hline septiembre & D & AX887HCLMG & 0.6861 & 0,5717 & 0.1748 \\
\hline septiembre & D & DM2738MGRR2 & 0.0039 & 0,9209 & 0.06124 \\
\hline septiembre & D & LT626VT3P & 0.1744 & 0,7257 & 0.1421 \\
\hline septiembre & D & P1780YR & 0.5493 & 0,6216 & 0.1947 \\
\hline septiembre & D & SY960TD/TG & 0.2029 & 0,7134 & 0.1460 \\
\hline
\end{tabular}

*Técnica de inoculación: A: inoculación en el canal de estigmas; B: testigo de técnica A; C: inoculación en grano; $\mathrm{D}$ : testigo de técnica $\mathrm{C}$. **Valores de $\mathrm{p}<0.05$ indican diferencias significativas en la interacción. 


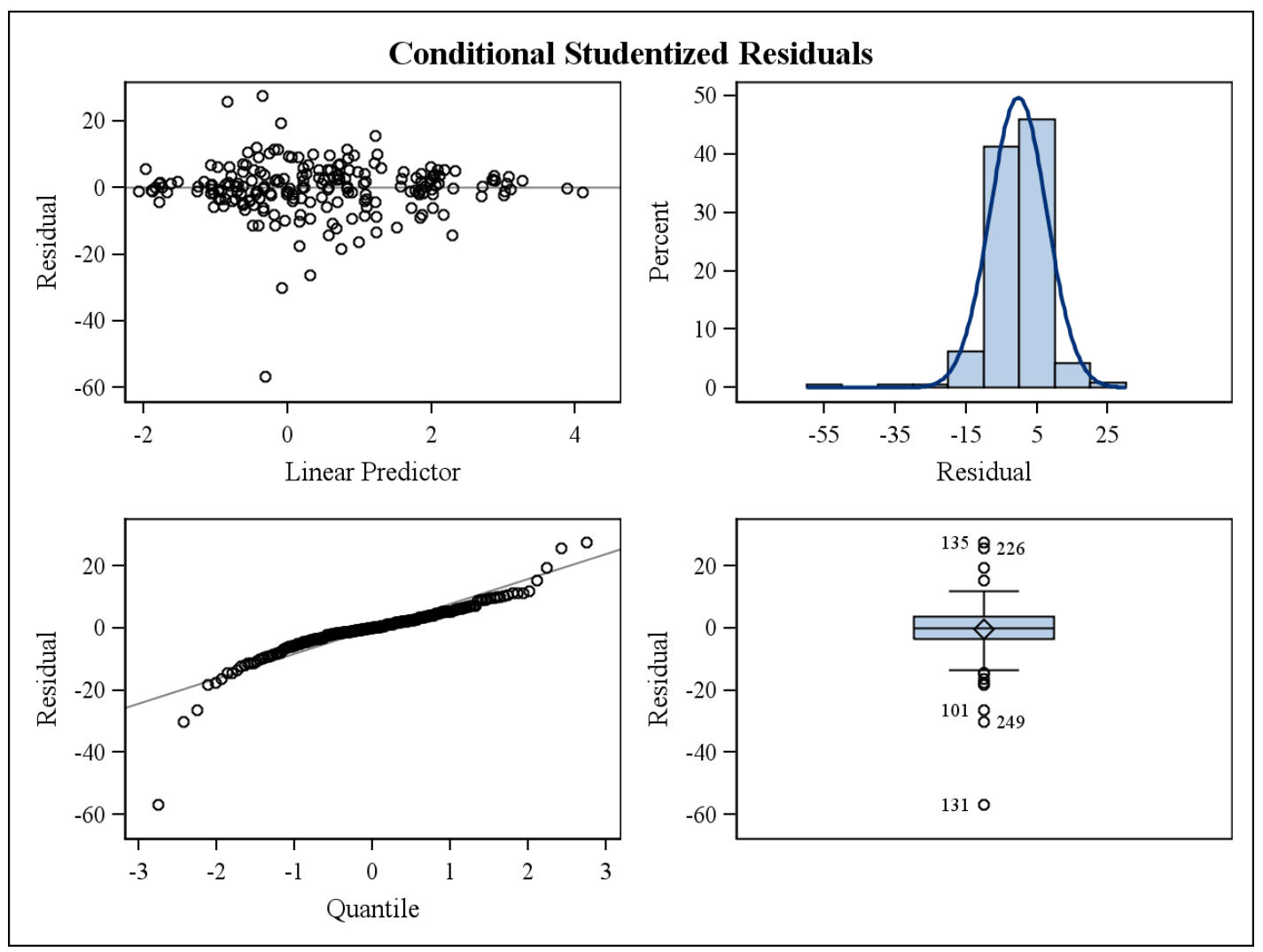

Figura 22: Supuestos para la variable incidencia de Aspergillus flavus en maíz.

\section{F.2.c. Fluorescencia bajo luz UV}

Tabla 15: Medias ajustadas y errores estándares para el factor fecha de siembra en el modelo utilizado para la detección de Aspergillus flavus por fluorescencia bajo luz UV.

Inversa de la función de enlace con efecto aleatorio $=0$

LSD Fisher (Alfa=0,05)

Procedimiento de corrección de p-valores: No

Fecha de siembra PredLin E.E. Media E.E.

Diciembre $\quad 9,11 \quad 589,02 \quad 1,00 \quad 0,06$ A

Septiembre $\quad 8,74 \quad 589,02 \quad 1,00 \quad 0,09$ A

Medias con una letra común no son significativamente diferentes $(p>0,05)$

Tabla 16: Medias ajustadas y errores estándares para el factor cultivar en el modelo utilizado para la detección de Aspergillus flavus por fluorescencia bajo luz UV.

Inversa de la función de enlace con efecto aleatorio $=0$

LSD Fisher (Alfa=0,05)

Procedimiento de corrección de p-valores: No

Híbrido PredLin E.E. Media E.E.

$\begin{array}{lrcccc}\text { DM2738MGRR2 } & 20,73 & 2499,01 & 1,00 & 2,5 \mathrm{E}-06 & \text { A } \\ \text { SY960TD/TG } & 20,73 & 2499,01 & 1,00 & 2,5 \mathrm{E}-06 & \mathrm{~A} \\ \text { AX887HCLMG } & 3,33 & 0,76 & 0,97 & 0,03 & \mathrm{~A} \\ \text { L6854xL4674 } & 3,33 & 0,76 & 0,97 & 0,03 & \text { A } \\ \text { P1780Y } & 3,33 & 0,76 & 0,97 & 0,03 & \text { A } \\ \text { LT626VT3P } & 2,11 & 0,48 & 0,89 & 0,05 & \text { A }\end{array}$

Medias con una letra común no son significativamente diferentes $(p>0,05)$ 
Tabla 17: Medias ajustadas y errores estándares para el factor técnicas de inoculación en el modelo utilizado para la detección de Aspergillus flavus por fluorescencia bajo luz UV.

Inversa de la función de enlace con efecto aleatorio $=0$

LSD Fisher (Alfa=0,05)

Procedimiento de corrección de p-valores: No

Técnica de inoculación* PredLin E.E. Media E.E.

\begin{tabular}{llllll}
\hline $\mathrm{A}$ & 9,96 & 589,02 & 1,00 & 0,03 & $\mathrm{~A}$ \\
$\mathrm{D}$ & 8,80 & 589,02 & 1,00 & 0,09 & $\mathrm{~A}$ \\
$\mathrm{~B}$ & 8,47 & 589,02 & 1,00 & 0,12 & $\mathrm{~A}$ \\
$\mathrm{C}$ & 8,47 & 589,02 & 1,00 & 0,12 & $\mathrm{~A}$ \\
\hline
\end{tabular}

Medias con una letra común no son significativamente diferentes $(p>0,05)$

*Técnica de inoculación: A: inoculación en el canal de estigmas; B: testigo de técnica A;

C: inoculación en grano; D: testigo de técnica C. 